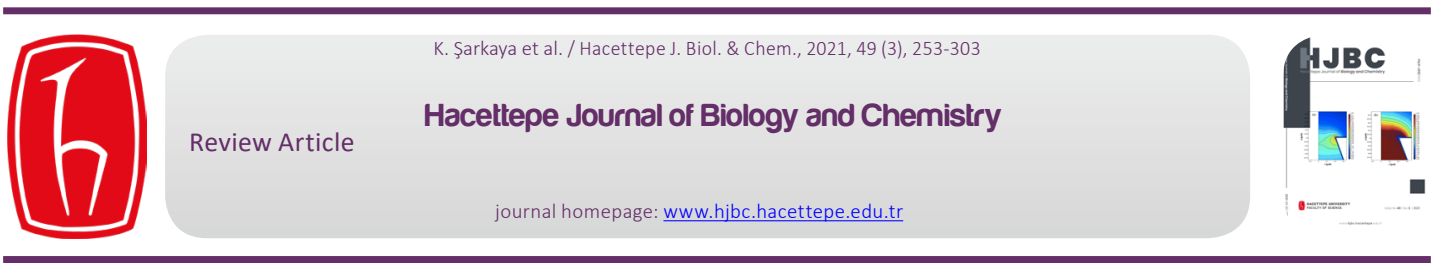

\title{
Chiral Separations by Capillary Electrophoresis and Related Techniques with Different Chiral Selectors: A Review
}

\section{Farklı Kiral Selektörler ile Kapiler Elektroforez ve İlgili Tekniklerle Kiral Ayrımlar: Bir Derleme}

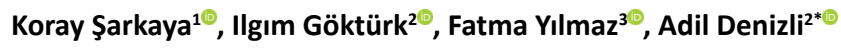 \\ ${ }^{1}$ Pamukkale University, Department of Chemistry, Faculty of Science and Art, Denizli, Turkey. \\ ${ }^{2}$ Department of Chemistry, Hacettepe University, Ankara, Turkey. \\ ${ }^{3}$ Vocational School of Gerede, Department of Chemistry Technology, Bolu Abant Izzet Baysal University, Bolu, Turkey.
}

\section{A BSTRACT}

ecognition mechanism and enantiomerically separations of the chiral compounds are subjects that always stimulate

the great interest of researchers in pharmacology and natural sciences, who are interested in finding solutions for both analytical purity and preparative purposes. Capillary Electrophoresis has become one of the most important analytical approaches for enantiomeric separations due to its superior properties, such as high resolution and high efficiency of chiral selectors. In this field, where researchers continue to be interested, the distinctions continue to develop day by day, with the introduction of new techniques developed on the basis of Capillary Electrophoresis philosophy in parallel with the development process of technology, as well as the chiral selectors of many different forms. In this review, besides some descriptive theoretical information about capillary electrophoresis and the techniques associated with it, studies on chiral separations using different chiral selectors or different chiral additives, such as molecularly imprinted polymers, cyclodextrins, Metal-organic frameworks, ionic liquids, nanoparticles and monoliths in the last nearly 10 years (2010-2020) were examined.

\section{Key Words}

Capillary electrophoresis, chiral selectors, chiral additives, chiral separations.

\section{öz}

\begin{abstract}
nalitik safıkta ve büyük ölçekli üretim çalışmaları için çözüm yolları bulmaya çalışan farmakoloji ve doğa bilimleriyle ilgilenen araştırmacıların ilgisini kiral bileşiklerin tayin ve enantiyomerik olarak ayrımı konuları çekmiştir. Kapiler Elektroforez, kiral selektörlerin yüksek ayırım gücü ve verimliliği gibi üstün özellikleri nedeniyle enantiyomerik ayırımlar için en önemli analitik yaklaşımlardan biri haline gelmiştir. Yüksek ayırma gücü ve yüksek etkinlik gösterme gibi sahip olduğu üstün özelliklerden dolayı kapiler elektroforez, enantiyomerik ayırmalarda kullanılan en önemli analitik yaklaşımlardan biri haline gelmiştir. Kapiler Elektroforez temeline dayanan teknolojinin gelişim sürecine paralel olarak kiral seçicilerin farklı formlardaki gelişimide süremektedir. Bu derlemede, kapiler elektroforezde kullanılan teknikleri açıklayan bazı tanımlayıcı teorik bilgilere yer verilmiştir. Ayrıca son 10 yılda gerçekleştilen (2010-2020) ve moleküler baskılı polimerler, siklodekstrinler metal-organik çerçeveler, iyonik sıvılar, nanopartiküller, monolitler gibi farklı kiral seçicilerin ve farklı kiral katkı maddelerin kullanıldığı kiral ayırmalara dayanan çalışmalarda incelenmiştir.
\end{abstract}

\section{Anahtar Kelimeler}

Kapiler Elektroforez, kiral selektörler, kiral katkı maddeleri, kiral ayırım.

Article History: Received: Oct 20, 2020; Revised: Dec 10, 2020; Accepted: Dec 20, 2020; Available Online: May 6, 2021.

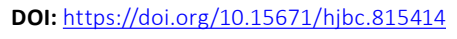

Correspondence to: A. Denizli, Department of Chemistry, Hacettepe University, Ankara, Turkey.

E-Mail: denizli@hacettepe.edu.tr 


\section{INTRODUCTION}

Materials having chiral properties are known as optically active compounds that have the ability to rotate the plane of vibration of polarized light. Stereoisomers that turn polarized light in different directions and do not coincide with their mirror image are classified as enantiomers. Chiral molecules contain at least one carbon atom to which four different atoms or groups, called stereogenic centers, are attached. The stereogenic center can also be named by various names such as chiral center, asymmetric center, and stereo-center. Chiral compounds are compounds that have two enantiomeric forms. Mixtures with an equal amount of enantiomer are called racemic mixtures or racemates. In environments where a chiral selector is not available, the enantiomers show similar physical and chemical properties, except for optical rotation motions. [1]. Their structure is generally composed of atoms (carbon, nitrogen, or sulfur) surrounded by at least four different functional groups as an asymmetric or chiral center.

Amino acids, sugars, peptides, proteins, and polysaccharides, which are the basic structural units of living things, represent a real feature of chirality at the molecular level. When comparing activities over the functionality of enantiomeric species, differences are often observed due to the sensitivity of stereochemistry in metabolic and regulatory processes mediated by biological systems [2]. Therefore, enantiomers are considered different compounds as they may have different properties in the biological context. Generally, for a substance to be optically active, it must be chiral and the amount of one enantiomer must be higher than the other. Chiral recognition has significant functionality in living systems due to the stereospecific interaction of optically active compounds with each other [3]. So, it is not difficult to understand that biological systems are generally sensitive to stereo selector.

Since each enantiomer has different biological activity, it exhibits different physiological effects through different ways of recognition in biological processes [4]. While one of the enantiomer types may have positive effects in physiological or biological conditions, the other may show harmful effects in the same environment as it is not active. [5]. For example, L-tryptophan can be used as a pharmaceutical agent in anti-depressant treatment as one of the essential amino acids. At the same time, D-tryptophan has no known biological activity and may occur as an impurity in L-tryptophan samples [6]. Enantiomeric separations are important topics of pharmaceutical chemistry, since each type of a drug containing racemic mixtures may have different physiological or biological properties in terms of the nature of drugs. For example, if the S-enantiomer of $\beta$-adrenoreceptor, one of the most widely used antihypertensive drugs, is taken, it has a high affinity for its $\beta$-adrenergic receptors. It acts as a blocking agent, whereas R-enantiomer of $\beta$-adrenoreceptor may have much less active, inactive, or even negative effects [7]. With the development of chiral separation methods, the recognition mechanisms of the drugs can be examined and the quality control analysis can be carried out. Consequently, there are obvious benefits to studying the properties of a chiral molecule in order to avoid the effectiveness and dangers of enantiomers. For this reason, the separation of enantiomers has been an important task for those who have adopted the principle of analytical precision for the last 30 years. Due to the demand for enantiomerically pure compounds, effective strategies are being developed day by day for analytical separation methods that can effectively separate enantiomers. Enantiomeric separation of racemic mixtures can be performed using capillary electrophoresis, crystallization, membrane, chromatography techniques, extraction or enzymatic kinetic resolution methods. The capillary electrophoresis method is a very attractive method compared to other methods, as it has advantages such as selectivity, inexpensive, simple, and rapid separation, as well as enabling the separation and analysis of enantiomers at very low volumes, high resolution and efficiency. In this regard, there is no doubt that capillary electrophoresis (CE) plays a very useful role today.

Some of the different methods used in the capillary electrophoresis technique are Capillary zone electrophoresis (CZE), Capillary gel electrophoresis (CGE), Capillary isotachophoresis (CITP), Capillary isoelectric focus (CIEF), Micellar capillary electrokinetic chromatography (MEKC) and Capillary electrochromatography. In the capillary electrophoresis method, separation of the components is performed by hydrodynamic or electrokinetic application of the sample by changing the buffer solution and the sample solution for a short time. Capillary electrochromatography (CEC) created by the combination of electrophoresis and chromatography technique is one of the most used capillary electrophoresis methods [8]. In addition to the development of chi- 
ral separation methods day by day, undoubtedly, one of the most significant supporting elements in chiral separations is the preparation of the chiral environment. For this purpose, many materials are used in these studies as chiral selective phase or chiral participants. While primarily cyclodextrin and its derivatives are the most popular chiral selectors, when we look at the statistics in recent studies, molecular imprinted polymers and monoliths are also preferred as chiral stationary phase (CSP) in this area.

While the studies related to nanoparticles (NPs) continue to be included in the literature in order to expand the surface area to increase enantioselectivity, there are very serious contributions for chiral additives such as ionic liquids (ILS) and antibiotics. Metal-organic frameworks (MOFs), which previously showed potential as a chiral stationary phase in High-Pressure Liquid Chromatography (HPLC) and Gas Chromatography (GC), have recently been used in electrophoresis systems, bringing a new dynamism to this field.

\section{Capillary Electrophoresis (Ce) and Principles}

The migration of ions in a solution through the applied electric potential is called electrophoresis. During the mobility of the ions, the cations migrate towards the cathode as the negatively charged electrode and the anions towards the anode, the positively charged electrode. In contrast to the applied electrical potentials, each ion has its specific migration rate. The basis of the migration of biomolecules in the silica capillary column through the applied electrical field is known as capillary electrophoresis (CE). Capillary electrophoresis (CE) is a highly effective micro-scale analytical technique based on the separation of compounds by charge/size ratios [9]. CE provides superiority over chromatographic methods thanks to its features such as analytical diversity, high efficiency of separation, high mass sensitivity, ability to work with very small sample volumes, low analysis times and cheapness [10]. Electrokinetic separations take place in a cylindrical capillary column with a 25-75 $\mu \mathrm{m}$ inner diameter, $330 \mu \mathrm{m}$ outer diameter, and 15-100

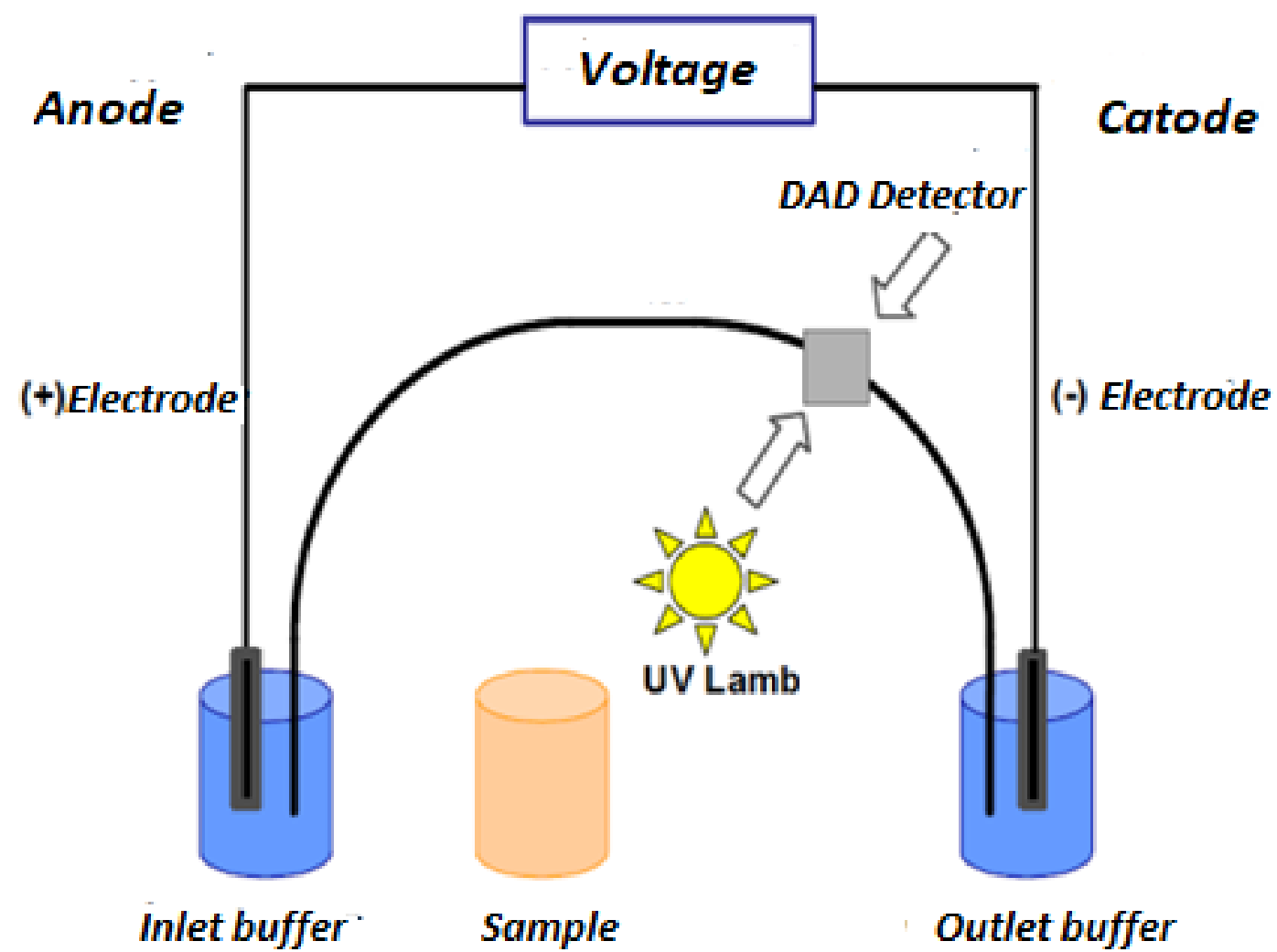

Figure 1.The simplified version of the capillary electrophoresis device. 


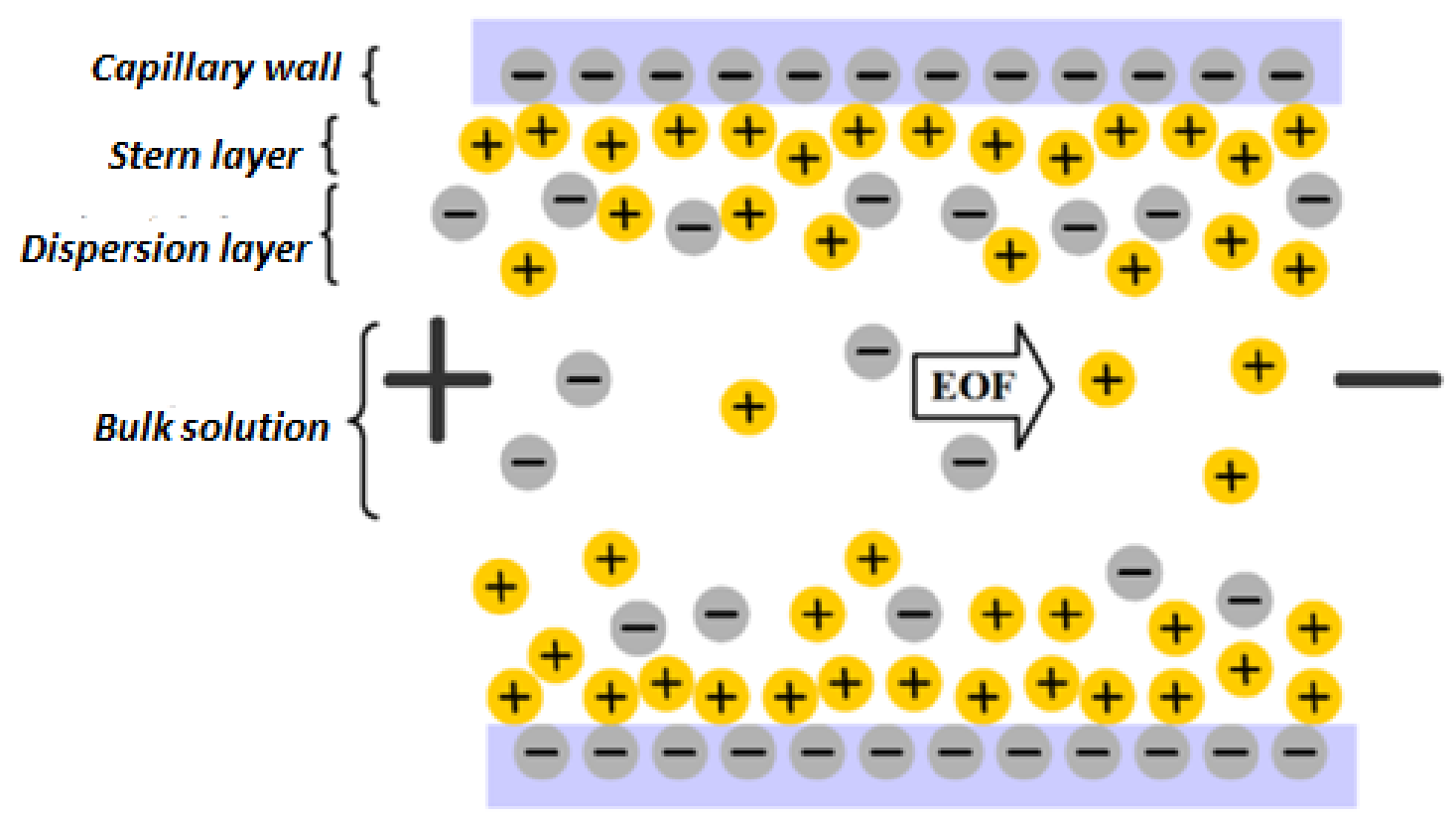

Figure 2. Electroosmotic flow (EOF) formation [14].

$\mathrm{cm}$ length, which is covered with silica on the inside and polyimide on the outside. The separation process is applied direct current potential of 5-30 kV between the two ends of the capillary columns [11]. The working principle of the capillary electrophoresis system is shown in Figure 1 in general. As can be understood from here, the silica capillary column, electrical voltage applicator, detector, UV lamp, electrolyte solutions and sample systems are the basic components.

The main driving force for the separation of analytes in capillary electrophoresis is electroosmotic flow (EOF). This situation also shows a common feature with the Capillary Electrochromatography method. Electroosmosis is a process dependent on the $\mathrm{pH}$ of the environment [12]. In this process, both the inner surface structure of the silica capillary column and the applied electric field effect are the force that mobilizes the entire solution in the capillary tubes to the other electrode as the $\mathrm{pH}$ increases. The capillary tubes used in the capillary electrophoresis method contain numerous silanol $(\mathrm{Si}-\mathrm{OH})$ groups formed by melting and shaping the silica. To activate this structure, which also includes an acidic group, potassium hydroxide $(\mathrm{KOH})$ or sodium hydroxide $(\mathrm{NaOH})$ solutions are often passed through the column. Figure 1 shows the formation of EOF in the silica capillary column. In basic conditions (or pH>3.5), silanol gro- ups on the silica capillary surface turn into negatively charged silanate groups, and the positive ions of the electrolyte solution are pulled by the negative surface to form an electrical double layer by electrostatic interaction. Most of the positive ions present in the electrolyte solution are in a second dispersion layer, and the application of an electric field describes the electroosmotic flow (EOF) of positive ions moving towards the cathode and negative ions towards the anode [13].

Schematic representation for the state of the ions present in the capillary column with the applied electrical field is shown in Figure 2. Ions are in motion along the column with the effect of EOF created by the application of the electric field. The species in the sample are separated from each other and leaving the column is provided by the electrical field applied by capillary electrophoresis. Thus, the electroosmotic flow (EOF) with its electrophoretic motions of ions has an enormous contribution to the movement of ions that are carried out with the mobile phase [15]. The uncharged compounds tend to trend in the same direction as the mobile phase in HPLC and CEC systems, and leave the system at different times according to their affinity to the stationary phase. However, if the sample contains charged components, the retention times of the analytes in the column may vary depending on the type and size of the 


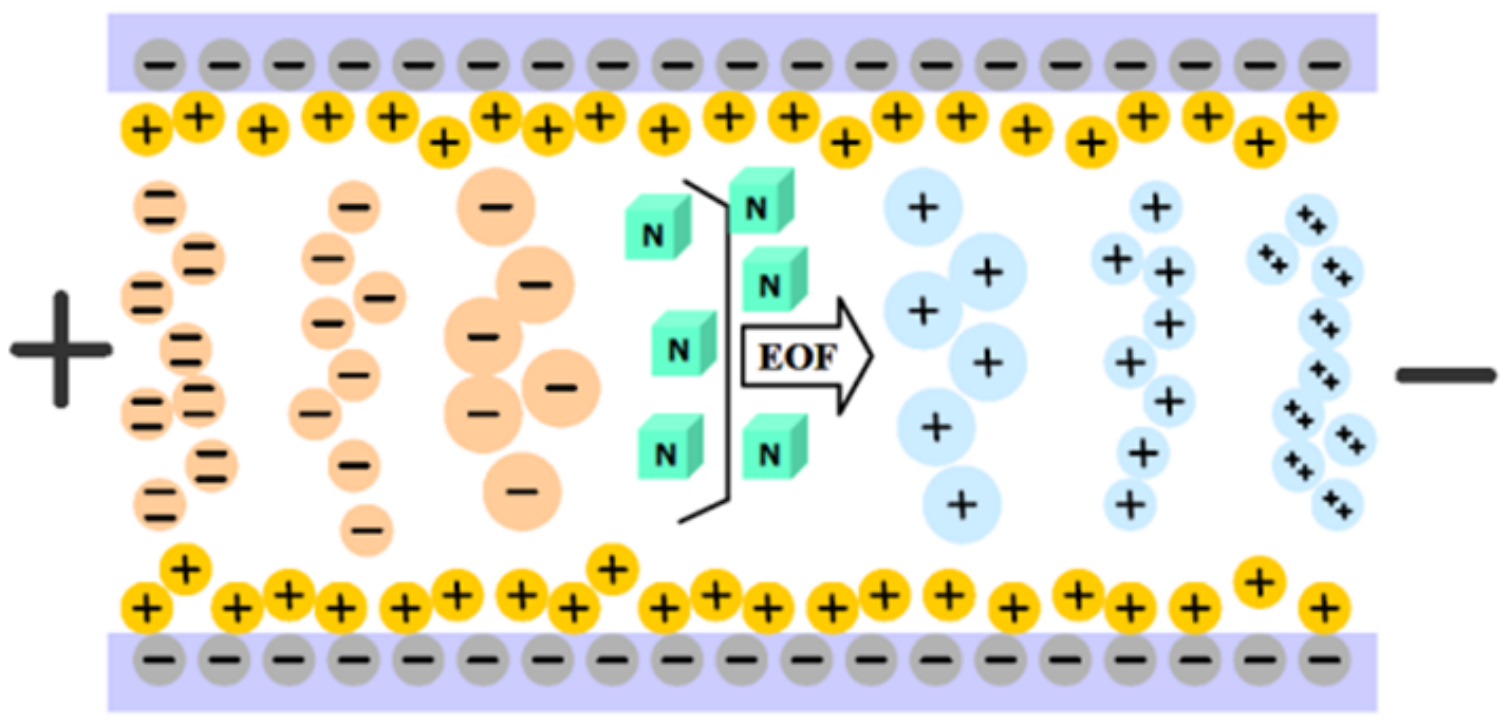

Figure 3. Electric field application in capillary column and movement of analytes with EOF.

ions' electrophoretic motions and orientations. If electroosmotic flow (EOF) and electrophoretic motions are in the same direction, the molecules leave the column faster. If the electrophoretic movement with EOF is not in the same direction and EOF is faster than the electrophoretic movement, the analyte leaves the column later than the EOF marker. Finally, if the opposite is the case, the EOF marker cannot leave the column and the components in the sample can be determined [16].

The electrical double layer consists of two zones, the tight and diffused layer. They become negatively charged as a result of ionization of the groups with ionization properties on the surface of the filler, and they interact with positively charged ions in the mobile phase, forming a tight and immobile region called "Stern Layer". Increasing charged ions are dispersed in the mobile phase. This scattered region where ions are found in an irregular way is called "Gouy Layer". The ions in this region show the solution component feature. An example presentation based on the Electrical Double Layer is shown in Figure 3.

Compared to the total ion concentration, the charge concentration in the Electrical Double Layer is known to be lower and this concentration difference increases even further as it moves away from the surface of the filling material, in other words, the total ion concentration decreases further. As a result of this, the electrical potential decreases in relation to the ion concentration. Zeta Potential, which has a value between 0-100 $\mathrm{mV}$, is defined as the electrical potential between the Stern Layer and the part where the Electrical Double Layer contains the ions and is indicated with " $\zeta$ ". Accordingly, the electrical potential continues to decrease as the charge density decreases as it moves away from the surface of the filler material. The thickness of the Electrical Double Layer is determined as the place where the potential of the zeta is 0.37 times and it is expressed as " $\delta$ ". The formula for calculating the zeta potential is presented in equation (Eq 1). Accordingly, the magnitude of the zeta potential varies according to the electrical double layer thickness " $\delta$ " and the amount of charge on the surface " $\sigma$ ", the electrical permeability is expressed by " $\varepsilon_{0}$ " and the dielectric constant is expressed by " $\varepsilon_{\mathrm{r}}$ ". Zeta potential, $\zeta$, can be calculated by the correlation in Eq 1.

$$
\zeta=\frac{\delta \sigma}{\varepsilon_{0} \varepsilon_{r}}
$$

Eq 1. 


\section{Surface shear}

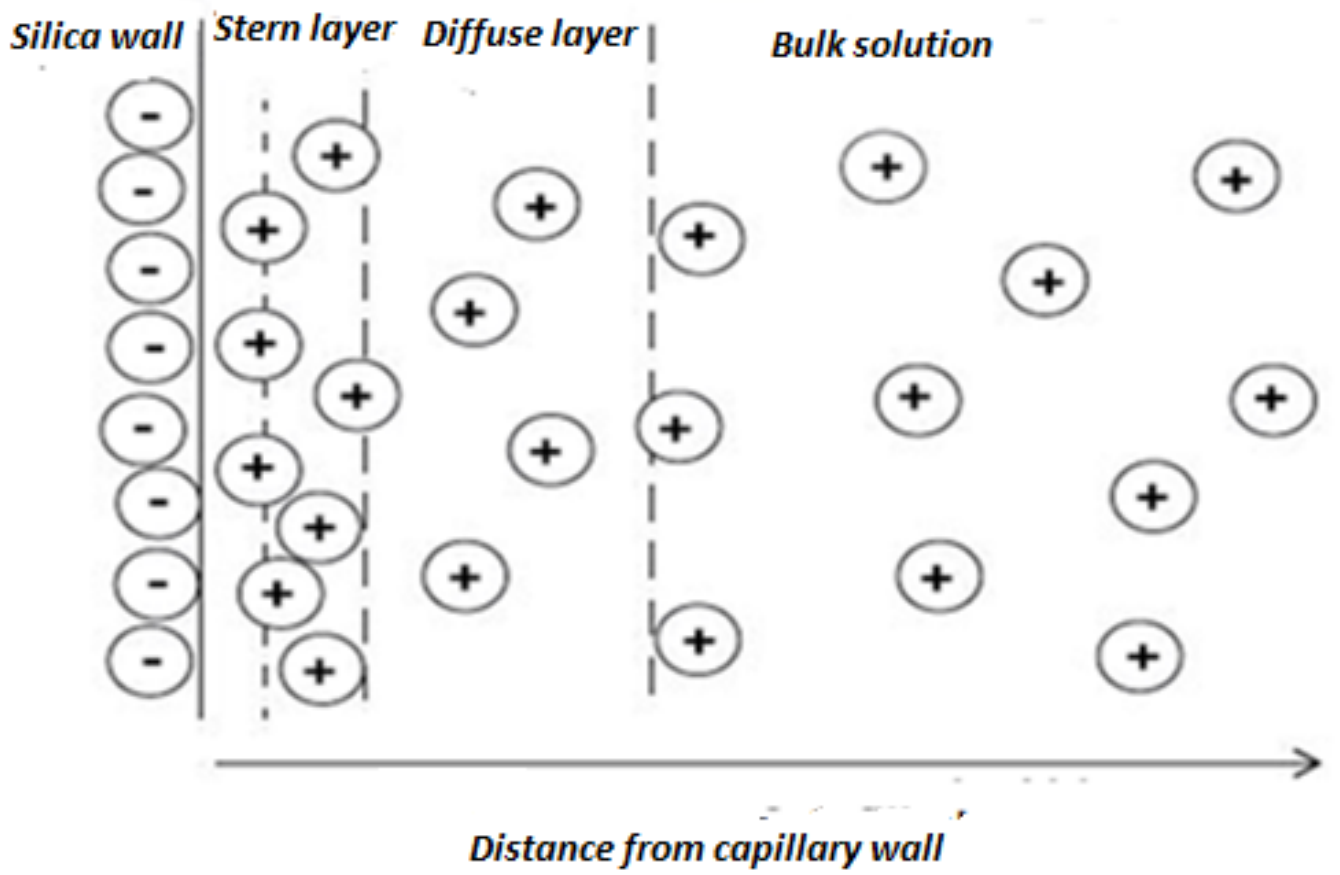

Figure 4. Electrical Double Layer structure on silica wall [17].

The electrical double layer thickness depends on the electrical permeability, " $\varepsilon_{r}$ " and the ionic strength of the electrolyte solution, "I". In the equation, $F, R^{*}$, and $T$ represent the Faraday constant, ideal gas constant and absolute temperature, respectively. Electrical Double Layer Thickness, " $\delta$ " is calculated as below Equation 2.

$$
\delta=\sqrt{\frac{\left(\varepsilon_{0} \times \varepsilon_{r} \times R^{*} \times T\right)}{\left(2 F_{2} \times I\right)}}
$$

The magnitude of the electroosmotic flow caused by the electrical field applied along the capillary column, and the " $\mu_{\mathrm{EOF}}$ " is directly proportional to the zeta potential, the viscosity of the mobile phase solution changes inversely with " $p$ " and the equation is found in the correlation in Equation 3.

$$
\mu_{E O F}=\frac{\varepsilon_{0} \varepsilon_{r} \zeta}{\rho}
$$

Eq 3.

As can be understood from Equation 2., the ionic strength of the solution and the electrical double layer thickness change inversely [18]. 


\section{Capillary Electrochromatography (CEC)}

Electrochromatography is one of the chromatography techniques that use the electroosmosis occurring in a tiny and filled column as the driving force instead of using hydraulic pressure in HPLC [19]. Electroosmosis is the process of executing the mobile phase in interaction with the stationary phase with the help of the electric field, and the electroosmotic flow is also provided by the Electrical Double Layer, which occurs between the mobile phase and the stationary phase [20]. Electrochromatography (CEC) as hybrid technology is defined as the combination of High-Performance Liquid Chromatography (HPLC) and Capillary Electrophoresis (CE) techniques. The fact that the mobile phase interacts with the stationary phase present in the capillary CEC column enabling electroosmotic flow (EOF), which provides several advantages such as high selectivity, high efficiency, and high resolution as well as the low amount of solvent consumption [17]. The sustainability of the electroosmotic flow (EOF) can be carried out through a variety of parameters such as $\mathrm{pH}$, ionic power and organic modifier groups. It is using hydraulic pressure as the driving force causes the parabolic flow to occur in the HPLC system, whereas in the CEC system, direct current is formed by applying the electric field and EOF with plug flow profile occurs. In this case, higher peak capacity with higher efficiency is achieved and effective chromatographic separation takes place $[10,21,22]$. EOF is the driving force commonly used in CEC and CE, and the separation of analytes is not only dependent on electrophoretic mobility, but the interaction between the mobile phase and the stationary phase is also of great importance. Unlike CE, CEC's interaction between the mobile phase and the stationary phase is provided by the Electrical Double Layer. CEC system has a higher peak capacity and selectivity since it contains a stationary phase in the column compared to CE and HPLC. High separation performance can be achieved with the EOF as the driving force formed by the filled column it contains [19]. There is a difference between CE and CEC methods in terms of source in order to contribute to the electroosmotic flow. In CE, the surface charge in the capillary wall provides EOF, while in CEC this feature is provided by the particles. Considering CEC, the variety of particles as well as the amount of silanol groups and other bound groups also have an impact on the EOF flow. Commercially available silica columns are used as a stationary phase, based on surface area and size difference. For this purpose, different methods are applied by various manufacturers in the process of attaching silica-bound alkyl groups [20]. Capillary electrochromatography can be expressed as separation process that takes place using chromatographic solid support material accepted as a stationary phase to which electrical field applied across.

Capillary electrochromatography columns are obtained with the reinforcement of filling material for approximately $100 \mathrm{~cm}$ long silica columns with an internal diameter between 50 and $100 \mu \mathrm{m}$. As a filler, silica gels with a diameter of between 1.5 and $10 \mu \mathrm{m}$ are generally used. Columns are usually prepared by loading the filling material by high-pressure pumps. The mobile phases in the CEC system contain solutions that ensure the continuity of the flow. Compared to liquid chromatography (LC), the number of organic modifying groups used in the CEC system is higher. For the mobile phase, it is preferred that the acetonitrile concentration is between $50-90 \%$. In the CEC system, where the photometric detector is used individually, the detector cell length in the CEC column is approximately two times smaller compared to its counterpart in the HPLC system, so it is 100 times less sensitive compared to HPLC analysis. The use of UV, fluorescence and mass detectors provides an alternative to the used detectors in the CEC system.

If the analytical sensitivity is improved 1000 times more, fluorescence determination is observed to be 1 to 4 times more sensitive than simple UV determination. When using a laser adapted fluorescence detector, it can reduce the determination level to approximately 10-16 $\mathrm{M}$, thereby increasing the sensitivity. When a mass detector is used, it can be determined at the micromolar level and can give an idea about the structure of the molecule. Along with these, different determination methods such as thermo-optical absorbance, NMR, photochemical reaction detection and light scattering studies are also included in the literature [23].

The most important advantage of CEC compared to liquid chromatography (LC) is that its effectiveness is very high. Van Demter graphics in CEC and LC are different from each other. The reason is that the difference in flow and eddy formation between the channels in the CEC is less. In addition, while stationary phase particles block the flow of the mobile phase in LC, they do not block in CEC, because electroosmotic flow 
occurs on particle surfaces. Since there is no pressure drop across the column in CEC, it is possible to use the columns. However, the main difference between LC and CEC is the use of functional monomers such as 2-acrylo amido, 2-methyl propane sulfonic acid (AMPS), $\mathrm{N}$-Methacryloyl-L-phenylalanine (MAPA), which can provide electroosmotic flow [24,25].

The parameters and calculations of the electrochromatographic separation conditions are as follows:

Here in the formula $\mu$ eof; electroosmotic motion, $L_{e}$ $(m)$; the effective length of the column, $L_{t}(m)$; the total length of the column, $\mathrm{V}$; applied electro voltage (volts) and $t_{R}$; It is the time elapsed for the non-detained species. In addition to being the main driving force of the CEC system, EOF is also an indicator of the permeability of the monolithic column. EOF can be calculated quantitatively.

$$
\mu_{E O F}=\frac{L_{e} \times L_{t}}{V \times t_{R}}
$$

Eq 4.

There is a significant retention time for each analyte in a column indicated by $t_{R}$. Retention time is the time elapsed until the sample is out of dedector after loading. If a column used in the separation system which does not retain sample on as a stationary phase, the time until this substance passes through the detector is indicated as $t_{0}$. Difference between $t_{R}$ and $t_{0}$ is called corrected retention time. However, if the sample contains two separate analytes relative retention time can be calculated with the help of retention times of these compounds abreviated as $t_{R 1}$ and $t_{R 2}$ by the following equation. The higher relative retention time, denoted by , is a sign that the detachments are happening.

$$
\alpha=\frac{t^{\prime} R_{1}}{t^{\prime} R_{2}}
$$

Eq 5.

The retention factor is the ratio of the time an analyte spends in the stationary phase to the time the analyte spends in the mobile phase. In reverse-phase chromatography, the polarity of the monolithic structure is expressed by the retention factor. In hydrophilic interaction chromatography, it is used as a parameter showing the hydrophobicity of the monolithic structure. The retention factor is usually calculated by the formula given below;

$$
k=\frac{t_{R}-t_{0}}{t_{0}}
$$

Theoretical plate number and height are important chromatographic parameters showing the efficiency and speed of the separation on the column. The efficiency of the column is directly proportional to the number of theoretical plates, that is, the higher the number of theoretical plates, the higher the efficiency of the column. The theoretical plate height is the indicator of the separation speed of the column and is inversely proportional to the $\mathrm{N}$ value.

$$
N=5.54 \times \frac{\left(t_{R}^{2}\right)}{\left(w_{1 / 2}^{2}\right)}
$$

$$
N=16 x\left(\left(t^{2}\right)\right) /\left(\left(w^{2}\right)\right) \quad \text { Eq } 8 .
$$

Here, w; the base width of the peak for the compound and $w_{1 / 2}{ }^{2}$; refers to the base width at the half peak height, $\mathrm{t}$; indicates the retention time of the compound.

The theoretical plate height is calculated by the formula below given; $\mathrm{H}$; theoretical plate height, $\mathrm{L}$; column length and $\mathrm{N}$; is the theoretical plate number.

$$
H=\frac{L}{N}
$$

Darcy equation [26] is used to calculate the column permeability. F; flow rate of the mobile phase, $\eta$; viscosity of the mobile phase, $L$; column length, $\Delta P$; back pressure of the column and $r$; is the inner diameter of the column. 


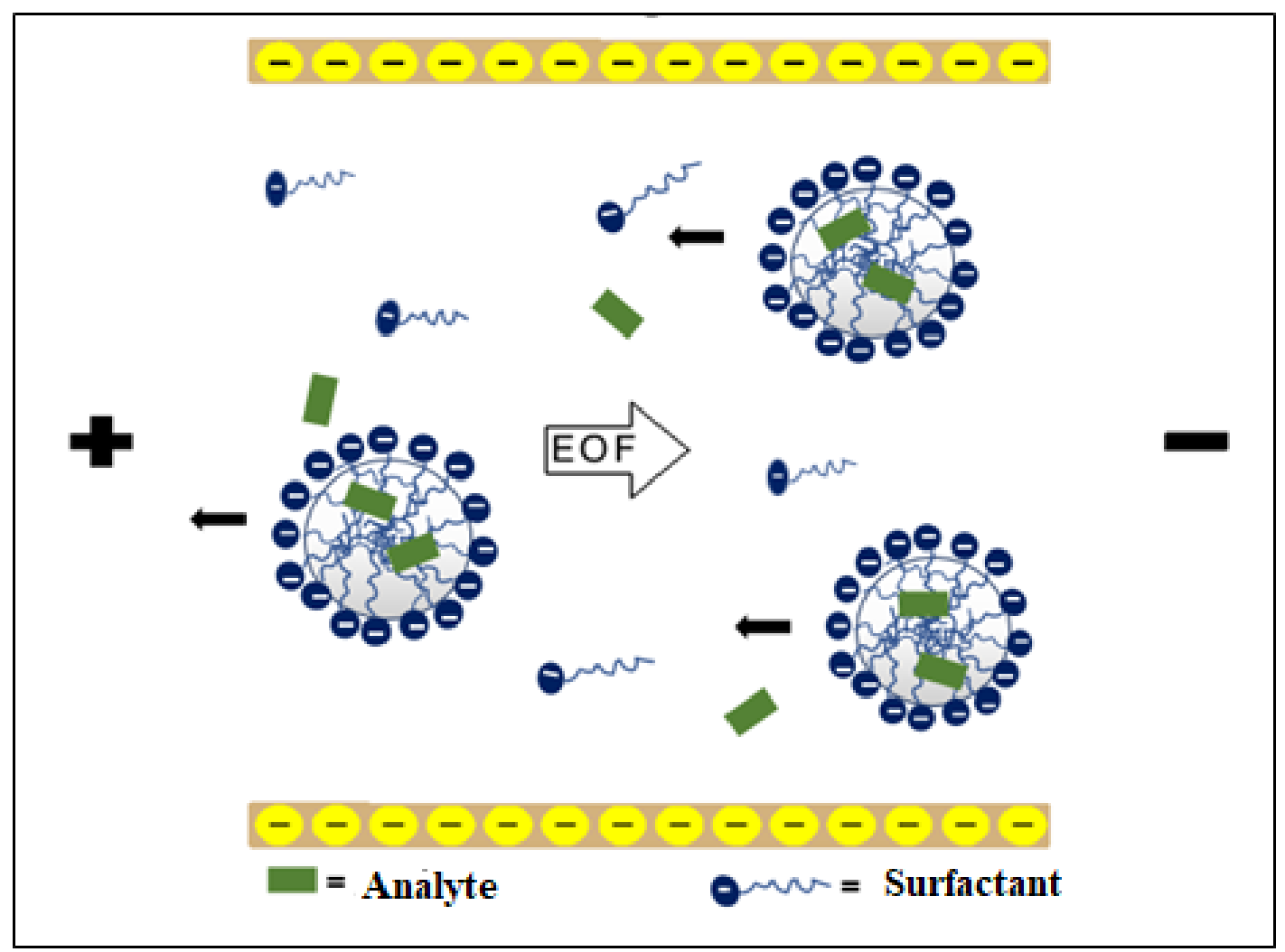

Figure 5. Schematic representation of separations in the MECC system [36].

$$
K=\frac{(F \times \eta \times L)}{\left(\Delta P \times \pi \times r^{2}\right)}
$$

Eq 10.

The capillary electrochromatography system is based on two techniques: packed column and micellar electrokinetic capillary chromatography. Among these techniques, micellar electrokinetic capillary chromatography (MECC) has found more research areas to work [27].

\section{Micellar Electrokinetic Capillary Chromatography (MEKC)}

Micellar electrokinetic capillary chromatography (MEKC) is one of the capillary electrophoresis methods consisting of a pseudo-stationary phase and a mobile phase. This method allows the separation of charged particles as well as uncharged particles.

The micellar capillary electrokinetic chromatography method is based on the different electrophoretic mobility of analytes that are desired to be separated. In this method, if the inner surface of the capillary tube is negatively charged, electroosmotic migration occurs towards the cathode. With such mobility, separations occur in the column in order of cations, neutral molecules and anions, respectively. As the charge of cations increases, elution time is decreased, as the charge of anions increases, on the contrary, elution time from the column becomes longer. If a positively charged surfactant is added to the solution, the inner surface of the capillary tube, having a negatively charged inner surface, becomes positive. Thus, the direction of the electroosmotic flow reverses, and electrophoretic migration occurs towards the anode, and this time the anions are the first molecules to leave the column. If a positively charged surfactant is added to the solution, the inner surface of the capillary tube having a negative inner surface becomes positive. Thus, the direction of the electroosmotic flow reverses, and electrophoretic migration occurs towards the anode, and this time the anions are the first molecules to leave the column. 
However, it is not possible to separate neutral molecules in both cases. Considering this issue, Terabe et al. developed a new method [28]. When sodium dodecyl sulfate surfactant is included in the medium within this method's scope, negatively charged spherical micelles occur. These chains, whose inner and middle parts are apolar, act as if apolar characterized solvent, and neutral organic molecules can be easily dissolved in these solvents. At the same time, neutral molecules are distributed between the apolar character solvent and the aqueous phase, creating a state of equilibrium [29,30]. Micelles act as a stationary phase in MEKC. For this reason, they are also known as pseudo- stationary phases. With the help of this phase, the separation of neutral molecules takes place in the MECC. Neutral molecules in the reaction medium reach equilibrium conditions within different periods. Thus, each molecule reaches the detector within different times and shows different peaks. As a result, neutral molecules are separated. In the absence of micelles, neutral molecules come together to the detector, so a single peak is observed in the system [31]. Different analyzes can be made in MEKC by adding different substances to the solution conditions. For example, when the cyclodextrins containing optically active groups are added enantiomers of small molecules reach the detector at different times due to their retention in the pores of these optically active groups. When the peaks of these structures are examined, it is seen that the chromatograms are generally composed of overlapping binary peaks [32].

The parameters and calculations of the separations in MEKC are as follows:

As with conventional chromatography, the retention factor is defined as k;

$$
k=\frac{n_{m c}}{n_{a q}}
$$

Here, $n_{m c}$ is the amount of analyte incorporated into the micelles, and $n_{a q}$ is the amount of analyte that surrounds the aqueous solution. In this case, the relationship between the retention factor and migration time can be expressed as follows

$$
k=\frac{\left(t_{R}-t_{0}\right)}{t_{0}-\left(1-\frac{t_{R}}{t_{m c}}\right)}
$$

Eq 12.

In its revised version, it can be written as follows:

$$
t_{R}=\frac{(1+k)}{1+\left(\frac{t_{0}}{t_{m c}}\right) k}
$$

Eq 13.

If the analyte does not participate in the micelle or interact with the micelle, the migration time of such solutes is equal to $t_{0}$, so $k=0$.

On the other hand, if the analyte interacts with micelles, the migration time " $t_{R}$ " and retention factor, " $k$ " will be infinitely large. Therefore, migration time is limited between $t_{0}$ and $t_{m c}$. When $t_{m c}$ is infinite or when the micelles do not come out of the capillary column, the absolute value of the electroosmotic velocity and the electrophoretic velocity of the micelles moving in the opposite direction will be as follows:

$$
t_{R}=(1+k) t_{0}
$$

This is the same as the conventional approach in chromatography, meaning that the migration time parameter is equal to infinity. The equation that occurs when $t_{0}$ reaches infinity or when the electroosmotic flow is completely stopped is as follows:

$$
t_{R}=\left(1+\frac{1}{k}\right) t_{m}
$$


In this case, the aqueous phase can never come out of the capillary column. Only micelles migrate through the aqueous phase towards the anode. In MECC, the separation factor can be calculated by the following equation:

$R_{s}=\left(\frac{N^{1 / 2}}{4}\right) \times\left[\left(\frac{\alpha-1}{\alpha}\right)\right] \times\left[\frac{k_{2}}{1+k_{2}}\right] \times\left[1-\left(\frac{t_{0}}{t_{m c}}\right)\right] \div\left[1+\left(\frac{t_{0}}{t_{m c}}\right) k_{1}\right]$

Eq 16.

Here $\mathrm{N}$ gives the number of theoretical plates. and are retention factors of analytes 1 and 2, respectively. The ratio $k_{2}$ to $k_{1}$ is equal to $\alpha$, which is the separation factor.

With the increase of the square root of the number of plates, the $\alpha$ value increases proportionally. Generally, the number of plates for most analytes is between 10.0000-20.0000. Commonly, the higher the theoretical plate number, the higher the voltage is applied unless there is too much joule overheating. Because the micelles have low diffusion coefficient, the high retention factors of the solutes give high plate numbers [37].

\section{Ligand Exchange Capillary Electrophoresis (LECE)}

Chiral ligand exchange chromatography (LECE), first applied by Davankov and Rogozhin [38] in 1970, is one of the methods that provide separation of enantiomeric molecules according to chirality. At first studies, original LEC phases are based on chlormethylated polystyrene-bound L-proline (L-Pro) residues [39]. The chiral selectors used in this separation interact with the analyte and form a diastomeric triple substance. Chiral recognition is based on the formation of triple mixed metal complexes between a chiral selective ligand and analyte ligand [40]. The complex ions form ionic, covalent or coordination bonds to the stable phase. In this case, the ligands can combine with the coordinating metal. Ligand modifiers with this structure are used to separate amino acids or similar organic structures that are difficult or impossible to separate [41]. For example, by using $\mathrm{Cu}$ (II) or other metal ions as complexing agents, the amino acid enantiomers are separated by an extraordinary separation factor [42].

Ligand exchange (LE) separation mechanism is based on the formation of diastereomeric triplet between the analyte and chiral selector ligand. The distinction is due to the difference between the analyte enantiomers of two mixed complexes and the complex stability constants [43]. The equilibrium reaction is described as follows:

$$
\begin{aligned}
& \mathrm{Cu}(\mathrm{L}-\mathrm{Sel})_{2}+\mathrm{S}-\mathrm{A} \Leftrightarrow \mathrm{Cu}(\mathrm{L}-\mathrm{Sel})(\mathrm{S}-\mathrm{A})+\mathrm{L}-\mathrm{Sel} \\
& \text { Sel: selector } \\
& \mathrm{Cu}(\mathrm{L}-\mathrm{Sel})_{2}+\mathrm{R}-\mathrm{A} \Leftrightarrow \mathrm{Cu}(\mathrm{L}-\mathrm{Sel})(\mathrm{R}-\mathrm{A})+\mathrm{L}-\mathrm{Sel} \\
& \mathrm{A}: \text { analyte }
\end{aligned}
$$

The LE principle is based on using the chiral selectormetal complex as an additive to the electrolyte in CE. First, the application of this technique in CE has been reported by the group of Zare [44] with the use of L-histidine-Cu (II) and aspartame-CU (II) complexes as chiral selectors for chiral separation of amino acids. The researchers observed that when the micelle-forming surfactant such as sodium tetradecyl sulfate (STS) was added, the separation improved. They also proved that the enantiomeric selectivity factor disappeared with the use of Co (II) instead of CU (II).

\section{Affinity Capillary Electrophoresis (ACE)}

This chromatography method is used for the purification of enzymes, hormones, antibodies, nucleic acid and some special proteins. [45]. Proteins that can form complexes with the ligands attach to the matrix and are retained in the column, while the free protein leaves the column. This separation takes place with a $\mathrm{pH}$ change, ionic intensity effect or addition of salt solution [46].

Affinity capillary electrophoresis (ACE) was first introduced in the early 90's to study protein-ligand interaction [45]. One of the improved varieties of the CE is the Affinity Capillary Electrophoresis (ACE), which is the method that provides the electrophoretic migration of analytes by combining it with a different biological agent or affinity ligand [47]. Among these biologic agents or ligands, some immobilized antibodies, some serum proteins or enzymes, as well as cyclodextrin-derived carbohydrates can be applied in enantiomeric separations in CE methods, acting as a chiral selector or as chiral binding agent $[48,49]$.

ACE applications are classified under two main titles: homogeneous methods and heterogeneous methods [50]. In a homogeneous method, the binding agent and analyte interact in a sample or in a solution that may 
occur in a CE working buffer. In the heterogeneous method, the binder is fixed to support used to assist the capture or isolation of the analyte to the inner surface of the CE system. This second approach can also be viewed as a kind of affinity chromatography combined with CE or using a binding agent in electrokinetic chromatography [51].

\section{Chiral Selectors or Chiral Stationary Phases in Enantiomeric Separations}

\section{Molecularly Imprinted Polymers (MIPS)}

Molecular imprinting technology is the preferred method of designing artificial receptors with selectivity and specificity for a given analyte [52]. Molecularly imprinted polymer (MIPs), which are polymeric matrices synthesized by molecular imprinting method, are synthetic or semi-synthetic molecular recognition elements that can mimic natural recognition found in the mechanism of antibody-antigen interactions, signal transduction, enzymatic catalysis, protein synthesis, DNA replication and biological receptors [53]. MIPs can be considered as recognition materials in chemical and biological processes, but they also have application areas such as biotechnology, environment, food, chromatography, sensor, catalyst, drug handling, synthetic antibody and receptors [54]. MIPs designed to be used in place of natural systems, also have advantages over natural systems. These can be listed as higher physical and mechanical strength, chemical stability, higher resistance to high temperature and pressure [55].

In the molecular imprinting method, suitable monomers, crosslinkers, template and target molecule-containing species coexist. In the solution medium, monomers and crosslinkers are organized with the support of strong interactions around the template molecule. First, a precomplexation reaction occurs between the template molecule and the functional monomer. The structure of functional monomer is arranged according to a specific sequence and orientation in the presence of template molecules, in the presence of crosslinkers and initiators, methods such as photo-, thermal- or electro-polymerization are stabilized and polymerization reaction takes place. After the polymerization process, template molecule is removed from the polymer matrice and there are gaps in the rest of the polymer that contain the steric and functional properties of the template molecule. These voids are chemically functionalized through a high crosslinker and about 30-80\% monomer amount [56] while allowing selectively rebonding of the template or a different analyte. Permanent pores formed in the matrix during the evaporation process form the inner and outer wide surfaces. In this respect, the effect of the solvent on the recognition behavior of the polymer is strong.

With the advantages of the MIPs mentioned above, it was also possible to evaluate these polymers as a chiral stationary phase (CSP) in the CE and CEC methods. Although MIPs are intended to be used for separations occurring in HPLC in previous periods, there are several disadvantages, such as a slow level of interaction kinetics and inhomogeneity of binding sites [57]. In addition, it will be expected that the CEC system is a hybrid technology designed as a combination of liquid chromatography (LC) and CE techniques, and using of MIPs in CEC with high efficiency and selectivity for separation, and these privileges will be further enhanced.

Most of the current research is on the development of new column technologies, and the starting point in this area is based on the periods when the separations were performed by HPLC. Packing materials in the CEC column have two important functions. The first is to provide appropriate units for the necessary interactions to take place, just as in HPLC, and the other is to ensure that EOF is created, one of the essential parts of CEC [58]. EOF can be generated in the presence of ionizable groups in the stationary phase. The driving force used for this purpose is EOF formed with the ionization of the silanol groups on the surface of the silica. However, stationary phases used in the HPLC systems cannot generally be considered suitable for CEC, as the silanol concentration decreases after derivatizing processes in the stationary phases used as seen in HPLC and this situation cannot meet the sufficient expectation for EOF formation [59]. Depending on the $\mathrm{pH}$ of the medium, EOF is formed from the stationary phase materials containing silica. At low $\mathrm{pH}$ values, silanol groups are protonated and this situation reduces the EOF. As the $\mathrm{pH}$ rises to higher values, the stability of the stationary phase material may not be suitable. In addition, undesirable conditions such as peak broadening and low column efficiency occur by adsorption of non-polar analytes on active silanol groups [60]. In addition to the fact that they can perform ionization and are not affected by the $\mathrm{pH}$ change, polymeric packing materials have the ability to form EOF with the fact that the charge density on their surface is at a controllable level [61]. 


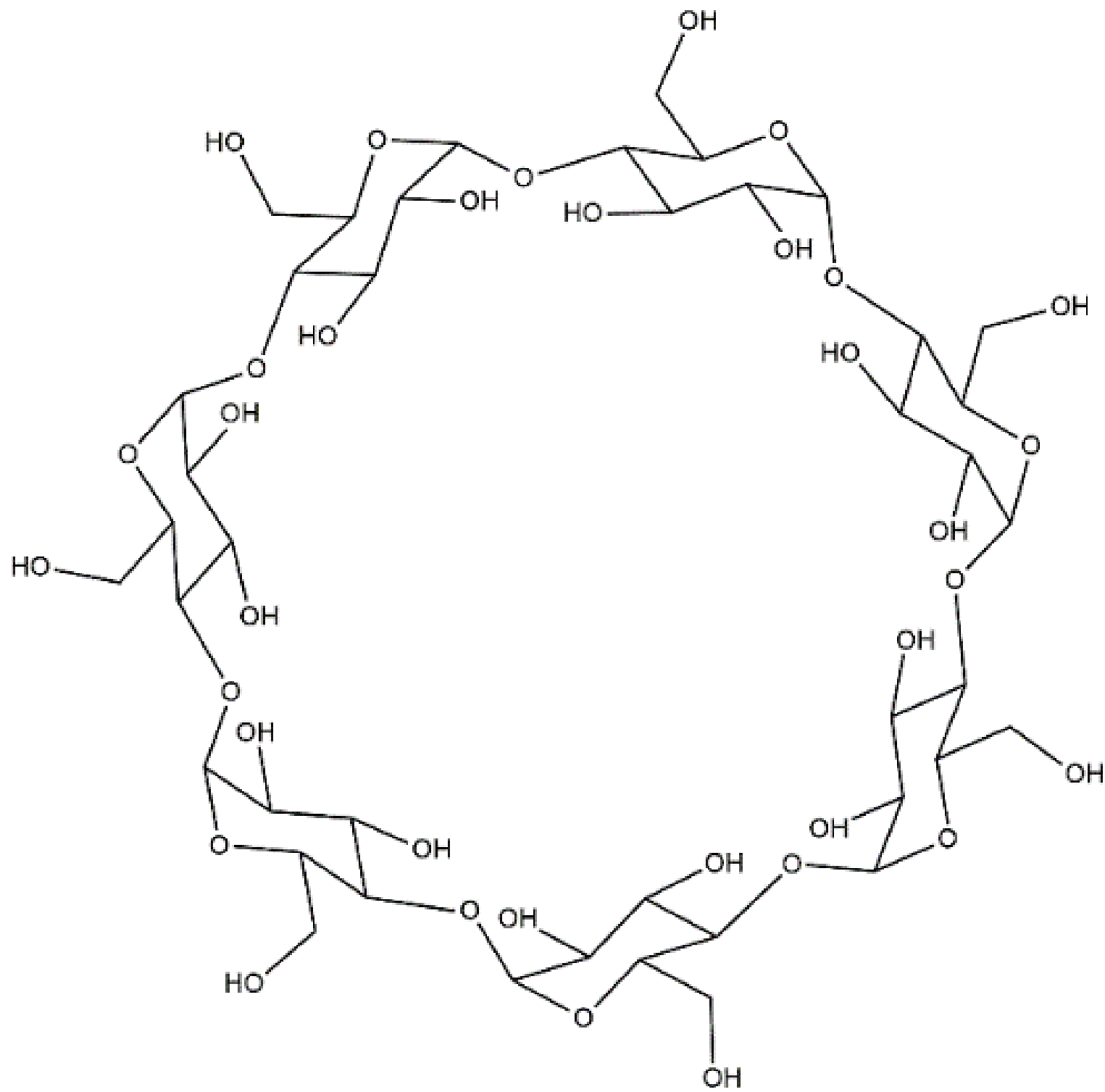

Figure 6. Positioning hydroxyl groups in the structure of the CD.

Columns most frequently used in CEC are generally evaluated under three headings: Open-Tubular (OT), packed and monolithic columns. There is no packing material in the open tubular columns, as a result of physical or chemical interactions, the capillary is formed on the column by being covered by a stationary phase. Molecular structures such as molecularly imprinted polymers (MIPs), host ligands, block copolymers, nanotubes, polysaccharides, nanoparticles, monoliths are structures that can be exemplified for use as stationary phase materials in OT columns [62]. Packed columns are formed by placing the particles between the frit with the help of high pressure. Frits are materials that ensure co- lumns stay in the particles. The use of packed columns is common due to its high sample capacity and more sensitivity compared to open-tubular columns [63]. Particle-filled columns require advanced experimental skills and experience to ensure stability and repeatability. One of the biggest challenges is the fabrication of frits that do not hinder the mobile phase flow and can properly hold the particles in the column. However, monolithic columns do not need frits as they fix themselves to the silica capillary column wall. Therefore, monolithic columns have a stable, sufficient mobile phase permeability and prevent bubble formation [64]. Since the early 1990s, monolithic stationary phases have 
become one of the most interesting micro-separation techniques with their evaluation as chromatographic material. Monolithic columns are macroporous polymeric materials prepared by in-situ polymerization of the monomers in the environment where the pore-forming mixture system and the initiator is also present [65]. The reason for the higher performance of monoliths is that they have mass transfer feature [66]. Since the diffusion path is very short, the analyte reaches the pore with a net flow instead of diffusion. The film resistance properties of monolithic columns are also different. The film thickness is considered to be smaller and the surface area larger. Both effects increase mass transfer and perform purification faster in the monolithic flow system [15]. Recently, monolithic columns have attracted more attention than particle-filled columns. Easy to fabricate and obtain the desired chemical properties are the most important advantages of monolithic columns. CEC is a widely used separation technique for medicine, pharmaceutical and environmental sciences as it has binding compatibility with Mass Spectrometry (Mass Spectrometer, MS) and Nuclear Magnetic Resonance Spectrometer (NMRS) [67].

\section{Cyclodextrins (CDS) and Its Derivatives}

Cyclodextrins (CDs) are biosynthetic ring oligomers consisting of anhydrous glycopyranose units linked together through $\alpha-1,4$-glycosidic bonds. Also known as cycloamyloses, cyclomaltoses and Schardinger dextrins. When the molecular shape of cyclodextrins is examined, it is seen that there are molecules in the hollow truncated cone structure $[68,69]$. It has a hydrophobic property as a result of an electron-rich medium provided by irreversible hydrogen atoms and most glycosidic oxygen atoms in the ring. Since the hydroxyl groups are located on the outside of the ring, the outer surface shows a hydrophilic feature. Thanks to these special structures, cyclodextrins can form a guest-host complex with these molecules by trapping the hydrophobic molecules in the liquid or solid form, which are large enough to fit in the cyclodextrin space, in the hydrophobic inner cavities. Cyclodextrins containing six glycopyranose units are called alpha $(\alpha)$, those containing seven are beta $(\beta)$, and those containing eight are gamma $(\gamma)$ cyclodextrin (CD). Theoretically, there are CDs containing more than eight glucopyranose units, $10 \varepsilon$ - (epsilon), 11\}- (zeta), $12 \eta$ - (eta), 130- (theta) glucopyranose units. However, it is not preferred much due to its low complexity and increased solubility in water [70].
Cyclodextrins can form host-guest type complex space relates to their diameter. Since $\alpha-C D$ has a small diameter $(5 \AA)$, it is not very suitable for complexing. The diameter of $\beta-C D$ is $6 \AA$, the diameter of $\gamma-C D$ is $8 \AA$ and it can form complexes with many molecules [71]. It is possible to derivatize cyclodextrins in order to increase their complex formation capacities, change their physicochemical properties and gain different properties. The modified cyclodextrins obtained may have better properties than natural cyclodextrins. CDs have a large number of functional groups. The presence of 18 hydroxyl groups on $\alpha-C D, 21$ on $\beta-C D$ and 24 on $\gamma-C D$ provided cyclodextrins a lot of chemical functions [72].

CDs are often used in separation techniques. In this regard, chiral selectivity values $(\alpha)$ of CDs in enantiomeric separations often do not exceed two. This situation, which seems to be disadvantageous, can be compensated by the high efficiency of capillary columns. In some cases, CDs provide baseline separation with high efficiency of 105-106 plates per meter despite low $\alpha$ values in the range 1.01-1.03 [73]. One of the most important parameters that negatively affect chiral selectivity is the poor solubility of analytes and selectors. However, CDs are capable of dissolving analytes through the inclusion phenomenon. Therefore, it can be an important parameter in improving the solubility of analytes and selectors if CDs are derivatized [74]. In order for CDs to be used in efficient separation techniques, the charge accumulation they have must match the concentration of background electrolyte (BGE) [74]. Due to their natural structure, each glucose unit of CDs has five chiral centers. In addition, each of the functional groups in chiral centers tends to have different directions. Also, if CDs can be functionalized with different suitable agents, new chiral centers will be created, thereby expanding the limits of chiral recognition. When it comes to the separation of enantiomers, CDs have the flexibility to conformationally change their shape in order to interact with one of the enantiomeric species. Thanks to their natural appeal, they are often preferred as chiral selectors in separation methods, although their selectivity values are not so high [75].

\section{Metal-Organic Frameworks (MOFS)}

A metal-organic frameworks (MOF)s are crystalline materials that can be thought of as a hybrid of two main components are a metal cation and an organic molecule called a binder (or bridging ligand). These compo- 
nents are defined as the primary structural units of MOF structures. A structural unit that combines a series of metal ions and ligands to form stiffer frames can be defined as secondary structure units (SBUs) [76]. Organic Ligand groups trap metal ions to their positions, so SBUs are used as large hard corners instead of metals. Therefore, the successful creation of rigid frames is focused on SBUs. Thus, expanded frames with high structural stability are produced [77]. Metal ions such as $\mathrm{Cr}^{+3}, \mathrm{Fe}^{+3}$ $\mathrm{Cu}^{+2}, \mathrm{Zn}^{+2}, \mathrm{Ti}^{+4}, \mathrm{Al}^{+3}$ or metal clusters with two or more metal atoms are used as metal binders for the synthesis of MOF structures. Transition metal ions, especially first order transition metal ions $\left(\mathrm{Ti}^{+4}, \mathrm{Cr}^{+3}, \mathrm{Mn}^{+7}, \mathrm{Fe}^{+3}\right.$, etc.) And some alkali metal ions $\left(\mathrm{Li}^{+1}, \mathrm{Na}^{+1}, \mathrm{~K}^{+1}\right.$, etc.). Alkaline earth metal ions $\left(\mathrm{Be}^{+2}, \mathrm{Mg}^{+2}, \mathrm{Ca}^{+2}\right.$, etc.) and rare earth metal ions $\left(\mathrm{SC}^{+3}, \mathrm{Y}^{+3}, \mathrm{La}^{+3}\right)$ are used for the construction of MOBs [78]. Organic ligands used as bridging materials that form the organic part in the MOF synthesis stage generally contain coordinating functional groups such as carboxylate, phosphate, sulfonate, amine or nitrile. The most commonly used organic ligand benzene1,4-dicarboxylic acid (BDC) [79]. Organic ligands or binders can donate a large number of lone electron pairs to metal ions. Metal ions are made up of empty orbital shells that can accept these lone pairs of electrons to form a metal-organic framework material [80].

The main methods used in the synthesis of MOFs are hydrothermal, solvothermal, mechanochemical, microwave-assisted, ultrasound-assisted and on-site binding synthesis methods. The properties of the synthesized MOFs are directly related to the method used during synthesis [81].

As a kind of crystalline materials, MOFs can be used in various applications such as; gas storage [82], catalysis [83], fuel cell [84], membranes [85] and drug delivery [86] thanks to high specific surface areas, high pore volume, pores opening to the back and flexible frame. In the processing for synthesis or design, various MOFs with different physical and chemical properties can be obtained by the modified combination of metal complexes and organic ligands. This flexible synthesis procedure enables the production of multi-functional MOFs in shape, pore size and chemical functionality. Thus, some reactions that cannot be carried out in solution are now carried out in the porous space of the MOFs. [87]. The adjustable chemistry, frame of its high porosity and excellent surface area are shown as the most promising feature of MOFs, then with the help of these exclusive properties, they are shown as the more demanded material compared to traditional porous materials such as zeolites and carbon molecular sieves [88]. Due to the strong chemical bonds in their structures, their thermal stability gives a life of up to approximately $500^{\circ} \mathrm{C}$. In addition, their sensitivity to the resulting linkdisplacement reactions makes chemically stable MOFs as a result of solvent treatment with solvents [89]. Flexibility is another notable feature of MOFs, perhaps due to minor disruption of pyridyl linkages or interactions between ligands, providing a dynamic behavior in materials. Thanks to this feature, it maintains its structural integrity and facilitates formation changes. For this reason, X-ray crystallography and other spectroscopic techniques can be performed in detail to monitor the chemical reactions occurring in the pores [90].

In recent years, with the use of mixtures in micro-scale separations [91], the potential of using MOFs as stationary phase in chromatographic studies has attracted attention. In the continuation of these developments, some of the studies investigating stationary phase performances of MOFs in HPLC [92] and GC [94] were carried out. In the study published in 2014, Fei reported for the first time that MOFs could be used in the CEC system as chiral stationary phase (CSP) [95]. In parallel with these developments, the ideas of using chiral MOFs as CSP for enantioseperation in open tubular-CEC and CSPs for packed-CEC system are also included in the literature. [96,97]. However, there are some disadvantages in the separation processes with respect to low phase ratio between the stationary phase and mobile phase and low sample capacity in OT-CEC. Various techniques such as modifying OT columns with the solgel coating to increase the available surface area, internal wall engraving and incorporation of nanoparticles into the column are recommended in the literature to improve separations in the CEC system. [99]. Also, it has been reported that by using chiral MOFs with features such as versatile functionality and high porosity, these problems can be solved successfully in the CEC system [95].

The possibility of almost unlimited combinations of metal and organic binders is a great privilege of these materials. It is possible to create the material that is intended to be designed theoretically by stretching one or both of the building blocks. The compatibility between the size and shape of the molecule and the pore architecture reveals the separation potential [100]. The 
rationale for the separation of enantiomers is that diastereomers or a diastereomeric complex occur, and molecular control of the pore structure to allow chiral interactions [101] is the most serious challenge in this area. MOFs can be transformed into chiral centers using a chiral enantiomer as an organic binder or by derivatization reactions (eg functionalization of an $\mathrm{N}$-group) [102]. The inclusion of metalo-ligands in the MOF structure as bridging binders is another proposal presented in this field [103].

\section{Applications of Chiral Separations by Capillary Electrophoresis and Related Techniques}

\section{(MIPS) as Chiral Stationary Phases}

Amino acids are essential ingredients for creating animal nutrition protein. Amino acids are a combination of DL- enantiomers in nature. The interaction and functionality of these molecules are different in nature. Therefore, studies are ongoing for the recognition and separation of amino acid enantiomers today. Wu et al. prepared MIPs containing magnetic nanoparticles combined with the microchip-CEC method to be used as CSP to separate mandelic acid and histidine enantiomers [104]. Denizli et al. prepared amino acid-imprinted monolithic columns to perform enantiomeric separations of hydrophobic amino acids (tryptophan, phenylalanine and tyrosine) and histidine enantiomers in CEC $[105,106]$. While L-forms of amino acids are preferred as template molecules, $\mathrm{N}$-methacryloyl-(L)-phenylalanine (MAPA) monomer was preferred as a functional monomer to implement the MIT. The monolithic column where the MAPA monomer is preferred as a functional monomer can form EOF. This is also the exclusive feature of the MAPA monomer [14]. MAPA can act as a weak cation exchange monomer due to deprotanization caused by the carboxylic acid $(-\mathrm{COOH})$ and amino $(-\mathrm{NH} 2)$ group in the phenylalanine part of the MAPA monomer at $\mathrm{pH}$ above the isoelectric point $(\mathrm{pl}=5.48)$. Because of its relatively high hydrophobicity, phenylalanine has made a significant contribution to hydrophobic interactions by molecular imprinting in chromatographic column preparation. Hrobonova and Lomoneva reported [107] that they prepared L-phenylalanine-imprinted polymers for enantiomeric separation of phenylalanine and used as CSP in HPLC. The analytical performance of L-phenylalanine-imprinted CSP was also examined in the study. Yue et al. evaluated the separation of tryptophan enantiomers using L-tryptophan imprinted- silica nanoparticles as pseudo stationary phase in EKC [108]. The process of removing the imprinted (template) molecule from the matrix in the molecular imprinting technique may present difficulties for various reasons, such as finding a desorption agent or required extract solvent for the removal of the template molecule. At this point, electrochemistry provides alternative technology as long as only electron transfer is involved with electrochemical oxidation or reduction. Conductive polymers and copolymers have been applied in the literature as chiral stationary phases in order to recognize the amino acid enantiomers as a result of the ability of monomers to be converted into polymers in matrices, also their chemical stability, electrical conductivity and redox reversibility [112]. In the class of conductive polymers, polypyrrole (o-PPy) subjected to excessive oxidation (over-oxidised) is most often applied in the separation of enantiomers as matrices of MIPs [117].

Among the enantiomeric forms of propranolol, which is widely used in treating angina, the S-(-) form is far more pharmacologically active than the R-(-) form. Since it is used as a racemic form in clinical treatment, the separation of propranolol enantiomers is given importance [118]. Liu et al. preferred molecularly imprinted polymers to separate the enantiomeric forms of propranol [119]. What makes this study interesting is that while propranolol-imprinted polymer synthesis is done, 4-4'-azobis (4-cyanovaleric) acid (ACVA), which is derivatized with a carboxyl group, was preferred instead of using functional monomer. Due to the carboxyl group it contains, ACVA is a compound that is applied as a radical initiator since it can interact with propranolol. Still, it also created complexation with the template molecule in the molecular imprinting method. Chen et al. [120] reported that they developed propranolol-imprinted organic-inorganic hybrid monolithic columns for the separation of propranolol enantiomers in OT-CEC. In this study, it was stated that 3-(trimethoxysilyl) propyl methacrylate ( $\gamma$-MPS) was used as a crosslinker, because of the presence of $\mathrm{Si}-\mathrm{OH}$ groups it contains, it does not require preliminary preparations for the capillary column by directly interacting with the capillary column.

Gutierrez-Climante has developed porous silica beads equipped with molecularly imprinted nanoparticles (MINPS) applied as CSP in LC [121]. In this study, some anti-depressant drugs were used as test compounds for enantiomeric separation. In another study, Gutierrez and his team presented a surface-imprinted CSP 
for the enantiomeric separation of citalopram [122] $\mathrm{N}, \mathrm{N}^{\prime}$-diethyl aminodithiocarbamoylpropyl (trimethoxy) silane was used as the silanizing agent for the surface modification of the solid silica support. Also, citalopram was used as an imprinted-molecule in this study. 1,1'-Bi-2-naphthol (BINOL) is an organic compound often used as a ligand for transition metal-catalyzed asymmetric synthesis. However, it can also act as a host for enantiomeric separations as chiral reagents [123]. To examine the enantiomeric separation of BINOL with $\mathrm{R}$ - and S- enantiomers, a coating with molecularly imprinted polymer was performed on silica gel [124]. Dong et al. produced a new CSP modified with MIP by using (R)-BINOL as a template molecule in the polymerization performed on the surface via Molecular Imprinting Technology (MIT).

Kulsing et al. presented novel strategies to be used for chiral separations by molecularly imprinted polymers in open tubular (MIP-PLOT) capillary column formats by capillary liquid chromatography (CLC) [126]. In their study in 2014, the MIP-coated capillaries were applied for the separations of the ketoprofen racemic mixture. At their second attempt in this field, they preferred layer-on-layer polymerization method for the preparation of MIP-PLOT capillary column used to separate racemic mixtures of Z-L-Asp-OH.

It has been reported that organic-inorganic hybrid MIPS have been developed in order to eliminate the limitations caused by the weak sensitivity of the MIP formats used in CEC to pH changes [127]. As an alternative approach, Zhao and his team reported that they developed MIP monolithic columns based on polyhedral oligomeric silsesquioxanes (POSS) to be used for the separation of naproxen, amlodipine and zopiclone enantiomers with the OT-CEC system [128]. Unique features such as easy chemical modification, suitability to $\mathrm{pH}$ tolerance, high temperature and oxidation resistance have made POSS a privileged building block for creating multifunctional materials.

Molecular crowding is a method developed in recent years to stabilize the interaction between template molecule and functional monomer in MIT. As a result of synthesis using a molecular crowding agent, it is determined that it strengthens the interaction between the functional monomer and the template molecule [129]. Also, synthesized MIPs have more binding capacity as well as stronger affinity accordingly. A similar indicator of this situation is demonstrated by the fact that MIPs synthesized using a molecule crowding agent show better enantiomeric separation ability in the examinations conducted in the CEC system as a result of using CSP [132].

One of the latest strategies updated for the development of host capacities and interaction selectivity for MIPs is using of dendrimers with these polymers. Dendrimers are attractive candidates for material design due to the high degree of crosslinking it contains [134]. The large structure of the dendrimers makes the inlet and outlet of the template molecule into the polymer matrix very easy. As a result, dendrimer-MIP has been reported to provide faster mass transfer, better capacity and enantioselectivity in CEC [135].

\section{Cyclodextrins and Its Derivatives as Chiral Selectors}

Among all CDs, $\beta-C D$ is the most preferred CS agent because it is versatile and can be easily derivatized by reacting with different compounds [138-141]. Although $\gamma$-CD has the largest gap, the presence of an odd number of glucose rings reduces the symmetry of the gap, thereby increasing the dissolving power of the $\beta-C D$ [142]. The unique features of $\beta-C D$ are that its molecule has 35 chiral centers, so chiral separations can be achieved through the interaction between chiral $\beta-C D$ and enantiomers of analytes. In the internal hydrophobic space, the enantiomer can interact well with the $\beta-C D$ through hydrophobic interactions such as host-guest or inclusion complex and Van der Waals force. In the outer part of the game, the $\beta$-CD has a symmetry gap of $C_{7}$ and 14 hydroxyl groups suitable for attracting with the polar substituents of the enantiomers via hydrophilic interaction or hydrogen bond. The use of different substituents alters the enantioselectivity of the modified $\beta$-CDs. Modified $\beta$-CDs can be created in neutral [141,143], cationic [144-146] and anionic forms $[147,148]$. Cyclodextrin (CD) and its derivatives are among the most preferred chiral selectors in CE due to their chemical resistance, conveniences related to their structural properties and low UV absorptions [149-151]. In addition, the plurality of CD derivatives across the spaces and substituents meets the possibility of enantiomeric separation for large-scale chiral compounds [152]. CDs act as chiral selectors to separate enantiomers and are suitable for related strategies, such as capillary derivatization, inclusion complex formation mec- 
hanism, chiral recognition, molecular modeling, quantitative approaches, also detection of analytes [153-163]. 15 different cyclodextrin derivatives were investigated as a chiral complexing reagent. And the enantiomers of asenapine maleate (ASN), which is used as a new antipsychotic against schizophrenia and bipolar I disorder, was separated for the first time by CD-modified chiral selector in CZE. In addition, experimental design supporting method development was performed using $\beta-C D$ as a chiral selector. NMR spectroscopy, ESI-MS and molecular modeling were applied to characterize the inclusion complex [164]. For example, Phatthiyaphaibuna et al. Performed chiral separation of pheniramine using Hydroxypropyl- $\beta$ - Cyclodextrin (HP- $\beta-C D$ ) as a chiral selector, placed in the capillary with the method of the partial filling technique [165]. In one of another study, $\beta$ - and $\gamma$-derivatives of 2-hydroxypropyl-CD's were used as chiral selectors to examine the separations of the enantiomers of Tapendatol, an analgesic agent. Based on the electrochromatography migration potentials of the isomers, 2-hydroxypropyl-p-CD was preferred as a chiral selector for the enantiomeric separation of S,R- and R,S-tapentadol isomers under acidic conditions provided by BGE. Also, enantiomeric separation of $S, S-$ and $R, R$ isomers was performed by 2-hydroxypropyl- $\gamma$-CD at the same conditions [166]. Sohajda and his team studied of enantioseparations of Imperanen, a polyphenolic compound of Imperata cylindrica, first time in the CE system. In this study, 27 different CDs was selected to investigate the effect of cavity size, side chain, degree of substitution, and the loading amount of cyclodextrins both on the stability and mobility of the inclusion complex, and also enantioseperations. After the operation of single CD chiral CE systems, dual CD systems have been extensively researched. Among the charged-chiral selectors of CDs, sulfoalkylated-cyclodextrins due to their high applicability in dual systems to develop chiral separations have been tested. It was reported that NMR spectroscopy was used to characterize the inclusion complex at the molecular level. Also, In their previous study, the same group proposed CD-based chiral separation method for the separation of sitagliptin enantiomers in CZE, fast and efficiently as it mentioned $[167,168]$. The heptakis (2,3,6-triO-methyl)- $\beta$-CD was used as a chiral selector for the first time to realize the separation of all enantiomers of Ketoconazol in EKC. In addition, SDS acted as an anionic selector, including the BGE, and also played a role in the transport of neutral ketoconazole [169]. Agonists are compounds that bind to cell receptors and produce a response in the cell and often mimic the behavior of naturally occurring substances. Agonists create action, while Antagonist compounds inhibit the formation of an action. Therefore, it is one of the key elements of body chemistry and pharmacology [170]. Although there are studies in the literature on the enantiomeric separation of $\beta$-agonists, Carboxymethyl-p-cyclodextrin $(C M-\beta-C D)$ as a chiral selector was used for the enantiomeric separation of sympathomimetic drugs such as bambuterol, tulobuterol, procaterol [171]. Nascimento et all. examined the enantioseparation mechanism of 4-hydroxypropranolol (4-OH-Prop) at the molecular level, using a sequential methodology involving molecular dynamic simulations. Comparing the experimental results obtained for the separation of 4-OH-Prop enantiomers in CE using CM- $\beta-C D$ as chiral selector, the proposed theoretical model is a good way to estimate chiral separation of 4-OH-Prop enantiomers [172]. Qi and Zhang used CM- $\beta-C D$ as CS to developed and validated for the enantiomeric purity determination of the Levamlodipine. They reported that the max value of (Rs = 9.8) was obtained at the room temperature conditions. $4 \mathrm{mM} \mathrm{CM}-\beta-C D$ was dissolved in $40 \mathrm{mM}$ phosphate buffer ( $\mathrm{pH} 3.5)$, and $30 \mathrm{kV}$ voltage, was applied with normal polarity [173]. The click chemistry is an effective method, because of not cause any by-product formation as a result of the reactions carried out under moderate conditions with high efficiency, so it can be applied for chiral separations in recent times as well as use in organic chemistry [161]. In the first of these applications, $\beta$-CD-click-derived silica gel columns were used. Tang et al. performed the chiral separations of many analytes in a short period of time with high recognition using the cationic $\beta-C D$ derivative compounds obtained as a result of their synthesis by using click chemistry as chiral selectors [174]. In the early stages, Tan and his team reported that the cationic $\beta$-CD derivative as a single isomer containing imidazolium groups may be a good chiral selector for dansyl amino acids, but it is known that the strong UV absorption of the imidazollium has a negative effect on analyte detection [175]. The group aimed to eliminate this disadvantage by replacing the imidazolium moiety with a saturated cyclic amine to obtain mono-6-deoxy-6-pyrrolidine (3R,4Rdihydroxypyrrolidine)- $\beta$-cyclodextrin chloride (dhypy$\mathrm{CDCl}$ ). The enantiomeric separation ability of the weak UV-absorbing and water-soluble four pyrrolinium substituted cationic $\beta-C D$ chiral selectors obtained for this purpose and has been successfully tested on hydroxy carboxylic acids as well as dansyl amino acids [176]. As a 
result of the modification changes made in the structure of the CDs, the stability of the complexes formed between the $C D$ and analyte will be affected and also this may change the resolution capacity of the chiral selector. At this stage, there are quite a few studies of alkylimidazolium-substituted CDs with different alkyl chain lengths used as chiral selectors [144,177,178]. Given the wide application of alkaline drugs, sulfated modifiednegatively charged CDs have become the most commonly used chiral selector, since it has obvious advantages in chiral separations. This can occur with the onset of new electrical interaction and ion exchange interaction, which can enable them to demonstrate improved enantiorecognition capacity [142,179-185]. For example, the potential of Chondroitin sulfate $D$ and Chondroitin sulfate $E$, two representatives of the glycosaminoglycans group, to be evaluated as chiral selectors, was tested for the first time in CE. The results determinated Chondroitin sulfate $\mathrm{E}$ has a better enantiorecognition capability than chondroitin sulfate D toward the tested drugs. As a chiral selector, Chondroitin sulfate, E showed full effect to separating abilities on alkaline drugs against limited performance of Chondroitin sulfate $D$ as chiral selector [186]. In another study, heptakis-(2,3diacetyl-6-sulfato)- $\beta$-cyclodextrin was applied as the chiral selector on separations of 12 pairs of basic analyte enantiomers some of including oxybutynin, bambuterol, tradinterol, clenbuterol. Conditions of the study applied at $\mathrm{pH} 2.5$ were found to be highly efficient for the separation of most enantiomers with normal polarity mode at $10 \mathrm{kV}$ [187]. Maltodextrin (MD) as a linear polysaccharide can be considered as a chiral selector for chiral separation of a wide variety of acidic and basic compounds in CE system with high efficiency [188]. As a supportive factor, the chiral recognition mechanism has been proven as a result of electrophoretic mobility and selectivity measurements using different buffer solutions and organic solvent additives. Sulfated maltodextrin (MD) was first applied as a new anionic chiral selector in capillary electrophoresis (CE) and the power of its separation ability was investigated on various drugs. Also, it was reported that uncharged-neutral MD was used as a chiral selector under the same conditions, but none of enantioseparations was observed, so it is meaning that the solubility of sulfated-MD was higher than uncharged-MD due to the strong electrostatic interaction between sulfated-MDs and protonated chiral drugs [189]. CDs have shown at the top of the most effective electrophoretic chiral selectors as a result of the high separation efficiency as well as the selectivity factor increase the efficiency in the separation of peptides and amino acids especially in LE-CE by establishing synergistic systems with chiral metal complexes $[42,190]$. CDs and their modified derivatives have been widely used as chiral selectors in CZE. In MEKC, the buffer contains a surface active agent that forms the micelle as a pseudo-stationary phase. Analytes are dispersed into the micelle differently and separation takes place. For enantiomeric separation, a micelle-forming surfactant, such as SDS, is traditionally used with the CDs added to form a secondary balance with the micelle. Sometimes a single chiral surfactant such as sodium salt can be used [191-193]. The performance of cyclofructans (CFs), another member of the macrocyclic oligosaccharides group, as chiral stationary phase, is investigated for SFC, HPLC and CE recently. While the enantioselectivity or enantioseparation potentials of the nonderivatized CFs show very limited performance, it leads to the improvement of enantioselectivity for primary, secondary, tertiary and quaternary amines, especially after derivatization of fructofuranose hydroxyl groups with sulfate groups [194].

\section{Metal-Organic Frames as Chiral Stationary Phases}

Ding et al. modified the Zeolitic Imidazole framework (ZIF) with the p(GMA-EDMA) monolithic column, in which pepsin was used as the chiral selector [195]. In this study, N-(3-aminopropyl) imidazole monomer not only allowed MOF to be hold on the monolithic column surface, but also enabled covalent interaction with pepsin. The enantiomeric separation performance of the pepsin-based ZIF modified monolithic column was found to increase even more than that of the MOF-free format. Enantiomers of six different drugs were separated in CEC. As reported, three of them have been included in the literature in which they differ for the first time as a result of the separation made by modifying the MOF. Ye et al. [196] separated the enantiomers of phenylalanine and tyrosine thanks to the homochiral MOF ( $\mathrm{Zn}_{2}(\mathrm{D}$ Cam $\left.)_{2}\left(4,4^{\prime} \text {-bpy) }\right]_{n}\right)$ as CSP obtained by modifying the walls of the capillary column with MOF particles. In the study of Geng et al. [197], they performed the enantioseparations of DL- phenylalanine via ZIF-8 nanocrystals coated capillary column. In addition, L-glutamic acid was used as a selective ligand in the separation process in CE. Svec et al. developed a monolithic column combined with MOF to be used for enantiomer separation in Nano-LC. CSP prepared by combining poly 
Table 1. Enantiomeric separations using cyclodextrins (CDs) and derivatives as chiral selectors.

\begin{tabular}{|c|c|c|c|}
\hline CS (chiral selector) & Analytes & Method & Reference \\
\hline Zn(II)- L-4-hydroxyproline/Y-CD & $\begin{array}{c}\text { Dns-Gly-DL-Phe, Dns-DL-Pro, Dns-DL-Thr, } \\
\text { Dns-Gly-DL-Ala, Dns-Gly-DL-Val, Dns-Gly- } \\
\text { DL-Phe }\end{array}$ & LE-CE & [42] \\
\hline $\begin{array}{l}\text { B-cyclodextrin and heptakis(2,6-di-O- } \\
\text { methyl)- } \beta \text {-cyclodextrin }\end{array}$ & $\begin{array}{c}\text { Racemic mixtures of six Tröger's base } \\
\text { derivatives }\end{array}$ & NACE & [138] \\
\hline Carboxymethyl- $\beta-C D$ & Racemic mixtures of pomalidomide & CZE & [139] \\
\hline 2-(hydroxypropyl)- $\beta-C D$ and methyl- $\gamma-C D$ & Duloxetine & CE & [140] \\
\hline Sulfobutyl- $\beta-C D$ and carboxymethyl- $\beta-C D$ & $\begin{array}{l}\text { Primaquine, tafenoquine, mefloquine, } \\
\text { chloroquine and quinacrine }\end{array}$ & CE & [141] \\
\hline$\alpha-, \beta-C D$ and sulfated $-\beta-C D$ & $\mathrm{R}, \mathrm{S}$-tolterodine, $\mathrm{R}, \mathrm{S}$-methoxytolterodine & CE & [142] \\
\hline $\begin{array}{c}\alpha-, \beta-, \gamma-\text { and heptakis(2,3-di-O-acetyl)- } \\
\beta-C D s\end{array}$ & Terbutaline & CE & [143] \\
\hline $\begin{array}{l}\text { 6A-ammonium-6C-butylimidazolium- } \beta \text { - } \\
\text { cyclodextrinchlorides (AMBIMCD) }\end{array}$ & $\begin{array}{l}\text { Some of acidic monomers, including } \\
\text { p-Hydroxy mandelic acid, } 3 \text {-phenyllactic } \\
\text { acid, p-Hydroxyphenyllactic acid, and } \\
\text { also some Dns-AAs }\end{array}$ & CE & [144] \\
\hline $\begin{array}{c}\text { Mono-6A-(3-methoxypropan-1- } \\
\text { ammonium)-6A- } \beta \text {-cyclodextrin chloride } \\
\text { (MPrAMCD) }\end{array}$ & $\begin{array}{l}\text { Some of acidic monomers, including } \\
\text { p-Hydroxy mandelic acid, } 3 \text {-phenyllactic } \\
\text { acid, p-Hydroxyphenyllactic acid, and } \\
\text { also some Dns-AAs }\end{array}$ & CE & [145] \\
\hline $\begin{array}{c}\text { Cationic- } \beta \text {-CD \& (SD-CSs) (dual chiral } \\
\text { selector system) }\end{array}$ & Kynurenine & CZE & [146] \\
\hline $\begin{array}{c}\text { (2,3-di-O--methyl-6-sulfo)- } \beta \text {-CD (HDMS- } \\
\beta \text {-CD), heptakis (2,3-di-O-acetyl-6-sulfo)- } \\
\beta-C D(\text { HDAS- } \beta \text {-CD) }\end{array}$ & $\begin{array}{c}\text { Acebutolol, atenolol, carazolol, carteolol, } \\
\text { carvedilol, propranolol, sotalol, and } \\
\text { talinolol }\end{array}$ & NA-CE & [147] \\
\hline $\begin{array}{c}\text { Mono(6-deoxy-6-sulfoethylthio)- } \beta \text {-CD } \\
\text { (SET- } \beta \text {-CD), mono[6-deoxy-6-(6-sulfooxy- } \\
\text { 5,5-bissulfooxymethyl) hexylthio]- } \beta \text {-CD } \\
\text { (SMHT- } \beta \text {-CD) }\end{array}$ & Pseudoephedrine, verapamil & CE & [148] \\
\hline $\begin{array}{l}\text { Native } \alpha-C D, \beta-C D \text {, heptakis (2,3-di-O- } \\
\text { acetyl-6-O-sulfo)- } \beta \text {-CD (HDAS- } \beta-C D) \text {, } \\
\text { heptakis(2,3-di-O-methyl-6-O-sulfo)- } \beta \text { - } \\
\text { CD (HDMS- } \beta-C D\end{array}$ & Norephedrine & CE & [149] \\
\hline $\begin{array}{l}\text { Heptakis (2,3-diacetyl-6-sulfo)- } \beta \text {-CD } \\
\text { (HDAS- } \beta \text {-CD) }\end{array}$ & Propranolol & NACE & [150] \\
\hline $\begin{array}{c}\text { Heptakis }\{2,6 \text {-di-O-[3-(1,3-dicarboxyl } \\
\text { propylamino)-2-hydroxypropyl]\}- } \\
\beta \text {-cyclodextrin (glutamic acid- } \beta \text { - } \\
\text { cyclodextrin) }\end{array}$ & $\begin{array}{l}\text { Terbutaline, clorprenaline, tulobuterol, } \\
\text { clenbuterol, procaterol, carvedilol, } \\
\text { econazole, miconazole, homatropine } \\
\text { methyl bromide, brompheniramine, } \\
\text { chlorpheniramine and pheniramine. }\end{array}$ & CE & [151] \\
\hline
\end{tabular}


Table 1. Enantiomeric separations using cyclodextrins (CDs) and derivatives as chiral selectors. Continue

(2,3,6-tri-o-methyl)-( $\alpha-, \beta-, \gamma)-C D s$

Ketoprofen

CE

[152]

2-amino-1-phenyl-ethanol,

$B-C D, C M-\beta-C D$

1-(4-methoxyphenyl)-2-(methylamine)

ethanol, salbutamol sulfate, sotolol

CE

hydrochloride

\begin{tabular}{|c|c|c|c|}
\hline CS (chiral selector) & Analytes & Method & Reference \\
\hline $\begin{array}{l}\text { Heptakis-(2,3,6-tri-O-methyl)- } \beta \text { - } \\
\text { cyclodextrin (TM- } \beta-C D)\end{array}$ & 12 trizole antifungal active compounds & EKC & [154] \\
\hline $\begin{array}{c}\text { 6-monodeoxy-6-mono-(3-hydroxy)- } \\
\text { propylamino- } \beta-C D \text { hydrochloride (PA- } \\
\beta-C D)\end{array}$ & $\begin{array}{c}\text { (S)-(+)-isomer of 3-isobutyl-GABA } \\
\text { (Pregabalin) }\end{array}$ & CZE & [155] \\
\hline Hydroxypropyl- - -cyclodextrin (HP- $\gamma-\mathrm{CD})$ & $\begin{array}{l}\text { lodiconazole and it's related triadimenol } \\
\text { analogues }\end{array}$ & $\mathrm{CE}$ & [156] \\
\hline $\begin{array}{l}\text { 6-Sulfated- } \beta-C D \\
\text { 6-Carboxymethyl- } \beta-C D \\
\text { 2,6-Sulfamic acid- } \beta-C D\end{array}$ & $\begin{array}{l}\text { Tulobuterol, chlorprenaline, tropicamide, } \\
\text { homatropine hydrobromide, } \\
\text { homatropine methylbromide, atropine, } \\
\text { atropine methobromide, anisodamine, } \\
\text { gatifloxacin, oflaxacin }\end{array}$ & $\mathrm{CE}$ & [157] \\
\hline $\begin{array}{l}\text { Heptakis (2-Omethyl-3,6-di-O-sulfo)- } \beta \text { - } \\
\text { CD } \\
\text { (HMDS- } \beta \text {-CD) }\end{array}$ & Brombuterol & CE & [158] \\
\hline $\begin{array}{l}\beta-C D, \gamma-C D \text {, heptakis }(2,3,6 \text {-tri-O- } \\
\text { methyl)- } \beta-C D(T M-\beta-C D) \text {, heptakis } \\
(2,6 \text {-di-O-methyl)- } \beta-C D(D M-\beta-C D) \text {, } \\
\text { carboxymethyl- } \beta-C D(C M-\beta-C D) \text { and } \\
\text { HS- } \beta-C D \text {, Heptakis(2,3-di-O-acetyl-6-O- } \\
\text { sulfo)- } \beta \text {-cyclodextrin (HDAS- } \beta-C D)\end{array}$ & $\begin{array}{l}\text { D,L-(alanine, valine, leucine, isoleucine, } \\
\text { proline, phenylalanine, methionine, } \\
\text { tryptophan, serine, threonine, asparagine, } \\
\text { glutamine, aspartate, glutamate, cysteine, } \\
\text { tyrosine, histidine, lysine and arginine) }\end{array}$ & CE & [159] \\
\hline Sulfated- $\alpha-C D$ & Bupropion & EKC & {$[162]$} \\
\hline Sulfated- $\beta-C D$ & $\begin{array}{l}\text { Enantiomers of phenylalanine amide and } \\
\mathrm{N} \text {--methyl derivatives, also some amino } \\
\text { alcohols }\end{array}$ & CE & {$[163]$} \\
\hline$\beta-C D$ & Asenapine maleate & CZE & [164] \\
\hline$H P-\beta-C D$ & Pheniramine & CE & {$[165]$} \\
\hline $\begin{array}{l}\text { 2-hydroxypropyl- }- \text { - CD, vancomycin- } \\
\text { based-2-hydroxypropyl- } \beta-C D\end{array}$ & Tapandelol and its derivatives & CE & [166] \\
\hline
\end{tabular}


Table 1. Enantiomeric separations using cyclodextrins (CDs) and derivatives as chiral selectors. Continue

HP- $\alpha$-CD, (2-hydroxy)propyl- $\alpha-C D$

HP- $\beta$-CD, (2-hydroxy)propyl- $\beta-C D$;

L-DOPA, L-3,4dihydroxyphenylalanine;

PA- $\beta$-CD, 6-monodeoxy-6-mono

(3-hydroxy)propylamino- $\beta$-cyclodextrin hydrochloride; SB- $\beta-C D$, sulfobutyl-

ether- $\alpha-C D$ sodium salt; $S B-\alpha-C D$,

sulfobutylether- $\beta-C D$ sodium salt; $S B-\beta$ -

$C D$, sulfobutyl-ether- $\gamma-C D$ sodium salt;

SP- $\gamma-C D$, sulfopropylated- $\beta-C D$ sodium

salt

Sulfo(2-hydroxy)-propylated- $\beta-C D$

Enantiomers of Sitagliptin

CZE

[168]

\begin{tabular}{|c|c|c|c|}
\hline CS (chiral selector) & Analytes & Method & Reference \\
\hline Heptakis (2,3,6-tri-O-methyl)- $\beta$-CD & All stereoisomers of Ketoconazole & EKC & [169] \\
\hline$C M-\beta-C D$ & $\begin{array}{c}\text { Clanbuterol, bambuterol, tulobuterol, } \\
\text { procaterol, salbutamol }\end{array}$ & CE & [171] \\
\hline$C M-\beta-C D$ & 4-hydroxypropranolol & $\mathrm{CE}$ & [172] \\
\hline$C M-\beta-C D$ & $\begin{array}{l}\text { (R,S)-amlodipine besylate, S-amlodipine } \\
\text { besylate and naloxone hydrochloride }\end{array}$ & CE & [173] \\
\hline $\begin{array}{l}\text { 6A-4-hydroxyethyl-1,2,3-triazolyl-6C-3- } \\
\text { methoxypropylamino- } \beta \text {-cyclodextrin }\end{array}$ & Several ampholytic and acidic racemates & CE & [174] \\
\hline
\end{tabular}

Mono-6-deoxy-6-pyrrolidine- $\beta$ -

cyclodextrin chloride (pyCDCl),

Mono-6-deoxy-6-(N-methyl-pyrrolidine)-

$\beta$-cyclodextrin chloride (N-CH3-pyCDCl),

Mono-6-deoxy-6-(N-(2-hydroxyethyl)pyrrolidine)- $\beta$-cyclodextrin chloride

Some of dansyl and carboxylic acid enantiomers

Mono-6-deoxy-6-(2-hydroxymethyl-

pyrrolidine)- $\beta$-cyclodextrin chloride

(2MeOH-pyCDCl)

Mono-6A-(2-methoxyethyl-1-

ammonium)- $6 \mathrm{~A}-\beta$-cyclodextrin chloride (MEtAMCD)

Heptakis (2,3-diacetyl-6-sulfo)- $\beta$-CD and heptakis (2,3-dimethyl-6-sulfo)-b-CD

Heptakis(2,3-di-O-methyl-6-O-sulfo)$\beta-C D$ and heptakis(2,3-di-O-acetyl-6-Osulfo)- $\beta-C D$ 
Table 1. Enantiomeric separations using cyclodextrins (CDs) and derivatives as chiral selectors. Continue

Heptakis(2-O-sulfo-3-O-methyl-6-Oacetyl)cyclomaltoheptaose

1-(naphthyl)ethylamine, and oxprenolol

SP-HPLC

Methyl- $\beta$-cyclodextrin, highly sulfated-

$\beta$-cyclodextrin and highly sulfated- $\gamma$ cyclodextrin

Sulfated- $\beta-C D$

Cathinone derivatives (Mephedrone, Butylone, Naphyrone)
CE

\section{R,S-talinolo}

(HDMS- $\beta-C D$ ) and heptakis (2,3-di-O

acetyl-6-sulfo)- $\beta-C D$ ) (HDAS- $\beta-C D$ ) (1-[4-cyclohexylureidophenoxy]-2- NA-CE hydroxy-3-tert-butylamino-propane)

\begin{tabular}{ccc}
\hline CS (chiral selector) & Analytes & Method Reference \\
\hline Sulfobutylether- $\beta$-cyclodextrin & Lenalidomide & CE
\end{tabular}

Chondroitin sulfate D and chondroitin sulfate $\mathrm{E}$
Amlodipine, laudanosine, nefopam,

sulconazole, Tryptophanmethylester,

citalopram, duloxetine, and propranolol
CE

\section{Oxybutynin, bambuterol,}

Tradinterol, clenbuterol, clorprenaline,

terbutaline, tulobuterol, citalopram,

Heptakis-(2,3-diacetyl-6-sulfato)- $\beta$ cyclodextrin phencynonate, fexofenadine, salbutamol and penehyclidine

Cetirizine (CTZ), (RS)-2-[2-((4-

chlorophenyl) phenylmethyl) piperazine-

1-yl] ethoxyacetic acid, Hydroxyzine

(HZ), (RS)-2-[2-((4-chlorophenyl)

CE

phenylmethyl)-piperazine-1-yl] ethoxy ethanol

\begin{tabular}{|c|c|c|c|}
\hline Sulfated-MD & $\begin{array}{l}\text { Amlodipine, hydroxyzine, } \\
\text { Fluoxetine, tolterodine, and tramado }\end{array}$ & $\mathrm{CE}$ & [189] \\
\hline $\begin{array}{l}M n(I I)-([E M I m][L-A l a] / \beta-C D \\
M n(I I)-[B M I m][L-A l a] / \beta-C D \\
M n(I I)-[H M I m][L-A l a]) / \beta-C D\end{array}$ & $\begin{array}{c}\text { Dns-D, L-(Thr, Val, Tyr, Leu, Ile, Pro, Met, } \\
\text { Ser, His, Ala, Phe, Asp, Glu,) }\end{array}$ & LE-CE & [190] \\
\hline $\begin{array}{c}\text { Sodium hexakis (2,3-O-dibenzyl-6-O- } \\
\text { sulfobutyl) cyclomaltohexaose, sodium } \\
\text { heptakis (2,3-O-dibenzyl-6-O-sulfobutyl) } \\
\text { cyclomaltoheptaose }\end{array}$ & DL-Ser & CZE & [191] \\
\hline $\begin{array}{l}\text { N-undecenoxy-carbonyl-I-leucinol } \\
\text { bromide/heptakis-(2,3,6-tri-O-methyl)- } \beta \text { - } \\
\text { cyclodextrin (L-UCLB/TM- } \beta \text {-CD) }\end{array}$ & $\begin{array}{l}\text { 1.1'-bi-2-naphthol, 7,8,9,10 tetrahydro- } \\
\text { benzo[a]pyren-7-ol, } \\
\text { 2,2,2-trifluoro-1-(9-anthryl) ethanol }\end{array}$ & $\mathrm{CE}$ & [193] \\
\hline $\begin{array}{l}\text { Cyclofructan (CF), isopropyl carbamate } \\
\text { cyclofructan, } \alpha \text {-cyclodextrin }(\alpha-C D) \text { and } \\
\beta \text {-cyclodextrin }(\beta-C D)\end{array}$ & $\begin{array}{l}\mathrm{R}, \mathrm{S}-1,1^{\prime} \text {-binaphthalene- } 2,2^{\prime} \text {-diyl } \\
\text { hydrogen phosphate }\end{array}$ & $\mathrm{CE}$ & [194] \\
\hline
\end{tabular}


(4-vinylpyridine-ethylene dimethacrylate) monolithic column with MOF [ $\mathrm{Zn}_{2}$ (benzene dicarboxylate)(L-lactic acid)(dmf)] was successfully used in the separations of methyl phenyl sulfoxide enantiomers [198]. Chen et al. obtained a new CSP by filling the homochiral MOF in the inner walls of the capillary column. Performance of AlaZnCl coated capillary column was tested by separating some drugs and monoamine neurotransmitters in OT-CEC. However, it has been reported that the separation efficiency of the MOF coated capillary column does not decrease even after 100 usages [199]. In another study performed by modifying the inner wall of the capillary column with the MOF, Ma et al. succeeded the attachment of the homochiral $\left.[\mathrm{Cu}(\mathrm{mal})(\mathrm{bpy})] \times \mathrm{H}_{2} \mathrm{O}\right]$ to the inner surface of the capillary column as a result of covalent interactions [200]. This homochiral MOF-CSP was applied in CEC system for the analysis of traditional Chinese medicine ephedra chosen as real sample.
Li-Ming Yuan and his team reported for the first time in the literature that Metal-Organic Cage (MOC) structures can be used as chiral stationary phase in CEC [201]. The team evaluated the enantiomeric separation performances of the three different MOC's coating the inner surface of the capillary column, for different racemates which are derivative compounds of amine, alcohol and ketones.

\section{Other Applications}

\section{Antibiotics as Chiral Selectors}

Due to the chirality of some antibiotics, they can make stereospecific interactions with chiral molecules since they have some optically active centers and functional groups allow them to over various strong interactions including chemical and physical bonds with chiral mole-

Table 2. Recent enantiomeric separation studies using Metal-Organic Frameworks or Cages (MOFs and MOCs) as chiral stationary phases.

\begin{tabular}{|c|c|c|c|}
\hline CSP, (MOFs or MOCs) & Analytes & Method & Reference \\
\hline$\left[\mathrm{Zn} 2(\mathrm{D}-\mathrm{Cam}) 2\left(4,4^{\prime}-\mathrm{bpy}\right)\right] \mathrm{n}$ & Praziquantel & OT-CEC & {$[95]$} \\
\hline ZIF- [poly (GMA-EDMA)] & $\begin{array}{l}\text { Hydroxychloroquine (HCQ), chloroquine } \\
(\mathrm{CHQ}) \text {, hydroxyzine (HXY), nefopam (NEF), } \\
\text { clenbuterol (CLE) and amlodipine (AML) }\end{array}$ & CEC & [195] \\
\hline$\left(\left[\mathrm{Zn} 2(\mathrm{D}-\mathrm{Cam}) 2\left(4,4^{\prime}-\mathrm{bpy}\right)\right] \mathrm{n}\right.$ & DL-phenylalanine, DL-tyrosine & CEC & {$[196]$} \\
\hline ZIF8 & DL-phenylalanine & CE & {$[197]$} \\
\hline $\begin{array}{l}\text { [Zn2(benzene dicarboxylate) (L-lactic } \\
\text { acid) (dmf)- poly (4-vinylpyridine- } \\
\text { ethylene dimethacrylate) }\end{array}$ & $( \pm)$-methyl phenyl sulfoxide & Nano-LC & {$[198]$} \\
\hline AlaZnCl & $\begin{array}{c}\text { Epinephrine, Isoproterenol, } \\
\text { norepinephrine, synephrine, terbutaline, } \\
\text { carvedilol }\end{array}$ & OT-CEC & {$[199]$} \\
\hline$[\mathrm{Cu}(\mathrm{mal})(\mathrm{bpy})] \times \mathrm{H} 2 \mathrm{O}$ (mal,L-(-)-malic acid & $\begin{array}{c}\text { DL-pencillamine, DL-phenylalanine, } \\
\text { Ephedrine (E) hydrochloride and } \\
\text { pseudoephedrine }\end{array}$ & CEC & {$[200]$} \\
\hline Zn3L12, Zn3L22, [Fe4L36](ClO4)8·DMF & $\begin{array}{l}\text { Ofloxacin, furoin, benzoin omeprazole, } \\
\text { bendroflumethiazide, warfarin sodium, } \\
\text { ofloxacin, mandelic acid, ketoprofen, } \\
\text { 1-(Naphthalen-1yl) ethanol, flavanone }\end{array}$ & CEC & {$[201]$} \\
\hline
\end{tabular}


cules, so they can be used as chiral selectors. In particular, the following two parameters stand out on the basis of macrolide class antibiotics such as erythromycin (ERY), azithromycin (AZI), clarithromycin and boromycin in the frequently chiral separations: a) Due to the lack of aromatic rings in their structures they cannot exhibit strong UV absorption, and (b) they do not interact with the UV detection of analytes because their structure consists of a macrocyclic lactone ring containing 14-16 [202]. It has been proven that some antibiotics can be used as a chiral selector as an additive directly added in BGE or can be used in conjunction with CE and its related techniques since it can be connected to a chiral stationary phase [203]. In a study conducted by Yu et al., the potential of clarithromycin lactobionate, which is a macrocyclic antibiotic class, was investigated as chiral selector [204]. Within the scope of this examination, the enantiomers of some drugs such as metoprolol, atenolol were separated by CE method. Another member of the macrocyclic antibiotics class, clindamycin phosphate, linked to the lincosamide group, has been proposed in the literature as a new chiral selector [205]. Enantiomeric separations of various racemic drug mixtures such as chlorphenamine, propranolol, nefopam were provided in the separations performed in the MEKC method. Propranolol, metoprolol and sertraline enantiomers were separated from each other by using rifampicin as a chiral selector, which belongs to Naphthalenic ansamycins group, in CE system [206]. It is noted that other members of the rifamycin family, which have different substituents on the naphtohydroquinone ring, can also be examined for their ability to enantiomeric separations for analytes with multi-ring groups. Azithromycin (AZM) has a 15-membered ring structure, as well as a few stereogenic centers and several hydroxyl groups, as well as two amino and an ester groups. In the study [207] conducted by Kumar and Park, the potential of Azithromycinthis compound to be chiral selector was examined in CE for the first time in the literature. For this purpose, separation of 5 different racemic drug mixtures as well as the enantiomers of tryptophan have been successfully accomplished. NonaqueousCE (NACE) is a powerful analytical method due to the higher resolution efficiency and different selectivity of some chiral selectors used in a non-aqueous environment, as well as the compatibility of the technique [208]. The low conductivity of electrolytes in NACE allows higher electrical current application and higher buffer concentration. Enantiomeric separations of various amino alcohols and amine-derived compounds were achieved using Erythromycin-derived clarithromycin (CLM) as a chiral selector in NACE. Citric acid (CA) and boric acid (BA) were used together as BGE in the methanol media, where the studies were conducted [209].

Boromycin, which was previously reported in the literature as a chiral selector in LC and SFC [210] as the chiral stationary phase, was investigated for the first time as a chiral selector in CE [211]. Enantiomeric separations of various primary amines were performed by using boromycinas as chiral selector in NACE in methanol medium. While it is reported that separations occur within 14 minutes, also separation values are above 1.5 in many experiments related to the study. In the study performed by Ren and his coworkers, Gamithromycin (Gam) as a new generation macrolide antibiotic type was tested for the first time as a chiral selector to be used for CE. In these experiments in which enantiomeric separations of primary amine compounds namely Primaquine (PMQ) and 1-amino (AMI) were performed, $\mathrm{N}$-Methylformamide was used as an anhydrous solvent for Gam, effectively [212]. Doxycycline (DOX) is a member of the tetracycline group, a broad-spectrum antibiotic derivative. In addition to its six chiral centers, it contains five hydroxyl groups, two carbonyl groups and an amide group [213]. The ability of these functional groups has strong interactions especially with acidic analytes. DOX was used for the first time in the CE method for separation of enantiomers are 2,4-dinitrobenzoyl amino acid and 8 different acidic chiral drugs as chiral addictive [214]. In that study, the content of BGE was reported together with DOX as acetonitrile/ methanol+acetic acid+triethylamine. Fusidic Acid (Fus) is a steroid-antibiotic and contains many chiral centers and functional group structures. These properties may enable it to enantiospecific interactions with chiral compounds, as well as being in the literature as a suitable potential for chiral separations with its easy availability and cheapness [215]. Streptomycin, one of the aminoglycoside antibiotics, has been used in the past for enantiomeric separations by coating the capillary column chirally with Diethylaminoethyl (DEAE) dextran hydrochloride [216]. In their study, Zhang et al. used streptomycin as chiral selector, without the need for capillary coating, and separated the enantiomers of in total 5 different acidic drugs containing phenyl groups such as ibuprofen, mandelic acid, adrenaline hydrochloride in the CZE method [217]. In the study in which streptomycin modified gold nanoparticles as chiral participant was added to the background electrolyte used 
Table 3. Recent studies using antibiotics as chiral stationary phase or chiral additives.

\begin{tabular}{|c|c|c|c|}
\hline CS (chiral selector, addtive) & Analytes & Method & Reference \\
\hline Clarithromycin lactobionate & $\begin{array}{l}\text { Metoprolol, atenolol, propranolol, } \\
\text { bisoprolol, esmolol, ritodrine, and } \\
\text { amlodipine, labetalol and nefopam }\end{array}$ & CE & [204] \\
\hline Clindamycin phosphate & $\begin{array}{l}\text { Nefopam, citalopram, tryptophan, } \\
\text { chlorphenamine, propranolol and } \\
\text { metoprolol, tryptophan methyl ester and } \\
\text { cetirizine }\end{array}$ & MEKC & [205] \\
\hline Rifampicin & Propranolol, metoprolol and sertraline & CE & {$[206]$} \\
\hline Azithromycin & $\begin{array}{l}\text { Varvedilol, cetrizine, citalopram } \\
\text { hydrobromide, darifenacin, sertraline } \\
\text { hydrochloride and tryptophan }\end{array}$ & CE & [207] \\
\hline Clarithromycin & $\begin{array}{c}\text { Alprenolol, atenolol, metoprolol, pindolol, } \\
\text { propra-nolol, sotalol, synephrine, } \\
\text { labetalol, clenbuterol, fenoterol, } \\
\text { methoxyphenamine }\end{array}$ & NACE & [209] \\
\hline Boromycin & $\begin{array}{c}\text { (-methylbenzylamine, R,S-tryptophanol, } \\
\text { R,S-norepinephrine, R,S-octopamine, } \\
\text { R,S-p-hydroxynorephedrine and R,S-2- } \\
\text { amino-1-phenylethano }\end{array}$ & NACE & {$[211]$} \\
\hline Doxycycline & $\begin{array}{l}\text { Flurbiprofen, ibuprofen, suprofen, } \\
\text { ketoprofen, Carprofen, tropic } \\
\text { acid, mandelic acid, warfarin, N-(3,5- } \\
\text { dinitrobenzoyl)-leucine and N-(3,5- } \\
\text { dinitrobenzoyl)-phenylglycine, }\end{array}$ & CE & [214] \\
\hline Fusidic acid & $\begin{array}{c}\text { Atenolol, bisoprolol fumarate, } \\
\text { chloroquine phosphate, esmolol } \\
\text { hydrochloride, hydroxychloroquine } \\
\text { sulfate, metoprolol tartrate, procaterol, } \\
\text { PMQ, primaquine phosphate }\end{array}$ & CE & [215] \\
\hline Streptomycin & $\begin{array}{l}\text { Ibuprofen, mandelic acid, adrenalin } \\
\text { hydrochloride, dipivefrin, hydrochloride } \\
\text { and isopropyl adrenaline hydrochloride }\end{array}$ & CZE & [217] \\
\hline Streptomycin-modified-AuPs & $\begin{array}{l}\text { Adrenaline, noradrenaline and } \\
\text { isoprenaline }\end{array}$ & CE & [218] \\
\hline Penicilin G & $\begin{array}{l}\text { Darifenacin, citalopram, sertraline, } \\
\text { propranolol and metoprolol }\end{array}$ & CE & [219] \\
\hline Eremomycin & $\begin{array}{l}\text { Ibuprofen, indoprofen, ketoprofen, } \\
\text { fenoprofen, flurbiprofen, mandelic, } \\
\text { 3-phenylbutiric, 2-phenoxypropionic, and } \\
\alpha \text {-methoxyphenylacetic acids) }\end{array}$ & CE & [220] \\
\hline
\end{tabular}


in the CE system the inner wall of capillary columns was used without the need of any coating process for the separation of adrenaline, noradrenaline and isoprenaline enantiomers [218].

In the study conducted by Dixit and Para, it was reported for the first time that Penicillin $G$ can be used as chiral selector in CE [219]. Enantiomers of five different basic drugs were studied in chiral separations using the potassium salt of Pen $\mathrm{G}$ as ion-pair chiral selector, which is a $\beta$-lactam antibiotic class. In another study [220] conducted with CE method, Eremomycin was used as chiral selector, and enantiomeric separations of some chiral center-containing carboxylic acid derivatives were performed by chitosan-coated capillary columns.

\section{Ionıc Liquids (ILS) as Chiral Additives}

Ionic liquids (ILS) consist mainly of cations and anions that are in liquid phase at room temperature. Thermally stable, low vapor pressure and non-flammable properties make them interesting compounds compared to conventional solvents. Similar to the situation in MOFs, their structure can be adjusted by changing cations or anions [221]. There are quite a lot of prospect combinations of possible ions that provide a wide range of physicochemical properties and functionality. ILs have been used in a wide variety of applications such as liquid-liquid extraction, solvents, catalysis and gas absorption [222].

ILs are successfully adapted in separation methods such as SP in GC [223], mobile phase additives in HPLC [224] and solvent in solid-liquid or liquid-liquid phase extraction [225]. Applications of ILs in CE are applied in the form of an electrolyte, buffer additives, surface coating or chemical derivatization of the capillary inner wall [226]. Chiral ionic liquids (CILs) are a subset of ILs with chiral cation, chiral anion, or both. The obvious superiority of chiral ILs to equal ILs is due to their ability to gain an extra enantiomeric recognition, so separating ability, while maintaining a "system modification" capability [227]. Based on their potential, which is related to ability for recognitions on chiral separations, scientific interest in CILs has warmly increased [228-246]. In chiral separations studies, it is observed that the performance of the systems created by modifying ionic liquids with SPs enhances the enantiorecognition ability compared to conventional type stationary phases alone [247]. However, in addition to the use of ionic liquids with stationary phases, their involvement as buffer additive in running buffer is one of the most remarkable approaches recently $[243,248,249]$. Also it has been reported in some works that achiral ILs help to observe more distinct separations by directly affecting the electroosmotic flow (EOF) and improving the peak shapes in the analyzes [242,250]. Amino acid-based ionic liquids (AAILs) being a natural chiral center originating from the amino acid derivative, makes it stand out as natural compatible functional compounds with their ability to establish a strong coordinated covalent bond with metal ions over the heteroatoms they contain. LECE is the most frequently used method in this field as a result of the compatible complexity of amino acids with metal ions. Some recent studies in the literature show that amino acid and similar amino amide-based ILs can be applied with high selectivity as chiral ligands, especially in the separation of amino acid enantiomers in LECE [251-256]. Cyclofructans (CFs), which are macrocyclic oligosaccharides (cycloinulo-oligosaccharides), are one of the new generation chiral selectors whose effectiveness is known. In a study performed by Stavrou et al. targeted the enantioseparation of huperzine $A$ and derivatives of coumarin to determine the chiral separating potential of 6 different CF- derivatives. Almost all of the CFs studied showed relatively low or even no chiral separation ability for Huperzine A. In order to increase both solubility and efficiency, chiral ionic liquid D-Alanine tert butyl ester lactate (D-AlaC4Lac) was added to BGE and separation of the peaks became more evident in consecutive studies and the value of $R_{s}=1.4$ was reported in the literature [257].

\section{Nanoparticles (NPs)}

Nanostructured materials can consist of many different structures. These structures include nanocrystals, nanoparticles, nanotubes, nanowires and nanofilms. The reasons for the difference in structures are size-volume properties. Nanoparticle vision expressed in nanotechnology has different morphologies and is named in a similar way, such as the core shell, doped, spherical, metallic and polymeric [261]. Nanoparticles (NPs) are generally smaller than $100 \mathrm{~nm}$ and these particles are the building block of nanotechnology. Preparation of nanoparticles is usually done according to the "Top to Bottom" and "Top to Top" approaches. In addition to these approaches, these nanoparticles can be prepared by chemical vapor condensation method (for hydrogen 
and oxide nanoparticles), hydrogen reduction, inert gas condensation, production from micro hydrogen systems, flame synthesis, metallic etching, spray prolysis and chemical precipitation methods [262]. Nanoparticles are very preferred materials because their physical and chemical properties differ from those of normal size. Nanoparticles are widely used commercially in home applications, material coatings, biomedical applications, biosensors and so on [203]. Nanomaterials are important for applications in separation science as well as electronic structures as a result of their distinctive features due to their high surface/volume ratio and easy to adapt for modifications. As nanoparticles have higher colloidal stability and wider surface area they are described as more advantageous materials compared to micelles used in MEKC. In similar approach, they can be used as strong buffer additives or as pseudo-phases to obtain more selective enantiomeric separations and recognition activites $[218,263]$. Due to their large sruface area, it helps to create more interactions betweeen chiral selector and analytes, so they act a role as modified component with chiral selector in CEC, also lately in microchip capillary electrophoresis (MCE) to improve efficiency and selectivity of enantioseparations with enhanced chemical stability. Various nanoparticles based on silica, polymer, gold, carbon or crystals are used for this purpose [264]. Recently, the $\beta$-cyclodextrin modified quantum dots as the pseudo-stationary phase was the first time applied for direct enantioseparations with the combined system of capillary electrophoresis with laser-induced fluorescence detection (CE-LIF). It was reported that inclusion complexation of $\beta-C D$ and the fluorescence intelligence of QD core, and also the composite QDs were added into the running buffer as pseudo-stationary phase. The new CE-LIF method provided enantioseparation for six groups of model analytes without need of capillary preparation or modification, also analyte derivatization [265]. GNPs (gold nanoparticles) can be shown as one of the most frequently used nanomaterials in separation methods because of their properties such as easy preparation, being suitable for active complexing with biological substances, tolerable particle size with narrow edition and large surface areas. Stationary phase applications prepared by modifying GNPs with chiral selectors are one of the methods used in enantiomeric separation studies. Yu et al. firstly immobilized GNPs on the fused-silica capillary modified with 3-mercaptopropyl-trimethoxysilane (MPTMS), then as a result of surface functionalization by selfassembly of thiol-derived cyclodextrin (SH- $\beta-\mathrm{CD})$, they obtained a new chiral stationary phase. Compared with the single layer of the GNP film capillary column, it was reported that the multi-layer GNP capillary column showed appropriate enantioseparation performance [266]. Yang et al. suggested for the first time the immobilization of GNP's onto thiol-derived $\beta$-cyclodextrins used as CSP for enantioseparations in OT-CEC. They reported that their stationary phase content could still be re-used for studies at least one month, if the participants were stored at $4^{\circ} \mathrm{C}$ [267]. Fang et al. prepared a OT-CEC chiral column by firstly electrostatic assembly of poly(diallydimethylammonium chloride) polymer onto the inner surface of a fused-silica capillary, then negatively charged GNPs modified $\mathrm{SH}-\beta$-cyclodextrin was self-adsorbed onto inner wall of the column [268]. Wang and his team provided enantiomeric separations of three different drugs in the chiral column they prepared by modifying the CD-GNP to the monolithic column, which was ready to be covalently attached with the preliminary reactions [269]. Wang et al. have developed a new chiral stationary phase system to separate tryptophan enantiomers in MCE [270]. In this approach, the stationary phase was created by mounting in layers, while PDA/GNPs and DNA were sequentially fixed on a glass microfluidic channel surface. The main advantage of the microchip prepared with this approach has been reported to simplify the immobilization methodology of the chiral selector of PDA/GNPs/DNA and greatly increases the specific surface volume of the microfluidic chip channel. Fang et al. have developed a chiral stationary phase system for use in OT-CEC. GNPs and carboxymethyl- $\beta$-cyclodextrin were blended and then attached to the inner surface of the capillary column. It has been reported that the modification type formed by the nesting of GNPs and negatively charged $\mathrm{SH}$ $C M-\beta-C D$ exhibits a wider separation range for neutral and basic drugs [271]. In another practical and feasible approach, the physical magnetic attraction approach for the preparation of functionalized magnetic packed columns attracts increased attention in studies in separation technologies. Yang et al. performed the enantiomeric separations of several dansyl amino acids via preparing a $\beta-C D$ stationary phase modified with $\mathrm{Fe}_{3} \mathrm{O}_{4}$ magnetic nanoparticles in OT-CEC. Also, they reported that high enantiomeric interaction capability and excellent reusability for analytes observed in their systems were compared to other methods in the literature [272]. Microfluidic analysis is considered as a very convenient platform for analytical separations as it provides highly effective separations in a short period of time. Ju et 
al. made rapid separations of ofloxacin enantiomers on chiral MD (microfluid device) integrated with magnetically adjustable MIP-NPs [273]. Microchip-based capillary electrophoresis (MCE) is widely used for chiral separation with advantageous aspects such as low consumption, high separation efficiency, low analysis times and system stability times. Poly (dimethylsiloxane) (PDMS) is one of the common polymeric materials used for microchips because of its easy and economical preparation, high permeability and optical transparency. However, due to the hydrophobic character of PDMS, it decreases the separation efficiency and their reusability performance, as well as exhibiting nonselective undetermined adsorption behaviors. In order to overcome these seemingly disadvantaged situations, a surface modification approach is envisaged. For this purpose, it is reported that MIP-NPS- PDMS microchip was developed and used for the first time in chiral separations [274]

Du et al. reported for the first time using carbon nanoparticles (CNPS) as PSPs to modify CPS combined with dextrin as chiral selector for the enantioseparations of various basic drugs in EKC [275]. Silica nanoparticles (SiNPs) have been recently shown as one of the alternative materials for chromatography applications due to their interesting properties such as high surface area, biocompatibility, high organic solvent resistance and easy derivatization with different functional groups. For enantiomeric separations, silica nanoparticles are usually first functionalized, and then added to the background electrolyte solution, similar to the general application of nanoparticles [276-280]. Apart from this, in another application option, it is attached to the interior-inner wall of the capillary column in order to change the EOF, increase the column capacity and improve the separation selectivity and column efficiency in electrophoretic applications. Gong et al. presented the approach that amino-modified silica nanoparticles (SiNPs) can be used as an additive to the background electrolyte solution to improve the chiral selectivity of capillary electrophoresis induced by the presence of CM- $\beta$-CD. As $\mathrm{NH}_{2}$-SiNPs were dispersed in the buffer solution, they would provide a large surface for CM$\beta-C D$ adsorption by electrostatic interaction, allowing a greater close contact between the $C M-\beta-C D$ and analytes. The coating layer absorbs the chiral selector of the CM- $\beta C D$ and then acts as a chiral stationary phase in the chiral separation process. [281]. Na Tang et al. enantioseparated enantiomers of tryptophan in
EKC by synthesizing L-Tryptophan-imprinted silica nanoparticles (L-Tryp-SiNPs) as a pseudo-stationary phase as a surface modification application [282]. In the study, which Ethanediamine- $\beta$-cyclodextrin was preferred as chiral selector, Du et al. Enantioseparated several drugs with CPS system they obtained by combining synthesized Poly(Glycidyl methacrylate)-based nanoparticles on the inner surface of the capillary column in OT-CEC [283]. Aydoğan et al. prepared a new chiral ligand exchange capillary electrophoresis method with the use of L-histidine modified nanoparticles as the chiral ligand and $\mathrm{CU}$ (II) as the central ion. With this approach, enantioseparation of ofloxazine was performed by LECE [284].

\section{Monoliths}

The monolith means single stone in Latin language, also are known as porous materials up today. Before 2000s, monolithic stationary phases have become one of the most interesting micro-separation techniques with their evaluation as chromatographic support material [285]. Monoliths are generally used in separation science and can be considered as a single porous particle. They have emerged as an alternative to particle filled columns that have been used for the years [286]. Monolithic columns are macroporous polymeric materials prepared by in-situ polymerization of the monomers in the capillary column under the condition of the pore-forming mixture system and the initiator. With the optimization of polymerization conditions, it is possible to obtain a material with low micrometer pores interconnected with each other. Thus, low back pressure can be achieved even when monoliths are exposed to high flow rates. Another feature of monoliths is their porosity that can reach up to $80 \%$ [287].

Monolithic columns can be evaluated under 3 groups as organic-polymer based, inorganic silica based and organic-inorganic (hybrid) silica based in terms of their development so far. Organic monoliths are prepared by 
Table 4. Recent studies using ionic liquids as chiral additives.

\begin{tabular}{|c|c|c|c|}
\hline Chiral additive (ILs)-CSP & Analytes & Method & Reference \\
\hline $\begin{array}{c}\text { (+)- } \mathrm{N}, \mathrm{N} \text {-dimethylephedrinium- } \\
\text { bis(trifluoromethanesulfon)imidate } \\
([\mathrm{DMP}]+[\mathrm{Tf} 2 \mathrm{~N}]-)\end{array}$ & Rabeprazole and omeprazole & NACE & {$[227]$} \\
\hline Tetramethylammonium-L- arginine/MD & $\begin{array}{l}\text { Nefopam, duloxetine, ketoconazole, } \\
\text { cetirizine, and citalopram }\end{array}$ & $\mathrm{CE}$ & [228] \\
\hline $\begin{array}{c}\text { 6-O-2-hydroxpropyltrimethylammonium- } \\
\beta \text {-cyclodextrintetrafluoroborate } \\
([\text { HPTMA- } \beta-C D][B F 4])\end{array}$ & $\begin{array}{l}\text { Chlorpheniramine, } \\
\text { Brompheniramine, promethazine, } \\
\text { liarozole, tropicamide, warfarin, } \\
\text { Pheniramine and bifonazole }\end{array}$ & CE & [229] \\
\hline (EtCholNTf2) $/ \psi$-CD & DL-Homocysteine & CE & [230] \\
\hline $\begin{array}{c}\text { AAILs/Y-CD } \\
\text { Tetrabutylammonium-aspartic } \\
\text { acid ([TBA][L-Asp]), tetramethyl- } \\
\text { ammonium-aspartic acid ([TMA][L-Asp]), } \\
\text { tetrabutylammonium-arginine ([TBA] } \\
\text { [L-Arg]), tetramethylammonium-arginine } \\
\text { ([TMA][L-Arg]), tetrabutylammonium- } \\
\text { isoleucine ([TBA][L-Iso]), } \\
\text { tetramethylammonium-isoleucine } \\
\text { ([TMA][L-Iso]), [TBA][L-Lys], [TMA][L-Lys), } \\
\text { [TBA]2[L-Glu], [TBA][L-Glu] and [TMA] } \\
\text { [L-Glu] }\end{array}$ & Ivabradine & EKC & [231] \\
\hline
\end{tabular}

\begin{tabular}{|c|c|c|c|}
\hline $\begin{array}{l}\text { (1-ethyl-3- methylimidazolium-L-lactate)/ } \\
\text { hydroxypropyl- } \beta-C D\end{array}$ & $\begin{array}{l}\text { Ofloxacin, propranolol hydrochloride, } \\
\text { dioxopromethazine hydrochloride, } \\
\text { isoprenaline hydrochloride, } \\
\text { chlorpheniramine maleate, } \\
\text { liarozole, tropicamide, amlodipine } \\
\text { benzenesulfonate, brompheniramine } \\
\text { maleate, and homatropine } \\
\text { methylbromide }\end{array}$ & CE & [232] \\
\hline (4-ATMCDCI) & $\begin{array}{l}\text { DL-Tryptophan, DL-Glutamic acid, DL- } \\
\text { Alanine } \\
\text { (DL-Leucine, DL-Isoleucine, DL- } \\
\text { Methionine, DL-Serine, DL-valine, DL- } \\
\text { Threonine, naproxen }\end{array}$ & CE & [233] \\
\hline $\begin{array}{c}([\mathrm{TMLV}]+[\mathrm{Tf} 2 \mathrm{~N}],([\mathrm{TMLP}]+[\mathrm{Tf} 2 \mathrm{~N}]- \\
([\mathrm{DMLP}]+[\mathrm{Tf} 2 \mathrm{~N}]-) \\
/ \mathrm{HP}-\beta-\mathrm{CD}\end{array}$ & $\begin{array}{l}\text { Nefopam hydrochloride, econazole } \\
\text { nitrate, sulconazole nitrate, ketoconazole } \\
\text { and amlodipine besylate }\end{array}$ & CE & [234] \\
\hline [L-Pro] [CF3COO]-Cu+2 & DL-Tryptophan & LECE & [235] \\
\hline TMA-LA/CP & $\begin{array}{c}\text { Propranolol, nefopam, citalopram, } \\
\text { chlorphenamine, metoprolol, bisoprolol, } \\
\text { andesmolol }\end{array}$ & CE & [236] \\
\hline
\end{tabular}


Table 4. Recent studies using ionic liquids as chiral additives. Continue

\begin{tabular}{|c|c|c|c|}
\hline Chiral additive (ILs)-CSP & Analytes & Method & Reference \\
\hline L-AlaC4Lac and D-AlaC4Lac & $\begin{array}{l}\text { Indoprofen, carprofen, ketoprofen, } \\
\text { ibuprofen, }\end{array}$ & CE & [237] \\
\hline ([TMA][L-OH-Pro] & $\begin{array}{l}\text { Tryptophan, phenylalanine, histidine, } \\
\text { tyrosine and 3,4-dihydroxyphenylalanine }\end{array}$ & LECE-MEKC & [238] \\
\hline $\begin{array}{c}\text { Tetramethylammonium L-Lysine- } \\
\text { hydroxypropyl- } \beta \text {-cyclodextrin ([TMA] } \\
{[\text { L-Lys])-HP- } \beta \text {-CD }} \\
\text { Tetrabutylammonium L-lysine- } \\
\text { hydroxypropyl- } \beta \text {-cyclodextrin ([TBA] } \\
{[\text { L-Lys])-HP- } \beta \text {-CD }} \\
\text { Tetramethylammonium L-glutamic acid- } \\
\text { hydroxypropyl- } \beta \text {-cyclodextrin ([TMA] } \\
{[\text { L-Glu])- HP- } \beta-C D}\end{array}$ & $\begin{array}{l}\text { Duloxetine, verapamil, terbutaline, } \\
\text { econazole and sulconazole }\end{array}$ & CE & [239] \\
\hline $\begin{array}{c}\text { Tertramethylammonium-D- } \\
\text { pantothenate-Maltodextrin } \\
\text { (TMA-D-PAN/MD) } \\
\text { Tertramethylammonium-D-quinate- } \\
\text { Maltodextrine } \\
\text { (TMA-D-QUI/MD) }\end{array}$ & $\begin{array}{c}\text { Propranolol hydrochloride, amlodipine } \\
\text { besylate, nefopam hydrochloride, } \\
\text { tropicamide, and duloxetine } \\
\text { hydrochloride }\end{array}$ & CE-173 & [240] \\
\hline$([T B A][L-A S P]-\beta-C D)$ & DL-phenylalanine, DL-tryptophan & CE & [241] \\
\hline
\end{tabular}

Tetramethylammonium-L-arginine (TMA-

$$
L-A r g) / \alpha-C D \text {, }
$$

Tetraethylammonium-L-arginine

(TEA-L-Arg)- $\alpha-C D$,

Tetrabutylammonium-L-arginine (TBA-L-

$$
\operatorname{Arg}) / \alpha-C D \text {, }
$$

Tetramethylammonium-L-proline (TMA-L-Pro)/ $\alpha-C D$,

Tetramethylammonium-L-glutamic acid (TMA-L-Glu)/ $\alpha-C D$

Amlodipine besylate, citalopram hydrobromide, nefopam hydrochloride, sulconazole nitrate and tryptophan
CE

1-butyl-3-methylimidazolium(T4)-bis[(2S)2-(hydroxy-KO)-3methylbutanoato- $\mathrm{KO}$ ] borate (BMIm+BLHvB-)-Dextrine (D)

1-butyl-3-methylimidazolium Duloxetine, ketoconazole, sulconazole and citalopram

(T-4) bis $[(\alpha S)-\alpha$-(hydroxy-kO)-4methylbenzeneacetato- $\mathrm{KO}$ ] borate

(BMIm+BSMB-)/Dextrine (D) 
Table 4. Recent studies using ionic liquids as chiral additives. Continue

\begin{tabular}{|c|c|c|c|}
\hline Chiral additive (ILs)-CSP & Analytes & Method & Reference \\
\hline 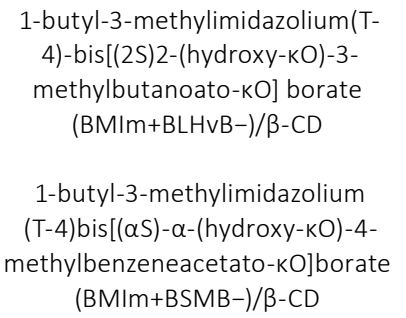 & $\begin{array}{c}\text { Propranolol hydrochloride, amlodipine } \\
\text { besylate, nefopam hydrochloride, } \\
\text { tropicamide, and duloxetine } \\
\text { hydrochloride }\end{array}$ & CE & {$[244]$} \\
\hline
\end{tabular}

Tert butyl ester bis (trifluoromethane) sulfonimide/vancomycin L-AlaC4NTf2/ vancomycin L-ValC4NTf2/vancomycin

Naproxen, carprofen, ibuprofen, ketoprofen and pranoprofen
CE

[245]

\begin{tabular}{|c|c|c|c|}
\hline $\begin{array}{l}\text { 1-ethyl-3-methylimidazolium-L-lactate/ } \beta \text { - } \\
\qquad C D\end{array}$ & $\begin{array}{l}\text { Zopiclone, repaglinide, chlorphenamine } \\
\text { maleate, brompheniramine maleate, } \\
\text { dioxopromethazine hydrochloride, } \\
\text { promethazine hydrochloride, liarozole, } \\
\text { carvedilol, homatropine hydrobromide, } \\
\text { homatropine methylbromide, venlafaxine, } \\
\text { and sibutramine hydrochloride }\end{array}$ & CE & [246] \\
\hline (TMA-LA) & $\begin{array}{c}\text { Atenolol, dulexetine, metoprolol, } \\
\text { nefopam }\end{array}$ & CE & [247] \\
\hline L-AlaC4NTf2 and L-ValC4NTf2 & Naproxen, pranoprofen, warfarin & CE & [248] \\
\hline TMA-L-Arg, TMA-L-Asp/glycogen & Nefopam, dulexotine, citalopram, & $\mathrm{CE}$ & [249] \\
\hline$[$ GTMA]CI/DM- $\beta-C D / T M-\beta-C D$ & Pindelol, oxprenolol, propranolol & CE & [250] \\
\hline Zn (II)-Leu/B-CD & DL-tyrosine, DL-valine, DL-phenylalanine & LECE & [251] \\
\hline $\begin{array}{c}{[\mathrm{L}-\mathrm{Phn}][\mathrm{CF} 3 \mathrm{COO}] 2 .[\mathrm{CF} 3 \mathrm{COO}] 2} \\
{\left[\begin{array}{c}\mathrm{L}-\mathrm{Aln}][\mathrm{CF} 3 \mathrm{COO}] 2,[\mathrm{~L}-\mathrm{Phn}][\mathrm{NO} 3] 2[\mathrm{~L}-\mathrm{Phn}] \\
{[\mathrm{SO} 4]}\end{array}\right.}\end{array}$ & DNS (DL-Met, DL-Ser, DL-Met) & LECE & [252] \\
\hline Zn (II)-L-Lys & DNS (DL-Met, DL-Ile, DL-Ser) & LECE & [253] \\
\hline
\end{tabular}


Table 4. Recent studies using ionic liquids as chiral additives. Continue

\begin{tabular}{|c|c|c|c|}
\hline Chiral additive (ILs)-CSP & Analytes & Method & Reference \\
\hline $\begin{array}{c}(\mathrm{TMA}-\mathrm{L}-\mathrm{Arg}) / \mathrm{Cu}(\mathrm{II}),(\mathrm{TMA}-\mathrm{L}-\mathrm{Glu}) / \mathrm{Cu}(\mathrm{II}) \\
\text { TMA-L-Pro)/Cu(II) }\end{array}$ & $\begin{array}{l}\text { DNS DL-(Alanine, Aspartic acid, Isoleucine } \\
\text {, Histidine, Threonine, Tryptophan, } \\
\text { Tyrosine and Phenylalanine) }\end{array}$ & LECE & [254] \\
\hline $\begin{array}{l}\text { [1-ethylpyridinium][L-lysine]/Zn(II), } \\
\text { 1- butylpyridinium][L-lysine]/Zn(II), } \\
\text { [1-hexylpyridinium][L-lysine]/Zn(II), } \\
\text { 1-[octylpyridinium][L-lysine]/Zn(II), }\end{array}$ & DNS (DL-Asn, DL-Ile, DL-Met) & LECE & [255] \\
\hline $\begin{array}{l}\text { [BMIm]Cl-Zn (II)-L-Arg, } \\
{[\text { BMIm]Br-Zn (II)-L-Arg, }} \\
{[\text { BMIm]BF4-Zn (II)-L-Arg, }}\end{array}$ & $\begin{array}{l}\text { Dns-D, L-serine (Dns-D, L-Ser), Dns-D, L- } \\
\text { methionine (Dns-D,L-Met), andDns-D, L- } \\
\text { isoleucine (Dns-D, L-lle) }\end{array}$ & LECE & {$[256]$} \\
\hline $\begin{array}{c}\text { ([TBA][L-Asp]), ([TMA][L-Asp]), ([TBA] } \\
{[\text { L-Arg]), ([TMA][L-Arg]), ([TBA][L-Iso]), }} \\
\text { ([TMA][L-Iso]), [TBA][L-Lys], [TMA][L-Lys), } \\
{[\text { TBA]2[L-Glu], [TBA][L-Glu] and [TMA] }} \\
{[\text { L-Glu] }}\end{array}$ & Ivabradine & EKC & [258] \\
\hline (TMA-CM- $\beta-C D)$ & $\begin{array}{c}\text { Atenolol, amlodipine, chlorphenamine, } \\
\text { metoprolol, ofloxacin salbutamolesmolol, } \\
\text { sotalol and propranolol labetalol, } \\
\text { Isoproterenol }\end{array}$ & CE & [259] \\
\hline (TMA-L-Hyp/CP) & $\begin{array}{l}\text { Propranolol, nefopam, citalopram, } \\
\text { chlorphenamine }\end{array}$ & CE & {$[260]$} \\
\hline $\begin{array}{l}\text { [native CF-6 and CF-7, isopropyl } \\
\text { cyclofructan-6 (IPCF-6), IPCF-7, sulfated } \\
\text { cyclofructan-6 (SCF-6), and SCF-7] }\end{array}$ & Huperzine A and coumarin-derivatives & CE & [257] \\
\hline
\end{tabular}


286 | K. Şarkaya et al. / Hacettepe J. Biol. \& Chem., 2021, 49 (3), 253-303

Table 5. Studies on nanoparticle-based stationary phases in literature for enantioseparations.

\begin{tabular}{|c|c|c|c|}
\hline CSP or BGE & Analytes & Method & Reference \\
\hline (ST-GNPS) & $\begin{array}{c}\text { Adrenaline, noradrenaline, and } \\
\text { isoprenaline }\end{array}$ & CE & {$[218]$} \\
\hline$\beta-C D-G N P s$ & $\begin{array}{c}\text { (DL-Val, Leu, Glu and Asp) } \\
\text { (chlorpheniramine, zopiclone and } \\
\text { carvedilol) }\end{array}$ & (PSP)-CEC & {$[263]$} \\
\hline
\end{tabular}

$\beta-C D / Q D s, H P-\beta-C D / Q D s$, and SBE- $\beta-C D /$

QDs

DL-Tyr, DL-Phe, DL-Tyrp CE-LIF

[265]

SH- $\beta-C D-G N P S$

(RS)-meptazinol

OT-CEC

[266]

CD-GNPS

Zopiclone, tropicamide and

OT-CEC

[267]

chlorpheniramine

Zopiclone, carvedilol, salbutamol,

SH- $\beta-C D-G N P S$

Terbutaline sulfate, phenoxybenzamine

OT-CEC

[268]

hydrochloride and ibuprofen

CD-GNP's

Chlorpheniramine, zopiclone,

tropicamide

CEC

[269]

PDA-GNPS-DNA

DL-Tryptophan

MCE

[270]

SH-CM- $\beta-C D-G N P S$

Tramadol hydrochloride and zopiclone

OT-CEC

[271]

MNP- $\beta-C D, M N P-\beta-C D-I L$

Dns DL-alanine, leucine, isoleucine, valine, methionine, glutamic acid

OT-CEC

[272]

MIP-NP-MD

Oflaxacin

CEC

[273]

(MIP-Fe $\left.\mathrm{O}_{4} @ P N E N P s\right)$

RS-mandelic acid, DL-histidine

MCE

[274]

(c-SWCNTS)/ $\beta-C D$

(c-MWCNTs) $\beta-C D$

Sulconazole, ketoconazole, citalopram

Chydrobromide and nefopam

EKC

[275]

hydrochloride

$\mathrm{Fe}_{3} \mathrm{O}_{4} @ P D A N P s$

DL-tyrosine, tryptophan, Gly-L-Phe

RS-oflaxacin,

OT-CEC

[276] 
Table 5. Studies on nanoparticle-based stationary phases in literature for enantioseparations. Continue

CSP or BGE Analytes Method Rerence

ILs-MWNTS/E(CSE)

CD-MMP
Laudonosine, propranolol, amlodipine, citalopram, nefopam
CE

[277]

Propranolol, ofloxacin, amlodipine, chlortrimeton, tropicamide, and atenolol

OT-CEC

\section{OT-CEC}

[278]

\begin{tabular}{|c|c|c|c|}
\hline (EMIML-Tar-GNPS), (EMIML-Lac-GNPS) & DL-phenylalanine, tryptophan, tyrosine & CE & {$[279]$} \\
\hline MCM-41/CDMPC & $\begin{array}{l}\text { Indapamide, Troger's base, pindolol, } \\
(\mathrm{R}, \mathrm{S}) \text {-octahydro1,10-bi-2-naphthol }\end{array}$ & OT-CEC & {$[280]$} \\
\hline (CM- $\beta-C D-N H 2-S i N P S$ & $\begin{array}{l}\text { Ephedrine, chlorpheniramine, } \\
\text { propranolol and amlodipine }\end{array}$ & CE & {$[281]$} \\
\hline L-Tryp-imp-SiNPs & DL-Tryptophan & EKC & [282] \\
\hline PGMA-NPs/Ethandiamine- $\beta-C D$ & Propranolol, amlodipine and metoprolol & OT-CEC & {$[283]$} \\
\hline L-His+Cu2+/-NPs & Oflaxacin & LECE & [284] \\
\hline
\end{tabular}


using monomer, crosslinker, initiator and pore-forming solvent materials together in a capillary tube. It can be obtained in desired size and porous surfaces together with the monitoring of polymerization conditions in general. Different chemicals and precursors can be used for the special modifications of columns. Organic polymer-based monolithic columns have some advantages such as simple, low cost, wide $\mathrm{pH}$ range effectiveness and easy modification of their surfaces using functional monomer and crosslinker [288]. On the other hand, if factors such as swelling in buffer solutions can affect reusability or reduce mechanical stability, problems such as shortening the service life of these materials may be encountered. In contrast to the this situation, inorganic silica-based monolithic columns are noteworthy for their solvent effect, as well as high column efficiency and high mechanical stability. As a result of the presence and ionization of silanol groups on surface of monoliths, electroosmotic flow (EOF) can be provided. Due to the low acidity of the silanol groups, silica-based monoliths can work in the mobile phase in conditions where the $\mathrm{pH}$ is higher than 5.0 to provide high EOF [289]. Analysis of acidic analytes in such sorbents is very difficult due to EOF. In this context, in contrast to the electrophoretic mobility of acidic analytes, the analysis times are quite long or there is no sample elution. On the other hand, the separation of basic compounds by inorganic silica-based monoliths due to the stiff adsorption between the ionization of the surface of the stationary phase and the charged solution causes the formation of tailed peaks. To solve this problem, ionic functional groups are immobilized to the surface of silica-based monoliths [290]. Silica-based monolithic columns can be prepared by controlling of the silica building blocks separately from the size and through pores by sol-gel treatment. Sol-gel network offers high permeability, high mechanical strength, high efficiency and resistance to organic solvents. However, the preparation of conventional silica-based monolithic columns, which involves creating individual silica matrices and subsequent chemical bonding, is a process that requires patience, but it is also difficult to control all reaction conditions, which leads to a negative impact on the reusability parameter [291]. Hsieh et al synthesized vancomycin-bouund silica monolithic columns for enantiomeric separations using the in situ sol-gel method for the first time in literature [292]. Alternatively, the initial incorporation of functional monomers instead of further modification of the silica rod may prevent the aforementioned drawbacks. Sol-gel chemistry provides a versatile approach to the synthesis of organic-inorganic hybrid materials under mild reaction conditions. In these latter type of column materials, the organic portion is covalently attached to a siloxane type, which can be hydrolyzed this time, to form a silica mesh by means of a non-hydrolyzed Si-C bond, which has more hydraulic stability than Si-OSi-C. For example, The approach of Sol-gel technology presents a comprehensive alternative for the synthesis of organic-inorganic hybrid materials due to the reactivity of siloxane and organosiloxane precursors [293]. These hybrid monoliths, which will be considered as a new generation silica based monolithic columns, are mechanically more stable and do not require extra modification compared to traditional silica based columns. For this reason, hybrid monolithic columns have taken place in the literature as a new alternative stationary phase in separation science. While hybrid monolithic columns were developed to overcome all these drawbacks, different inorganic species were recommended in the literature instead of silica based, including alümina, titania, hafnia or zirconia. Thanks to its excellent thermal stability and unique surface chemistry, Zirconia has the potential to be used in chromatographic separations for chiral monolithic columns. Zirconia has lower specific surface area and pore volume compared to silica. However, due to its higher density, the surface area and porosity present in a chromatographic column are similar to silica [294]. So then, the performance of zirconia coated-hybrid columns in enantiomeric separations is remarkable. It is reported that in the reactions, which zirconium-based hybrid monolithic columns are employed as CSP, the elution times are shortened, and the $\mathrm{pH}$ problem experienced in silica-based materials is resolved with improved mechanical stability [295-302].

In recent years, by combining the chiral recognition capability of CDs and the flexibility of the monolithic materials, various CD-functionalized monolithic columns have been investigated in detail [303-312]. The strategy that has been recently used in the preparation of CD-derivatized monoliths is one-step or one-pot approach. Instead of a two-step post-modification and copolymerization strategy, the one-step strategy with a CD-derived functional monomer is a potential approach to facilitate synthesis and increase reusability [313-320].

Methacrylate-based monolithic columns are one of the materials most prone to development. In addition to being practical, it is shown that the column can be applied sometimes without requiring any silanization pro- 
cess $[105,106,321-323]$ Denizli et al. synthesized chiral monolithic capillary column based on butyl methacrylate in their studies in which the enantiomeric separations of including some of hydrophobic amino acids investigated, which N-Metacryloyl-L-Histidine monomer (MAH) and N-Metacryloyl-L-Glutamic Acid (MAGA) was used as chiral selectors, resptectively in CEC [324,325].

In the first approaches for the use of nanoparticles for enantiomeric separation studies, NPs were first functionalized and then added to the background electrolyte solution, or it was coated to increase column capacity and increase separation selectivity and column efficiency in CE or CEC $[326,327]$. However, this method has emerged as a disadvantage because the dynamic coating layer is unstable. Another limitation is the necessity to create a stable, usual heterogeneous nanoparticle solution in the electrolyte. Stabilizing NPs in capillaries is a good choice to achieve a chiral stationary phase. The addition of NPs to the content of the monolithic column is perceived as an effective approach as immobilization of SiNPs or CNT as chiral selector is ideal support for holding NPs and thus allows the use of a wide variety of different selectivity offered by the unique properties of the NPs $[280,328,329]$.

\section{CONCLUSION}

In this review, the enantiomeric separations in the last ten years are discussed. There are many molecules in enantiomeric forms in nature, and each enantiomeric form of these molecules has different physiological or biological, even toxic effects. For this reason, chiral separations of enantiomers are an important issue in itself. For this purpose, Capillary electrophoresis and related techniques are still one of the most frequently used methods on chiral separations today. In the process of technology development, new hybrid methods are emerging depending on the electrophoretic foundations. With the development of column technology, the interest in new types of chiral selectors or chiral stationary phases increases. Again in this review, the most used chiral stationary phases for chiral separations are given and described.

\section{Acknowledgments}

There is no conflict of interest.

Table 6. Monoliths for recent enantioseparation studies.

\begin{tabular}{|c|c|c|c|}
\hline CS or CSP & Analytes & Method & Reference \\
\hline Vancomycin-SM & $\begin{array}{l}\text { Thalidomide, warfarin, bupivacaine, } \\
\text { alprenolol, metoprolol, pindolol }\end{array}$ & CEC & [292] \\
\hline (CDMPC-ZM) & $\begin{array}{c}\text { Tröger's base, 2,2,2-trifluoro-1-anthryl } \\
\text { ethanol, transstilbene oxide, -methyl-1- } \\
\text { naphthalenemethanol, } \\
\text { 4-phenyl-1,3-dioxane, -methylbenzyl } \\
\text { cyanide,- } \\
\text { (trifluoromethyl) benzyl alcohol, } \\
\text { epoxiconazole, } \\
\text { benalaxyl and tetramethrin }\end{array}$ & RP-CEC & [295] \\
\hline (TEOSPC-ERY-ZM) & $\begin{array}{l}\text { Propranolol, cetirizine, citalopram, } \\
\text { Metoprolol, sertraline and indapamide }\end{array}$ & CEC & [296] \\
\hline (TEOSPC-AZI-ZM) & $\begin{array}{l}\text { Ketoprofen, carprofen, flurbiprofen, } \\
\text { ibuprofen, suprofen, warfarin }\end{array}$ & NACE & [297] \\
\hline
\end{tabular}


290 | K. Şarkaya et al. / Hacettepe J. Biol. \& Chem., 2021, 49 (3), 253-303

Table 6. Monoliths for recent enantioseparation studies. Continue

CS or CSP Analytes Method Refence

(CLIP-TEOSPC-ZM)

Citalopram, Tröger's base, indapamide, metoprolol, cetirizine and atropine,

CEC sertraline, propranolol

Carprofen, flurbiprofen, ibuprofen, mandelic acid, suprofen, tropic

(QUI-S/ZHM) acid, warfarin, ketoprofen, $\mathrm{N}-(3,5-$ dinitrobenzoyl)-Leucine, $\mathrm{N}-(3,5$ dinitrobenzoyl)-phenylglycine

(CLIP-ZM) Ibuprofen, suprofen, indoprofen, ketoprofen, propranolol, atenolol pindolol, propranolol

Carprofen, flurbiprofen, ibuprofen,

indoprofen, suprofen, tropic acid,

(QUI-SHM) warfarin, ketoprofen, mandelic acid and tert-butylcarbamoylquinine

Zopiclone, chlorphenamine maleate, brompheniramine maleate, dioxopromethazine hydrochloride,

sibutramine hydrochloride and terbutaline sulfate

$\mathrm{Br}-\beta-\mathrm{CD}-\mathrm{M}$ 
Table 6. Monoliths for recent enantioseparation studies. Continue

CS or CSP Analytes Method Refence

B-CD-AGH DL-mandelic acid and its derivatives [309]

2,3,6-tris(phenylcarbamoyl)- $\beta$-CD-6methacrylate $\alpha$ - and $\beta$-blockers, anti-inflammatory

drugs, antifungal drugs, dopamine

antagonists, norepinephrine-dopamine

reuptake inhibitors, catecholamines,

sedative hypnotics, diuretics,

antihistaminics, anticancer drugs

and antiarrhythmic drugs. alprenolol,

v

bufuralol, carbuterol, cizolertine,

desmethylcizolertine, eticlopride,

ifosfamide, 1-indanol, propranolol,

tebuconazole, tertatolol and

o-methoxymandelic acid 2-chloro-mandelic acid, 2-bromo-

mandelic acid, 4-chloro-mandelic

acid, Benzoyl-DL-Leucine, 2-chloro-

benzoyl-Leucine, 3,5-DNB Phenbromate,

Suprofen, Idoprofen, Ibuprofen,

CEC

[312]

2-(-3-chlorophenoxy)-propionic acid,

Haloxyfop, tropic acid, 2-Phenylpropionic

acid
09]
poly(GMA-EDA- $\beta-C D-E D M A)$,

poly(GMA-HDA- $\beta$-CD-EDMA
Ibuprofen, fenoprofen and indoprofen

$\mu-H P L C$

[313]

2-bromomandelic acid, 4-chloromandelic acid, and 4-bromomandelic acid

$\mu-H P L C$

[314]

poly(GMA-mono-NH2- $\beta$-CD-EDMA)

13 different racemats

CLC

Chlorpheniramine, brompheniramine, homatropine, homatrophine methylbromide, clorprenaline,

CEC tropicamide

$\mathrm{N}$-benzyloxycarbonyl-DL-aspartate, (RS)-

$\beta$-CD-UF
$\mathrm{CLC}$ 
Table 6. Monoliths for recent enantioseparation studies. Continue

CS or CSP

Allyl- $\beta-C D$ with PETMP
Analytes

Method

Flavanone, flubiprofen, naproxen synephrine,

Isoprenaline sulfate, ketoprofen, and

atropine sulfate monohydrate

GMA/ $\beta-C D$ - vinylbenzyl

trimethylammonium
Enantiomers of (phenoxy) propionic acid, mandelic acid,
CEC-MS

[319]

Flavanone, mandelic acid methyl ester, homatropine methylbromide and some chiral drugs
CE
DL-malonic acid, tyrosine, phenylalanine, histidine, glutamic acid, aspartic acid
LECE

Mandelic acid derivatives, nonsteroidal anti-inflammatory drugs, $\mathrm{N}$-derivatized amino acids, and herbicides

CEC
$p(M A)-\beta-C D$

$\mathrm{p}(\mathrm{GMA})-C D M P C$
CEC
Trans-stilbene oxide, benzoin, 2-phenyl1-propanol, Tröger's base, mefloquin, propranolol, ibuprofen, naproxen, phenylalanine

\begin{tabular}{rr} 
propranolol, ibup \\
phenyla \\
\hline p(BMA)-MAH & DL-tyrosine, tryptop \\
\hline (BMA)-MAGA & tyro \\
\hline References & \\
\hline
\end{tabular}

1. G. Gübitz, M.G. Schmid, Chiral separation by capillary electromigration techniques, J. Chromatogr. A, 1204 (2008) 140-156.

2. E. Sánchez-López, M. Castro-Puyana, M.L. Marina, A.L. Crego, Chiral Separations by Capillary Electrophoresis, Anal. Sep. Sci. Wiley-VCH Verlag GmbH \& Co. KGaA, Weinheim, Germany, 2 (2015) 731-775.

3. B. Preinerstorfer, M. Lämmerhofer, W. Lindner, Advances in enantioselective separations using electromigration capillary techniques, Electrophoresis, 30 (2009) 100-132.

4. C. Tano, S.-H. Son, J. Furukawa, T. Furuike, N. Sakairi, Enantiomeric separation by MEKC using dodecyl thioglycoside surfactants: Importance of an equatorially oriented hydroxy group at C-2 position in separation of dansylated amino acids, Electrophoresis, 30 (2009) 27432746.

5. A.P. Kumar, J.H. Park, Chiral separation of basic compounds on a cellulose 3,5-dimethylphenylcarbamate-coated zirconia monolithin basic eluents by capillary electrochromatography, J. Chromatogr. A, 1218 (2011) 6548-6553.

6. J. Yang, D.S. Hage, Characterization of the binding and chiral separation of $d$ - and I-tryptophan on a high-performance immobilized human serum albumin column, J. Chromatogr. A, 645 (1993) 241-250.

7. G. Sagratini, M. Buccioni, G. Marucci, E. Poggesi, M. Skorski, S. Costanzi, D. Giardinà, Chiral analogues of (+)-cyclazosin as potent $\alpha 1 B$-adrenoceptor selective antagonist, Bioorganic Med. Chem., 26 (2018) 3502-3513. 
8. K.D. Altria, I.H. Grant, Methods in Molecular Biology, Capillary Electrophoresis Guidebook, Principles, Operation and Applications, Capillary Electrophoresis Guidebook. Humana Press, 52 (2003) 197-210.

9. V. Houbart, M. Fillet, Advances in Microfluidics-New Applications in Biology, Energy, and Materials Sciences. InTech, Edited by Xiao-Ying Yu, (2016) 1-30.

10. Tagliaro, F., Deyl, Z., Mikš ík, I., Ulfelder, K. J., J Concepts and principles of high performance capillary electrophoresis John Wiley \& Sons, Ltd, (2006) 41-63.

11. F.U. Aşıcıoğlu, S.T. Koluaçık, B.Ü. Çetinkaya, F. Akyüz, Tıp Kurumu Başkanlığı Biyoloji ìtisas Dairesi, A., Kapiller Elektroforez Teknolojisinin Klinik ve Adli Amaçlı DNA Analizlerinde Kullanımı: Geleneksel Jel Elektroforez Yöntemi Ile Karşılaşıırma. n.d. Adli Tıp Derg., 16 (2002) 88-93.

12. S. Aşır, D. Sarı, A. Derazshamshir, F. Yılmaz, K. Şarkaya, A. Denizli, Dopamine-imprinted monolithic column for capillary electrochromatography, Electrophoresis, 38 (2017) 3003-3012.

13. C.A. Lucy, R.S. Underhill, Characterization of the cationic surfactant induced reversal of electroosmotic flow in capillary electrophoresis, Anal. Chem., 68 (1996) 300-305.

14. S. Aşır, A. Derazshamshir, F. Yılmaz, A. Denizli, Triazine herbicide imprinted monolithic column for capillary electrochromatography, Electrophoresis, 36 (2015) 2888 2895.

15. C. Aydoğan, A. Gökaltun, A. Denizli, Z. El Rassi, Biochromatographic applications of polymethacrylate monolithic columns used in electro- and liquid phaseseparations $\Psi$, J. Liq. Chromatogr. Relat. Technol., 41 (2018) 572-582.

16. G. Gübitz, M.G. Schmid, Chiral separation principles in chromatographic and electromigration techniques, Mol. Biotechnol., 32 (2006) 159-179.

17. H. Poppe, A. Cifuentes, W.T. Kok, Theoretical description of the influence of external radial fields on the electroosmotic flow in capillary electrophoresis, Anal. Chem., 68 (1996) 888-893.

18. M.G. Cikalo, K.D. Bartle, P. Myers, Influence of the electrical double-layer on electroosmotic flow in capillary electrochromatography, J. Chromatogr. A, 836 (1999) 35-51.

19. J.H. Knox, Terminology and nomenclature in capillary electroseparation systems, J. Chromatogr. A, 680 (1994) 3-13.

20. A Denizli, Ö.i. Küfrevioğlu, Pozitif Matbaacılık, Ankara, Protein kromatografisi ve yeni nesil polimerik sistemler (2010).

21. T. Gündüz, Gazi Kitabevi, Kromatografi ve elektroforez (2015).

22. J.H. Knox, I.H., Grant, Miniaturisation in pressure and electroendosmotically driven liquid chromatography: Some theoretical considerations, Chromatographia, 24 (1987) 135-143.

23. A.M. Enlund, G. Hagman, R. Isaksson, D. Westerlund, Capillary electrochromatography of basic compounds in pharmaceutical analysis, TrAC-Trends Anal. Chem., 21 (2002) 412-427.

24. S. Aşır, D. Sarı, A. Derazshamshir, F. Yılmaz, K. Şarkaya, A. Denizli, Dopamine-imprinted monolithic column for capillary electrochromatography, Electrophoresis, 38 (2017) 3003-3012.
25. C. Aydogan, A. Denizli, Electrochromatographic Enantioseparation of Amino Acids Using Polybutylmethacrylate-based Chiral Monolithic Column by Capillary Electrochromatography, Chirality, 24 (2012) 606609.

26. S. Tanwar, R. Bhushan, Enantioresolution of Amino Acids: A Decade's Perspective, Prospects and Challenges, Chromatographia, 78 (2015) 1113-1134.

27. Z.-X. Zheng, J.-M. Lin, F. Qu, T. Hobo, Chiral separation with ligand-exchange micellar electrokinetic chromatography using aD-penicillamine-copper(II) ternary complex as chiral selector, Electrophoresis, 24 (2003) 4221-4226.

28. Terabe, K. Otsuka, K. Ichikawa, A. Tsuchiya, T. Ando, Electrokinetic Separations with Micellar Solutions and Open-Tubular Capillaries, Anal. Chem., 56 (1984) 111-113.

29. K. Otsuka, S. Terabe, T. Ando, Electrokinetic chromatography with micellar solutions. Separation of phenylthiohydantoinamino acids, J. Chromatogr. A, 332 (1985) 219-226.

30. S. Terabe, K. Otsuka, T. Ando, Electrokinetic Chromatography with Micellar Solution and Open-Tubular Capillary, Anal. Chem., (1985) 834-841.

31. J. Palmer, D.S. Burgi, N.J. Munro, J.P. Landers, Electrokinetic injection for stacking neutral analytes in capillary and microchip electrophoresis, Anal. Chem., 73 (2001) 725-731.

32. S. Kodama, A. Yamamoto, Y. Saitoh, A. Matsunaga, K. Okamura, R. Kizu, K. Hayakawa, Enantioseparation of vinclozolin by $\gamma$-cyclodextrin-modified micellar electrokinetic chromatography, J. Agric. Food Chem., 50 (2002) 1312-1317.

33. Aumatell, R.J. Wells, Enantiomeric differentiation of a wide range of pharmacologically active substances by cyclodextrin-modified micellar electrokinetic capillary chromatography using a bile salt, J. Chromatogr. A, 688 (1994) 329-337.

34. T. Ueda, F. Kitamura, R. Mitchell, T. Metcalf, T. Kuwana, A. Nakamoto, Chiral Separation of naphthalene-2,3dicarboxaldehyde-labeled amino acid enantiomers by cyclodextrin-modified micellar electrokinetic chromatography with laser-induced fluorescence detection. Anal. Chem., 63 (1991) 2979-2981.

35. Dobashi, T. Ono, S. Hara, J. Yamaguchi, Optical resolution of enantiomers with chiral mixed micelles by electrokinetic chromatography, Anal. Chem., 61 (1989) 1984-1986.

36. D. Sarı, A. Derazshamshir, S. Aşır, I. Göktürk, F. Yılmaz, A. Denizli, Separation of $D$, L-ampicillin by ligand exchangemicellar electrokinetic chromatography., Biointerface Res. Appl. Chem., (2019) 4522-4533.

37. C.P. Palmer, S. Terabe, Micelle Polymers as Pseudostationary Phases in MEKC: Chromatographic Performance and Chemical Selectivity, Anal. Chem., 69 (1997) 1852-1860.

38. V.A. Davankov, S.V. Rogozhin, Ligand chromatography as a novel method for the investigation of mixed complexes: stereoselective effects in $\alpha$-amino acid copper(II) complexes, J. Chromatogr. A, 60 (1971) 284-312.

39. M.G. Schmid, R. Rinaldi, D. Dreveny, G. Gübitz, Enantioseparation of $\alpha$-amino acids and dipeptides by ligand-exchange capillary electrophoresis of various L-4hydroxyproline derivatives, J. Chromatogr. A, 846 (1999) 157-163. 
40. M.G. Schmid, N. Grobuschek, O. Lecnik, G. Gubitz, Chiral Ligand-Exchange Capillary Electrophoresis, 48, 2, (2001) 143-154.

41. Z. Chen, T. Hobo, Chemically L-phenylalaninamide-modified monolithic silica column prepared by a Sol-Gel process for enantioseparation of dansyl amino acids by ligand exchange-capillary electrochromatography, Anal. Chem., 73 (2001) 3348-3357.

42. X. Mu, L. Qi, J. Qiao, X. Yang, H. Ma, Enantioseparation of dansyl amino acids and dipeptides by chiral ligand exchange capillary electrophoresis based on Zn(II)-I-hydroxyproline complexes coordinating with $y$-cyclodextrins, Anal. Chim. Acta, 846 (2014) 68-74.

43. M.G. Schmid, M. Laffranchini, D. Dreveny, G. Gübitz, Chiral separation of sympathomimetics by ligand exchange capillary electrophoresis, Electrophoresis, 20 (1999) 2458 2461.

44. P. Gozel, H. Michelsen, R.N. Zare, E. Gassmann, Electrokinetic Resolution of Amino Acid Enantiomers with Copper(II) Aspartame Support Electrolyte, Anal. Chem.,50 (1987) 44 49.

45. T.C. Bøg-Hansen, Crossed immuno-affinoelectrophoresis, An analytical method to predict the result of affinity chromatography, Anal. Biochem., 56 (1973) 480-488.

46. K.M. Łącki, F.J. Riske, Affinity Chromatography: An Enabling Technology for Large-Scale Bioprocessing, Biotechnol. J., 15 (2020) 1800397.

47. Y.H. Chu, L.Z. Avila, J. Gao, G.M. Whitesides, Affinity Capillary Electrophoresis, Acc. Chem. Res., 28 (1995) 461-468.

48. Y.H. Chu, L. Z. Avila, H.A. Biebuyck, G.M. Whitesides, Using Affinity Capillary Electrophoresis to Identify the Peptide in a Peptide Library that Binds Most Tightly to Vancomycin. J. Org. Chem. 58 (1993) 648-652.

49. M. Azad, L. Hernandez, A. Plazas, M. Rudolph, F.A. Gomez, Determination of binding constants between the antibiotic ristocetin A and D-Ala-D-Ala terminus peptides by affinity capillary electrophoresis, Chromatographia, 57 (2003) 339 343.

50. Zhang, D.S. Hage, Capillary Electromigration Separation Methods. Chapter 18-Clinical Chemistry Applications of Capillary Electromigration Methods, Elsevier (2018) 423 452.

51. Zhang, A.G. Woolfork, K. Suh, S. Ovbude, C. Bi, M. Elzoeiry, D.S. Hage, Clinical and pharmaceutical applications of affinity ligands in capillary electrophoresis: A review, J. Pharm. Biomed. Anal., 177 (2020) 112882.

52. Ekberg, K. Mosbach, Molecular imprinting: A technique for producing specific separation materials, Trends Biotechnol. 7 (1989) 92-96

53. T. Sajini, M.G. Gigimol, B. Mathew, A brief overview of molecularly imprinted polymers supported on titanium dioxide matrices, Mater. Today Chem., 11 (2019) 283-295.

54. Turiel, A. Martín-Esteban, Molecularly imprinted polymers for sample preparation: A review, Anal. Chim. Acta, 668 (2010) 87-99.

55. G. Vasapollo, R.D. Sole, L. Mergola, M.R. Lazzoi, A. Scardino, S. Scorrano, G. Mele, Molecularly Imprinted Polymers: Present and Future Prospective, Int. J. Mol. Sci., 12 (2011) 5908-5945.

56. J. Wackerlig, P.A. Lieberzeit, Polymers, Molecularly Imprinted, Ullmann's Encyclopedia of Industrial Chemistry, Wiley-VCH Verlag GmbH \& Co. KGaA, Weinheim, Germany (2016) 1-20.
57. Z.-S. Liu, C. Zheng, C. Yan, R.-Y. Gao, Molecularly imprinted polymers as a tool for separation in CEC, Electrophoresis, 28 (2007) 127-136.

58. Malik, Advances in sol-gel based columns for capillary electrochromatography: Sol-gel open-tubular columns, Electrophoresis, 23 (2002) 3973-3992.

59. A.P. McKeown, M.R. Euerby, C.M. Johnson, M. Koeberle, H. Lomax, H. Ritchie, P. Ross, An evaluation of unbonded silica stationary phases for the separation of basic analytes using capillary electrochromatography, Chromatographia, 52 (2000) 777-786.

60. H. Engelhardt, F.T. Hafner, Porous and non-porous stationary phases for capillary electrochromatography under conditions of reversed phase chromatography, Chromatographia, 52 (2000) 769-776.

61. Chaiyasut, Y. Takatsu, S. Kitagawa, T. Tsuda, Estimation of the dissociation constants for functional groups on modified and unmodified silica gel supports from the relationship between electroosmotic flow velocity and $\mathrm{pH}$, Electrophoresis, 22 (2001) 1267-1272.

62. W.J. Cheong, S.H. Yang, Open tubular molecular imprinted phases in chiral capillary electrochromatography, Methods Mol. Biol., 970 (2013) 469-487.

63. Y. Xue, X. Gu, Y. Wang, C. Yan, Recent advances on capillary columns, detectors, and two-dimensional separations in capillary electrochromatography, Electrophoresis, 36 (2015) 124-134.

64. N.W. Smith, Z. Jiang, Developments in the use and fabrication of organic monolithic phases for use with high-performance liquid chromatography and capillary electrochromatography, J. Chromatogr. A, 1184 (2008) 416440.

65. K. Şarkaya, A. Denizli, Moleküler Baskılama Yöntemi ile Kapiler Elektrokromatografi (CEC) Sisteminde Hidrofobik Amino Asitlerin Enantiyomerlerinin Ayrılması. 2018.

66. J. Ou, Z. Liu, H. Wang, H. Lin, J. Dong, H. Zou, Recent development of hybrid organic-silica monolithic columns in CEC and capillary LC, Electrophoresis, 36 (2015) 62-75.

67. P. Kuś, J. Kusz, M. Książek, E. Pieprzyca, M. Rojkiewicz, Spectroscopic characterization and crystal structures of two cathinone derivatives: N-ethyl-2-amino-1-phenylpropan1-one (ethcathinone) hydrochloride and $\mathrm{N}$-ethyl-2-amino1-(4-chlorophenyl) propan-1-one (4-CEC) hydrochloride, Forensic Toxicol., 35 (2017) 114-124.

68. B.B. Mamba, R.W. Krause, T.J. Malefetse, E.N. Nxumalo, Monofunctionalized cyclodextrin polymers for the removal of organic pollutants from water, Environ. Chem. Lett., 5 (2007) 79-84.

69. A.E. Holmes, Cyclodextrins and their complexes: Chemistry, analytical methods, applications, Chirality, 19 (2007) 162162.

70. M. Arslan, S. Sayin, M. Yilmaz, Enantioselective sorption of some chiral carboxylic acids by various cyclodextrin-grafted iron oxide magnetic nanoparticles, Tetrahedron Asymmetry, 24 (2013) 982-989.

71. N. Li, J. Chen, Y.P. Shi, Magnetic reduced graphene oxide functionalized with $\beta$-cyclodextrin as magnetic solidphase extraction adsorbents for the determination of phytohormones in tomatoes coupled with high performance liquid chromatography, J. Chromatogr. A, 1441 (2016) 24-33.

72. L.A. Kartsova, N.V. Komarova, Influence of $\alpha$ - and $\beta$-Cyclodextrins on the Separation of Positional Isomers of Benzoic Acid Nitro, Amino, Chloro, and Hydroxy Derivatives by Capillary Electrophoresis, J. Anal. Chem., 58 (2003) 972978. 
73. S. Fanali, Enantioselective determination by capillary electrophoresis with cyclodextrins as chiral selectors, J. Chromatogr. A, 875 (2000) 89-122.

74. Perrin, Y.V. Heyden, M. Maftouh, D.L. Massart, Rapid screening for chiral separations by short-end injection capillary electrophoresis using highly sulfated cyclodextrins as chiral selectors, Electrophoresis, 22 (2001) 3203-3215.

75. J. Zhou, J. Tang, W. Tang, Recent development of cationic cyclodextrins for chiral separation, TrAC-Trends Anal. Chem. 65 (2015) 22-29.

76. Z.-X. Fei, M. Zhang, J.-H. Zhang, L.-M. Yuan, Chiral metalorganic framework used as stationary phases for capillary electrochromatography, Anal. Chim. Acta, 830 (2014) 49-55.

77. Kuila, N.A. Surib, N.S. Mishra, A. Nawaz, K.M. Leong, L.C. Sim, P. Saravanan, S. Ibrahim, Metal Organic Frameworks: A New Generation Coordination Polymers for Visible Light Photocatalysis, ChemistrySelect, 2 (2017) 6163-6177.

78. Li, Y. Zhang, D. Ma, L. Li, G. Li, G. Li, Z. Shi, S. Feng, A strategy toward constructing a bifunctionalized MOF catalyst: Postsynthetic modification of MOFs on organic ligands and coordinatively unsaturated metal sites, Chem. Commun., 48 (2012) 6151-6153.

79. M. Ma, D. Zacher, X. Zhang, R.A. Fischer, N. Metzler-Nolte, A method for the preparation of highly porous, nanosized crystals of isoreticular metal-organic frameworks, Cryst. Growth Des., 11 (2011) 185-189.

80. T. Grancha, J. Ferrando-Soria, D. Armentano, E. Pardo, Synthesis of a chiral rod-like metal-organic framework from a preformed amino acid-based hexanuclear Wheel, J. Coord. Chem., 72 (2019) 1204-1221.

81. J.R. Li, J. Sculley, H.C. Zhou, Metal-organic frameworks for separations, Chem. Rev., 112 (2012) 869-932.

82. O.K. Farha, A.Ö. Yazaydin, I. Eryazici, C.D. Malliakas, B.G. Hauser, M.G. Kanatzidis, S.T. Nguyen, R.Q. Snurr, J.T. Hupp, De novo synthesis of a metal-organic framework material featuring ultrahigh surface area and gas storage capacities, Nat. Chem., 2 (2010) 944-948.

83. T. Zhang, F. Song, W. Lin, Blocking bimolecular activation pathways leads to different regioselectivity in metal-organic framework catalysis, Chem. Commun., 48 (2012) 8766-8768

84. G. Wang, Y. He, S. Hwang, D.A. Cullen, M.A. Uddin, L. Langhorst, B. Li, S. Karakalos, A.J. Kropf, E.C. Wegener, J. Sokolowski, M. Chen, D. Myers, D. Su, K.L. More, S. Litster, G. Wu, Highly active atomically dispersed CoN 4 fuel cell cathode catalysts derived from surfactant-assisted MOFs: Carbon-shell confinement strategy, Energy Environ. Sci., 12 (2019) 250-260.

85. J. Zhu, L. Qin, A. Uliana, J. Hou, J. Wang, Y. Zhang, X. Li, S. Yuan, J. Li, M. Tian, J. Lin, B. Van der Bruggen, Elevated performance of thin film nanocomposite membranes enabled by modified hydrophilic MOFs for nanofiltration, ACS Appl. Mater. Interfaces, 9 (2017) 1975-1986.

86. J. Zhuang, C.H. Kuo, L.Y. Chou, D.Y. Liu, E. Weerapana, E., C.K. Tsung, Optimized metal-organic-framework nanospheres for drug delivery: Evaluation of small-molecule encapsulation, ACS Nano 8 (2014) 2812-2819.

87. N. Stock, S. Biswas, Synthesis of metal-organic frameworks (MOFs): Routes to various MOF topologies, morphologies, and composites, Chem. Rev., 112 (2012) 933-969.

88. N. Rangnekar, N. Mittal, B. Elyassi, J. Caro, M. Tsapatsis, Zeolite membranes-a review and comparison with MOFs, Chem. Soc. Rev., 44 (2015) 7128-7154.
89. H. Furukawa, K.E. Cordova, M. O'Keeffe, O.M. Yaghi, The chemistry and applications of metal-organic frameworks, American Association for the Advancement of science (AAAS) 341, (2013) 374-385.

90. A.J. Fletcher, K.M. Thomas, M.J. Rosseinsky, Flexibility in metal-organic framework materials: Impact on sorption properties, J. Solid State Chem., 178 (2005) 2491-2510.

91. S. Han, Y. Wei, C. Valente, I. Lagzi, J.J. Gassensmith, A. Coskun, J.F. Stoddart, B.A. Grzybowski, Chromatography in a single metal-organic framework (MOF) crystal, J. Am. Chem. Soc., 132 (2010) 16358-16361

92. C.X. Yang, X.P. Yan, Metal-organic framework MIL-101(Cr) for high-performance liquid chromatographic separation of substituted aromatics, Anal. Chem., 83 (2011) 7144-7150.

93. C.-X. Yang, Y.-J. Chen, H.-F. Wang, X.-P. Yan, High-performance separation of fullerenes on metal-organic framework MIL101(Cr). Chem. - A Eur. J., 17 (2011) 11734-11737.

94. Z-Y. Gu, D-Q. Jiang, H-F. Wang, X-Y. Cui, X-P. Yan, Adsorption and separation of xylene isomers and ethylbenzene on two Zn-terephthalate metal-organic frameworks, J. Phys. Chem., 114 (2010) 311-316.

95. Z-X. Fei, M. Zhang, J-H. Zhang, L-M. Yuan, Chiral metalorganic framework used as stationary phases for capillary electrochromatography, Anal. Chim. Acta, 830 (2014) 49-55.

96. S.M. Xie, M. Zhang, Z.X. Fei, L.M. Yuan, Experimental comparison of chiral metal-organic framework used as stationary phase in chromatography, J. Chromatogr. A, 1363 (2014) 137-143.

97. Z.-X. Fei, M. Zhang, S.-M. Xie, L.-M. Yuan, Capillary electrochromatographic fast enantioseparation based on a chiral metal-organic framework, Electrophoresis, 35 (2014) 3541-3548.

98. M.T. Matyska, J.J. Pesek, A. Katrekar, Open tubular capillary electrochromatography using etched fused-silica tubing modified with chemically bonded liquid crystals, Anal. Chem., 71 (1999) 5508-5514.

99. X. Wang, C. Cheng, S. Wang, M. Zhao, P.K. Dasgupta, S. Liu, Nanocapillaries for open tubular chromatographic separations of proteins in femtoliter to picoliter samples, Anal. Chem., 81 (2009) 7428-7435.

100. Z-G. Gu, C. Zhan, J. Zhang, X. Bu, Chiral chemistry of metalcamphorate frameworks, Chem. Soc. Rev., 45 (2016) 31223144

101. S. Lim, K. Suh, Y. Kim, M. Yoon, H. Park, D.N. Dybtsev, K. Kim, Porous carbon materials with a controllable surface area synthesized from metal-organic frameworks, Chem. Commun., 48 (2012) 7447-7449.

102. R. Das, P. Pachfule, R. Banerjee, P. Poddar, Metal and metal oxide nanoparticle synthesis from metal organic frameworks (MOFs): Finding the border of metal and metal oxides, Nanoscale, 4 (2012) 591-599.

103. M.M. Wanderley, C. Wang, C. De Wu, W. Lin, A chiral porous metal-organic framework for highly sensitive and enantioselective fluorescence sensing of amino alcohols, J. Am. Chem. Soc., 134 (2012) 9050-9053.

104. L.L. Wu, R.P. Liang, J. Chen, J.D. Qiu, Separation of chiral compounds using magnetic molecularly imprinted polymer nanoparticles as stationary phase by microchip capillary electrochromatography, Electrophoresis, 39 (2018) 356-362.

105. K. Şarkaya, S. Aşir, I. Göktürk, S. Ektirici, F. Yilmaz, H. Yavuz, A. Denizli, Separation of histidine enantiomers by capillary electrochromatography with molecularly imprinted monolithic columns. Sep. Sci. Plus (2020) 3:235-245. 
106. K. Şarkaya, S. Aşir, I. Göktürk, F. Yilmaz, H. Yavuz, A. Denizli, Electrochromatographic separation of hydrophobic amino acid enantiomers by molecularly imprinted capillary columns, Process Biochem., 92 (2020) 69-77.

107. K. Hroboň Ová, A. Lomenova, Molecularly imprinted polymer as stationary phase for HPLC separation of phenylalanine enantiomers. Monatshefte für Chemie- Chemical Monthly 149 (2018) 939-946.

108. C-Y. Yue, G-S. Ding, F-J. Liu, A-N. Tang, Water-compatible surface molecularly imprinted silica nanoparticles as pseudostationary phase in electrokinetic chromatography for the enantioseparation of tryptophan, J. Chromatogr. A, 1311 (2013) 176-182.

109. H.J. Liang, T.R. Ling, J.F. Rick, T.C. Chou, Molecularly imprinted electrochemical sensor able to enantroselectivly recognize d and I-tyrosine, Anal. Chim. Acta., 542 (2005) 83 89.

110. S.H. Ou, L.S. Pan, J.J. Jow, H.R. Chen, T.R. Ling, Molecularly imprinted electrochemical sensor, formed on Ag screen printed electrodes, for the enantioselective recognition of D and L phenylalanine, Biosens. Bioelectron., 105 (2018) 143-150.

111. J. Zhou, Q. Chen, Y. Wang, Q. Han, Y. Fu, Stereoselectivity of tyrosine enantiomers in electrochemical redox reactions on gold matrices, Electrochim. Acta, 59 (2012) 45-48.

112. X. Chen, S. Zhang, X. Shan, Z. Chen, Derivative chiral copper(II) complexes as template of an electrochemical molecular imprinting sol-gel sensor for enantiorecognition of aspartic acid, Anal. Chim. Acta, 1072 (2019) 54-60.

113. Z. Iskierko, A. Checinska, P.S. Sharma, K. Golebiewska, K. Noworyta, P. Borowicz, K. Fronc, V. Bandi, F. D'Souza, W. Kutner, Molecularly imprinted polymer based extendedgate field-effect transistor chemosensors for phenylalanine enantioselective sensing, J. Mater. Chem. C, 5 (2017) 969977.

114. Y. Kong, J. Wei, W. Wang, Z. Chen, Separation of tryptophan enantiomers with polypyrrole electrode column by potential-induced technique, Electrochim. Acta, 56 (2011) 4770-4774.

115. H.S. Lee, J. Hong, Chiral and electrokinetic separation of amino acids using polypyrrole-coated adsorbents, J. Chromatogr. A, 868 (2000) 189-196.

116. V. Syritski, J. Reut, A. Menaker, R.E. Gyurcsányi, A. Öpik, Electrosynthesized molecularly imprinted polypyrrole films for enantioselective recognition of I-aspartic acid Electrochim. Acta, 53 (2008) 2729-2736.

117. J. Gu, H. Dai, Y. Kong, Y. Tao, H. Chu, Z. Tong, Chiral electrochemical recognition of cysteine enantiomers with molecularly imprinted overoxidized polypyrrole-Au nanoparticles, Synth. Met., 222 (2016) 137-143.

118. S. Lee, Y. Choi, S. Lee, K. Jeong, S. Jung, Chiral recognition based on enantioselective interactions of propranolol enantiomers with cyclosophoraoses isolated fromRhizobium meliloti, Chirality, 16 (2004) 204-210.

119. W. Liu, C. Holdsworth, L. Ye, Synthesis of molecularly imprinted polymers using a functionalized initiator for chiralselective recognition of propranolol, Chirality, 32 (2020) 370-377.

120. G.-N. Chen, N. Li, T. Luo, Y.-M. Dong, Enantiomers Recognition of Propranolol Based on Organic-Inorganic Hybrid OpenTubular MIPs-CEC Column Using 3-(Trimethoxysilyl) Propyl Methacrylate as a Cross-Linking Monomer, J. Chromatogr. Sci., 55 (2017) 471-476.
121. R. Gutierrez-Climente, A. Gomez-Caballero, A. Guerreiro, D. Garcia-Mutio, N. Unceta, M.A. Goicolea, R.J. Barrio, Molecularly imprinted nanoparticles grafted to porous silica as chiral selectors in liquid chromatography, J. Chromatogr. A, 1508 (2017) 53-64.

122. R. Gutiérrez-Climente, A. Gómez-Caballero, M. Halhalli, B. Sellergren, M.A. Goicolea, R.J. Barrio, Iniferter-mediated grafting of molecularly imprinted polymers on porous silica beads for the enantiomeric resolution of drugs, J. Mol. Recognit., 29 (2016) 106-114.

123. J.M. Brunel, BINOL: A versatile chiral reagent. Chem. Rev. 2005, 105, 857-897.

124. H. Dong, D. Zhang, H. Lin, Y. Wang, L. Liu, M. Zheng, X. Li, C. Zhang, J. Li, P. Zhang, J. So, A surface molecularly imprinted polymer as chiral stationary phase for chiral separation of 1,1'- binaphthalene-2-naphthol racemates, Chirality, 29 (2017) 340-347.

125. Kulsing, R. Knob, M. Macka, P. Junor, R.I. Boysen, M.T.W. Hearn, Molecular imprinted polymeric porous layers in open tubular capillaries for chiral separations, J. Chromatogr. A, 1354 (2014) 85-91.

126. Kulsing, Y. Yang, J.M. Chowdhury, R.I. Boysen, M.T.W. Hearn, Use of peak sharpening effects to improve the separation of chiral compounds with molecularly imprinted porous polymer layer open-tubular capillaries, Electrophoresis, 38 (2017) 1179-1187.

127. J. Ou, X. Li, S. Feng, J. Dong, X. Dong, L. Kong, M. Ye, H. Zou, Preparation and evaluation of a molecularly imprinted polymer derivatized silica monolithic column for capillary electrochromatography and capillary liquid chromatography, Anal. Chem., 79 (2007) 639-646.

128. Q-L. Zhao, J. Zhou, L-S. Zhang, Y-P. Huang, Z-S. Liu, Coatings of molecularly imprinted polymers based on polyhedral oligomeric silsesquioxane for open tubular capillary electrochromatography, Talanta, 152 (2016) 277-282.

129. H.Y. Zong, X. Liu, Z.S. Liu, Y.P. Huang, Molecular crowdingbased imprinted monolithic column for capillary electrochromatography, Electrophoresis, 36 (2015) 818-824.

130. L.N. Mu, X.H. Wang, L. Zhao, Y.P. Huang, Z.S. Liu, Low crosslinked molecularly imprinted monolithic column prepared in molecular crowding conditions, J. Chromatogr. A, 1218 (2011) 9236-9243.

131. X.X. Li, X. Liu, L.H. Bai, H.Q. Duan, Y.P. Huang, Z.S. Liu, Preparation of imprinted monolithic column under molecular crowding conditions, Chinese Chem. Lett., 22 (2011) 989-992.

132. X-H. Wang, Q. Dong, L-L. Ying, S-S. Chi, Y-H. Lan, Y-P. Huang, Z-S. Liu, Enhancement of selective separation on molecularly imprinted monolith by molecular crowding agent, Anal. Bioanal. Chem., 409 (2017) 201-211.

133. X.-X. Shi, L. Xu, H.-Q. Duan, Y.-P. Huang, Z.-S. Liu, CEC separation of ofloxacin enantiomers using imprinted microparticles prepared in molecular crowding conditions, Electrophoresis, 32 (2011)N1348-1356.

134. H. Wang, Q. Xu, J. Wang, W. Du, F. Liu, X. Hu, Dendrimer-like amino-functionalized hierarchical porous silica nanoparticle: A host material for 2,4-dichlorophenoxyacetic acid imprinting and sensing, Biosens. Bioelectron., 100 (2018) 105-114.

135. W-F. Song, Q-L. Zhao, X-J. Zhou, L-S. Zhang, Y-P. Huang, Z-S. Liu, A star-shaped molecularly imprinted polymer derived from polyhedral oligomeric silsesquioxanes with improved site accessibility and capacity for enantiomeric separation via capillary electrochromatography, Microchim. Acta, 186 (2019) 1-7. 
136. X. Li, Z. Zhou, Enantioseparation performance of nove benzimido- $\beta$-cyclodextrins derivatized by ionic liquids as chiral stationary phases, Anal. Chim. Acta, 819 (2014) 122129.

137. J. Zhao, X. Lu, Y. Wang, J. Lv, "Click" preparation of a novel "native-phenylcarbamoylated" bilayer cyclodextrin stationary phase for enhanced chiral differentiation, J. Chromatogr. A, 1381 (2015) 253-259.

138. P. Řezanka, D. Sýkora, M. Novotný, M. Havlík, V. Král, Nonaqueous Capillary Electrophoretic Enantioseparation of Water Insoluble Tröger's Base Derivatives Using $\beta$-Cyclodextrin as Chiral Selector, Chirality, 25 (2013) 810813

139. Z.-I. Szabó, L. Szőcs, D.-L. Muntean, B. NoszáL, G. Tóth, Chiral Separation of Uncharged Pomalidomide Enantiomers Using Carboxymethyl- $\beta$-Cyclodextrin: A Validated Capillary Electrophoretic Method, Chirality, 28 (2016) 199-203.

140. Sánchez-López, A. Salgado, A.L. Crego, M.L. Marina, Investigation on the enantioseparation of duloxetine by capillary electrophoresis, NMR, and mass spectrometry, Electrophoresis, 35 (2014) 2842-2847.

141. K. Németh, G. Tárkányi, E. Varga, T. Imre, R. Mizsei, R. Iványi, J. Visy, J. Szemán, L. Jicsinszky, L. Szente, M. Simonyi, Enantiomeric separation of antimalarial drugs by capillary electrophoresis using neutral and negatively charged cyclodextrins, J. Pharm. Biomed. Anal., 54 (2011) 475481.

142. P. Lehnert, A. Přibylka, V. Maier, J. Znaleziona, J. Ševčík, M. Douša, Enantiomeric separation of $\mathrm{R}, \mathrm{S}$-tolterodine and $\mathrm{R}, \mathrm{S}$ -methoxytolterodine with negatively charged cyclodextrins by capillary electrophoresis, J. Sep. Sci., 36 (2013) 1561-1567.

143. Gogolashvili, L. Chankvetadze, N. Takaishvili, A. Salgado, B. Chankvetadze, Separation of terbutaline enantiomers in capillary electrophoresis with neutral cyclodextrin-type chiral selectors and investigation of the structure of selectorselectand complexes using nuclear magnetic resonance spectroscopy, Electrophoresis, 41 (2020) 1023-1030.

144. Y. Dai, S. Wang, J. Zhou, J. Tang, W. Tang, A family of single-isomer, dicationic cyclodextrin chiral selectors for capillary electrophoresis: Mono-6 A -ammonium-6 C -butylimidazolium- $\beta$-cyclodextrin chlorides, Electrophoresis, 34 (2013) 833-840.

145. Y. Dai, S. Wang, J. Zhou, Y. Liu, D. Sun, J. Tang, W. Tang, Cationic cyclodextrin as versatile chiral selector for enantiomeric separation in capillary electrophoresis, J. Chromatogr. A, 1246 (2012) 98-102.

146. A.S. Rizvi, G. Murtaza, M. Irfan, Y. Xiao, F. Qu, Determination of Kynurenine Enantiomers by Alpha-Cyclodextrin, CationicBeta-Cyclodextrin and Their Synergy Complemented with Stacking Enrichment in Capillary Electrophoresis, J. Chromatogr. A, 1622 (2020) 461128.

147. Y. Feng, T. Wang, Z. Jiang, B. Chankvetadze, J. Crommen, Comparative enantiomer affinity pattern of $\beta$-blockers in aqueous and nonaqueous $C E$ using single-component anionic cyclodextrins, Electrophoresis, 36 (2015) 1358-1364

148. J. Boonleang, J.F. Stobaugh, New single isomer negatively charged $\beta$-cyclodextrin derivatives as chiral selectors in capillary electrophoresis, Electrophoresis, 34 (2013) 1232 1240.
149. K. Lomsadze, E.D. Vega, A. Salgado, A.L. Crego, G.K.E. Scriba, M.L. Marina, B. Chankvetadze, Separation of enantiomers of norephedrine by capillary electrophoresis using cyclodextrins as chiral selectors: Comparative CE and NMR studies, Electrophoresis, 33 (2012) 1637-1647.

150. K. Lomsadze, A. Salgado, E. Calvo, J. Antonio López, B. Chankvetadze, Comparative NMR and MS studies on the mechanism of enantioseparation of propranolol with heptakis(2,3-diacetyl-6-sulfo)- $\beta$-cyclodextrin in capillary electrophoresis with aqueous and non-aqueous electrolytes, Electrophoresis, 32 (2011) 1156-1163.

151. Y. Liu, M. Deng, J. Yu, Z. Jiang, X. Guo, Capillary electrophoretic enantioseparation of basic drugs using a new single-isomer cyclodextrin derivative and theoretical study of the chiral recognition mechanism, J. Sep. Sci., 39 (2016) 1766-1775.

152. S. Samakashvili, A. Salgado, G.K.E. Scriba, B. Chankvetadze, Comparative Enantioseparation of Ketoprofen with Trimethylated $\alpha-, \beta$-, and $\gamma$-Cyclodextrins in Capillary Electrophoresis and Study of Related Selector-Selectand Interactions Using Nuclear Magnetic Resonance Spectroscopy, Chirality, 25 (2013) 79-88.

153. L. Li, X. Li, Q. Luo, T. You, A comprehensive study of the enantioseparation of chiral drugs by cyclodextrin using capillary electrophoresis combined with theoretical approaches, Talanta, 142 (2015) 28-34.

154. W. Li, L. Zhao, H. Zhang, X. Chen, S. Chen, Z. Zhu, Z. Hong, $Y$. Chai, Enantioseparation of new triadimenol antifungal active compounds by electrokinetic chromatography and molecular modeling study of chiral recognition mechanisms, Electrophoresis, 35 (2014) 2855-2862.

155. S. Béni, T. Sohajda, G. Neumajer, R. Iványi, L. Szente, B. Noszál, Separation and characterization of modified pregabalins in terms of cyclodextrin complexation, using capillary electrophoresis and nuclear magnetic resonance, J. Pharm. Biomed. Anal., 51 (2010) 842-852.

156. W. Li, G. Tan, L. Zhao, X. Chen, X. Zhang, Z. Zhu, Y. Chai, Computer-aided molecular modeling study of enantioseparation of iodiconazole and structurally related triadimenol analogues by capillary electrophoresis: Chiral recognition mechanism and mathematical model for predicting chiral separation, Anal. Chim. Acta, 718 (2012) 138-147.

157. X. Guo, Z. Wang, L. Zuo, Z. Zhou, X. Guo, T. Sun, Quantitative prediction of enantioseparation using 2-cyclodextrin derivatives as chiral selectors in capillary electrophoresis, Analyst, 139 (2014) 6511-6519.

158. Gogolashvili, E. Tatunashvili, L. Chankvetadze, T. Sohajda, M. Gumustas, S.A. Ozkan, A. Salgado, B. Chankvetadze, Separation of brombuterol enantiomers in capillary electrophoresis with cyclodextrin-type chiral selectors and investigation of structure of selector-selectand complexes using nuclear magnetic resonance spectroscopy, Electrophoresis, 40 (2019) 1904-1912.

159. Fradi, A.C. Servais, C. Lamalle, M. Kallel, M. Abidi, J. Crommen, M. Fillet, Chemo- and enantio-selective method for the analysis of amino acids by capillary electrophoresis with in-capillary derivatization, J. Chromatogr. A, 1267 (2012) 121-126. 
160. J. Tang, L. Pang, J. Zhou, S. Zhang, W. Tang, Per(3-chloro-4methyl) phenylcarbamate cyclodextrin clicked stationary phase for chiral separation in multiple modes highperformance liquid chromatography, Anal. Chim. Acta, 946 (2016) 96-103.

161. X. Li, X. Yao, Y. Xiao, Y. Wang, Enantioseparation of single layer native cyclodextrin chiral stationary phases: Effect of cyclodextrin orientation and a modeling study, Anal. Chim. Acta, 990 (2017) 174-184.

162. M. Castro-Puyana, I. Lammers, J. Buijs, C. Gooijer, F. Ariese, Sensitized phosphorescence as detection method for the enantioseparation of bupropion by capillary electrophoresis, Electrophoresis, 31 (2010) 3928-3936.

163. A. Aranyi, A. Péter, I. llisz, F. Fülöp, G.K.E. Scriba, Cyclodextrinmediated enantioseparation of phenylalanine amide derivatives and amino alcohols by capillary electrophoresisRole of complexation constants and complex mobilities, Electrophoresis, 35 (2014) 2848-2854.

164. Z.I. Szabó, G. Tóth, G. Völgyi, B. Komjáti, G. Hancu, L. Szente, T. Sohajda, S. Béni, D.L. Muntean, B. Noszál, Chiral separation of asenapine enantiomers by capillary electrophoresis and characterization of cyclodextrin complexes by NMR spectroscopy, mass spectrometry and molecular modeling, J. Pharm. Biomed. Anal., 117 (2016) 398-404.

165. K. Phatthiyaphaibun, W. Som-Aum, M. Srisa-Ard, J. Threeprom, Chiral separation of pheniramine by capillary electrophoresis partial-filling technique using hydroxypropyl- $\beta$-cyclodextrin as chiral selector, J. Anal. Chem., 65 (2010) 803-808.

166. J. Znaleziona, I. Fejos, J. Ševčík, M. Douša, S. Béni, V. Maier, Enantiomeric separation of tapentadol by capillary electrophoresis-Study of chiral selectivity manipulation by various types of cyclodextrins, J. Pharm. Biomed. Anal., 105 (2015) 10-16.

167. T. Sohajda, Z. Szakács, L. Szente, B. Noszál, S. Béni, Chiral recognition of imperanene enantiomers by various cyclodextrins: A capillary electrophoresis and NMR spectroscopy study, Electrophoresis, 33 (2012) 1458-1464.

168. T. Sohajda, W.H. Hu, L.L. Zeng, H. Li, L. Szente, B. Noszál, S. Béni, Evaluation of the interaction between sitagliptin and cyclodextrin derivatives by capillary electrophoresis and nuclear magnetic resonance spectroscopy, Electrophoresis, 32 (2011) 2648-2654.

169. W.A. Wan Ibrahim, S.R. Arsad, H. Maarof, M.M. Sanagi, H.Y. Aboul-Enein, Chiral Separation of Four Stereoisomers of Ketoconazole Drugs Using Capillary Electrophoresis, Chirality, 27 (2015) 223-227.

170. M. Steinhoff, N. Vergnolle, S.H. Young, M. Tognetto, S. Amadesi, H.S. Ennes, M. Trevisani, M.D. Hollenberg, J.L. Wallace, G.H. Caughey, S.E. Mitchell, L.M. Williams, P. Geppetti, E.A. Mayer, N.W. Bunnett, Agonists of proteinaseactivated receptor 2 induce inflammation by a neurogenic mechanism, Nat. Med., 6 (2000) 151-158.

171. J. Zhou, H. Yao, H. Shao, Y. Li, Z. Zhang, Enantioseparation of $\beta$-agonists with carboxymethyl- $\beta$-cyclodextrin by CE, J. Liq Chromatogr. Relat. Technol., 35 (2012) 50-58.

172. Soares Nascimento, J. Fedoce Lopes, L. Guimarães, K. Bastos Borges, Molecular modeling study of the recognition mechanism and enantioseparation of 4-hydroxypropranolol by capillary electrophoresis using carboxymethyl- $\beta$ cyclodextrin as the chiral selector, Analyst, 139 (2014) 39013910.
173. Y. Qi, X. Zhang, Determination of enantiomeric impurity of levamlodipine besylate bulk drug by capillary electrophoresis using carboxymethyl- $\beta$-Cyclodextrin, Cell Biochem. Biophys., 70 (2014) 1633-1637.

174. J. Zhou, Y. Wang, Y. Liu, J. Tang, W. Tang, Methoxypropylamino $\beta$-cyclodextrin clicked AC regioisomerforenantioseparations in capillary electrophoresis, Anal. Chim. Acta, 868 (2015) 73-79.

175. I.W. Muderawan, T.T. Ong, W.H. Tang, D.J. Young, C.B. Ching, S.C. Ng, Synthesis of ammonium substituted $\beta$-cyclodextrins for enantioseparation of anionic analytes, Tetrahedron Lett., 46 (2005) 1747-1749.

176. Y. Xiao, Y. Wang, T.-T. Ong, L. Ge, S.N. Tan, D.J. Young, T.T.Y. Tan, S.-C. Ng, Chiral capillary electrophoresis with cationic pyrrolidinium- $\beta$-cyclodextrin derivatives as chiral selectors, J. $\quad$ Sep. Sci., 33 (2010) 1797-1805.

177. S. Wang, Y. Dai, J. Wu, J. Zhou, J. Tang, W. Tang, Methoxyethylammonium monosubstituted $\beta$-cyclodextrin as the chiral selector for enantioseparation in capillary electrophoresis, J. Chromatogr. A, 1277 (2013) 84-92.

178. S. Kodama, A. Taga, S. Aizawa, T. Kemmei, Y. Honda, K. Suzuki, A. Yamamoto, Direct enantioseparation of lipoic acid in dietary supplements by capillary electrophoresis using trimethyl- $\beta$-cyclodextrin as a chiral selector, Electrophoresis, 33 (2012) 2441-2445.

179. A.C. Servais, A. Rousseau, M. Fillet, K. Lomsadze, A. Salgado, J. Crommen, B. Chankvetadze, Separation of propranolol enantiomers by $C E$ using sulfated $\beta-C D$ derivatives in aqueous and non-aqueous electrolytes: Comparative CE and NMR study, Electrophoresis, 31 (2010) 1467-1474.

180. A.C. Servais, A. Rousseau, G. Dive, M. Frederich, J. Crommen, M. Fillet, Combination of capillary electrophoresis, molecular modelling and nuclear magnetic resonance to study the interaction mechanisms between single-isomer anionic cyclodextrin derivatives and basic drug enantiomers in a methanolic background electrolyte, J. Chromatogr. A, 1232 (2012) 59-64.

181. Tutu, G. Vigh, Synthesis, analytical characterization and initial capillary electrophoretic use in an acidic background electrolyte of a new, single-isomer chiral resolving agent: Heptakis(2-0-sulfo-3-0-methyl-6-0-acetyl)- $\beta$-cyclodextrin, Electrophoresis, 32 (2011) 2655-2662.

182. P. Nowak, M. Garnysz, M. Woźniakiewicz, P. Kościelniak, Fast separation of warfarin and 7-hydroxywarfarin enantiomers by cyclodextrin-assisted capillary electrophoresis, J. Sep. Sci., 37 (2014) 2625-2631.

183. S. Mohr, S. Pilaj, M.G. Schmid, Chiral separation of cathinone derivatives used as recreational drugs by cyclodextrinmodified capillary electrophoresis, Electrophoresis, 33 (2012) 1624-1630.

184. L. Chankvetadze, A.C. Servais, M. Fillet, A. Salgado, J. Crommen, B. Chankvetadze, Comparative enantioseparation of talinolol in aqueous and non-aqueous capillary electrophoresis and study of related selector-selectand interactions by nuclear magnetic resonance spectroscopy, J. Chromatogr. A, 1267 (2012) 206-216.

185. Z.I. Szabó, M. Foroughbakhshfasaei, R. Gál, P. Horváth, B. Komjáti, B. Noszál, G. Tóth, Chiral separation of lenalidomide by liquid chromatography on polysaccharide-type stationary phases and by capillary electrophoresis using cyclodextrin selectors, J. Sep. Sci., 41 (2018) 1414-1423. 
186. Q. Zhang, Y. Du, J. Chen, G. Xu, T. Yu, X. Hua, J. Zhang, Investigation of chondroitin sulfate $D$ and chondroitin sulfate $\mathrm{E}$ as novel chiral selectors in capillary electrophoresis, Analytical and Bioanalytical Chemistry. Springer (2014) 1557-1566.

187. Y. Yao, P. Song, X. Wen, M. Deng, J. Wang, X. Guo, Chiral separation of 12 pairs of enantiomers by capillary electrophoresis using heptakis-(2,3-diacetyl-6-sulfato)- $\beta$ cyclodextrin as the chiral selector and the elucidation of the chiral recognition mechanism by computational methods, J. Sep. Sci., 40 (2017) 2999-3007.

188. S. Nojavan, A.R. Fakhari, Chiral separation and quantitation of cetirizine and hydroxyzine by maltodextrin-mediated CE in human plasma: Effect of zwitterionic property of cetirizine on enantioseparation, Electrophoresis, 32 (2011) 764-771.

189. Tabani, M. Mahyari, A. Sahragard, A.R. Fakhari, A. Shaabani, Evaluation of sulfated maltodextrin as a novel anionic chiral selector for the enantioseparation of basic chiral drugs by capillary electrophoresis, Electrophoresis, 36 (2015) 305311.

190. Y. Su, X. Mu, L. Qi, Development of a capillary electrophoresis system with $\mathrm{Mn}$ (ii) complexes and $\beta$-cyclodextrin as the dual chiral selectors for enantioseparation of dansyl amino acids and its application in screening enzyme inhibitors, RSC Adv.,5 (2015) 28762-28768.

191. J.A. McKee, T.K. Green, Synthesis of 2,3-O-dibenzyl-6-Osulfobutyl- $\alpha$ and $\beta$ cyclodextrins: new chiral surfactants for capillary electrophoresis, Tetrahedron Lett., 56 (2015) 44514454.

192. Terabe, S., Procedia Chemistry. Twenty-five years of micellar electrokinetic chromatography 2 (2010), 2-8.

193. Y. Liu, S.A. Shamsi, Combined use of chiral ionic liquid surfactants and neutral cyclodextrins: Evaluation of ionic liquid head groups for enantioseparation of neutral compounds in capillary electrophoresis, J. Chromatogr. A 1360 (2014) 296-304.

194. Přibylka, M. Švidrnoch, E. Tesařová, D.W. Armstrong, V. Maier, The empirical comparison of cyclofructans and cyclodextrins as chiral selectors in capillary electrophoretic separation of atropisomers of R,S-1,1'-binaphthalene-2,2' diyl hydrogen phosphate, J. Sep. Sci., 39 (2016) 973-979.

195. W. Ding, T. Yu, Y. Du, X. Sun, Z. Feng, S. Zhao, X. Ma, M. Ma, C. Chen, A metal organic framework-functionalized monolithic column for enantioseparation of six basic chiral drugs by capillary electrochromatography, Microchim. Acta, 187 (2020) $1-10$

196. N. Ye, J. Ma, J. An, J. Li, Z. Cai, H. Zong, Separation of amino acid enantiomers by a capillary modified with a metalorganic framework, RSC Adv., 6 (2016) 41587-41593.

197. Z. Geng, Q. Song, B. Yu, H. Cong, Using ZIF-8 as stationary phase for capillary electrophoresis separation of proteins, Talanta, 188 (2018) 493-498

198. X. Wang, A. Lamprou, F. Svec, Y. Bai, H. Liu, Polymer-based monolithic column with incorporated chiral metal-organic framework for enantioseparation of methyl phenyl sulfoxide using nano-liquid chromatography, J. Sep. Sci., 39 (2016) 4544-4548.

199. Pan, W. Wang, H. Zhang, L. Xu, X. Chen, In situ synthesis of homochiral metal-organic framework in capillary column for capillary electrochromatography enantioseparation, J. Chromatogr. A, 1388 (2015) 207-216.
200. J. Ma, N. Ye, J. Li, Covalent bonding of homochiral metalorganic framework in capillaries for stereoisomer separation by capillary electrochromatography, Electrophoresis, 37 (2016) 601-608.

201. L. He, C. Tian, J. Zhang, W. Xu, B. Peng, S. Xie, M. Zi, L. Yuan, Chiral metal-organic cages used as stationary phase for enantioseparations in capillary electrochromatography, Electrophoresis, 41 (2020) 104-111.

202. Pérez-Quintanilla, S. Morante-Zarcero, I. Sierra, Preparation and characterization of mesoporous silicas modified with chiral selectors as stationary phase for high-performance liquid chromatography, J. Colloid Interface Sci., 414 (2014) 14-23.

203. M. Greño, M. Castro-Puyana, M.Á. García, M.L. Marina, Analysis of antibiotics by CE and CEC and their use as chiral selectors: An update, Electrophoresis, 39 (2018) 235-259.

204. T. Yu, Y. Du, B. Chen, Evaluation of clarithromycin lactobionate as a novel chiral selector for enantiomeric separation of basic drugs in capillary electrophoresis, Electrophoresis, 32 (2011) 1898-1905.

205. Chen, Y. Du, Evaluation of the enantioseparation capability of the novel chiral selector clindamycin phosphate towards basic drugs by micellar electrokinetic chromatography, J. Chromatogr. A, 1217 (2010) 1806-1812.

206. S. Dixit, J.H. Park, Application of rifampicin as a chiral selector for enantioresolution of basic drugs using capillary electrophoresis, J. Chromatogr. A, 1453 (2016) 138-142.

207. A.P. Kumar, J.H. Park, Azithromycin as a new chiral selector in capillary electrophoresis, J. Chromatogr. A, 1218 (2011) 1314-1317.

208. Chankvetadze, G. Blaschke, Enantioseparations using capillary electromigration techniques in nonaqueous buffers, Electrophoresis, 21 (2000) 4159-4178.

209. M.V. Lebedeva, A.F. Prokhorova, E.N. Shapovalova, O.A. Shpigun, Clarithromycin as a chiral selector for enantioseparation of basic compounds in nonaqueous capillary electrophoresis, Electrophoresis, 35 (2014) 27592764.

210. D.A. Jayawardhana, J.A. Crank, Q. Zhao, D.W. Armstrong, X. Guan, Nanopore stochastic detection of a liquid explosive component and sensitizers using boromycin and an ionic liquid supporting electrolyte, Anal. Chem., 81 (2009) 460464.

211. V. Maier, V. Ranc, M. Švidrnoch, J. Petr, J. Ševčík, E. Tesařová, D.W. Armstrong, Study on the use of boromycin as a chiral selector in capillary electrophoresis, J. Chromatogr. A, 1237 (2012) 128-132.

212. S. Ren, Q. Zhang, S. Xue, S. Liu, M. Rui, Use of Gamithromycin as a Chiral Selector in Capillary Electrophoresis, J. Chromatogr. A, 1624 (1624) 461099.

213. A.C. Kogawa, H. Regina, N. Salgado, Hoxycyclıne Hyclate: A review of Propertıes, Applicatıons and Analytıcal methods. International Journal of Life Science and Pharma Research, 2, 4 (2012) 11-25.

214. M.G. Jang, M.D. Jang, J.H. Park, Doxycycline as a new chiral selector in capillary electrophoresis, J. Chromatogr. A, 1508 (2017) 176-181.

215. Q. Zhang, S. Ren, S. Xue, Investigation of fusidic acid as a chiral selector in capillary electrophoresis, Sep. Purif. Technol., 242 (2020) 116768. 
216. Nishi, K. Nakamura, H. Nakai, T. Sato, Enantiomer separation by capillary electrophoresis using DEAE-dextran and aminoglycosidic antibiotics, Chromatographia, 43 (1996) 426-430.

217. X. Zhang, S. Qi, C. Liu, X. Zhao, Enantiomeric separation of five acidic drugs via capillary electrophoresis using streptomycin as chiral selector, J. Chromatogr. B Anal. Technol. Biomed. Life Sci., 1063 (2017) 31-35.

218. Liu, J. Zhang, X. Zhang, L. Zhao, S. Li, Enantiomeric separation of adrenaline, noradrenaline, and isoprenaline by capillary electrophoresis using streptomycin-modified gold nanoparticles, Microchim. Acta, 185 (2018) 1-7.

219. S. Dixit, J.H. Park, Penicillin $G$ as a novel chiral selector in capillary electrophoresis, J. Chromatogr. A, 1326 (2014) 134 138

220. A.F. Prokhorova, M.A. Kuznetsov, E.N. Shapovalova, S.M. Staroverov, O.A. Shpigun, Enantioseparations of aromatic carboxylic acid by capillary electrophoresis using eremomycin as a chiral selector in a chitosan-modified capillary Procedia Chemistry, 2 (2010), 9-13.

221. S. Zhang, N. Sun, X. He, X. Lu, X. Zhang, Physical properties of ionic liquids: Database and evaluation, J. Phys. Chem. Ref. Data, 35 (2006) 1475-1517.

222. Olivier-Bourbigou, L. Magna, D. Morvan, Ionic liquids and catalysis: Recent progress from knowledge to applications, Appl. Catal. A Gen., 373 (2010) 1-56.

223. W. Weber, J.T. Andersson, lonic liquids as stationary phases in gas chromatography-An LSER investigation of six commercial phases and some applications, Anal. Bioanal. Chem., 406 (2014) 5347-5358.

224. Q. Wang, X. Chen, B. Qiu, L. Zhou, H. Zhang, J. Xie, Y. Luo, B. Wang, lonic liquid as a mobile phase additive in highperformance liquid chromatography for the simultaneous determination of eleven fluorescent whitening agents in paper materials, J. Sep. Sci., 39 (2016) 1242-1248.

225. Zhao, Y. Meng, J.L. Anderson, Polymeric ionic liquids as selective coatings for the extraction of esters using solid phase microextraction, J. Chromatogr. A, 1208 (2008) 1-9.

226. Y. Su, X. Mu, L. Qi, Development of a capillary electrophoresis system with $\mathrm{Mn}$ (ii) complexes and $\beta$-cyclodextrin as the dual chiral selectors for enantioseparation of dansyl amino acids and its application in screening enzyme inhibitors, RSC Adv., 5 (2015) 28762-28768

227. Z. Ma, L. Zhang, L. Lin, P. Ji, X. Guo, Enantioseparation of rabeprazole and omeprazole by nonaqueous capillary electrophoresis with an ephedrine-based ionic liquid as the chiral selector, Biomed. Chromatogr., 24 (2010) 1332-1337.

228. Chen, Y. Du, X. Sun, Investigation of maltodextrin-based synergistic system with amino acid chiral ionic liquid as additive for enantioseparation in capillary electrophoresis, Chirality, 29 (2017) 824-835

229. Yu, L. Zuo, H. Liu, L. Zhang, X. Guo, Synthesis and application of a chiral ionic liquid functionalized $\beta$-cyclodextrin as a chiral selector in capillary electrophoresis, Biomed. Chromatogr. 27 (2013) 1027-1033.

230. Greño, M.L. Marina, M. Castro-Puyana, Effect of the combined use of $\gamma$-cyclodextrin and a chiral ionic liquid on the enantiomeric separation of homocysteine by capillary electrophoresis, J. Chromatogr. A, 1568 (2018) 222-228.

231. Casado, A. Salgado, M. Castro-Puyana, M.Á. García, M.L. Marina, Enantiomeric separation of ivabradine by cyclodextrin-electrokinetic chromatography. Effect of amino acid chiral ionic liquids, J. Chromatogr. A, 1608 (2019) 460407.
232. Y. Cui, X. Ma, M. Zhao, Z. Jiang, S. Xu, X. Guo, Combined Use of Ionic Liquid and Hydroxypropyl- $\quad \beta$-Cyclodextrin for the Enantioseparation of Ten Drugs by Capillary Electrophoresis, Chirality, 25 (2013) 409-414.

233. J. Li, T. Yu, G. Xu, Y. Du, Z. Liu, Z. Feng, X. Yang, Y. Xi, J. Liu, Synthesis and application of ionic $\quad$ i i q u i d functionalized $\beta$-cyclodextrin, mono-6-deoxy-6-(4-amino1,2,4-triazolium)- $\beta$-cyclodextrin chloride, as chiral selector in capillary electrophoresis, J. Chromatogr. A, 1559 (2018) 178-185.

234. X. Ma, Y. Du, X. Sun, J. Liu, Z. Huang, Synthesis and application of amino alcohol-derived chiral ionic liquids, as additives for enantioseparation in capillary electrophoresis, J. Chromatogr. A, 1601 (2019) 340-349.

235. H. Qing, X. Jiang, J. Yu, Separation of Tryptophan Enantiomers by Ligand-Exchange Chromatography With Novel Chiral Ionic Liquids Ligand, Chirality, 26 (2014) 160-165.

236. X. Sun, K. Liu, Y. Du, J. Liu, X. Ma, Investigation of the enantioselectivity of tetramethylammonium-lactobionate chiral ionic liquid based dual selector systems toward basic drugs in capillary electrophoresis, Electrophoresis, 40 (2019) 1921-1930.

237. M.C. Mavroudi, C.P. Kapnissi-Christodoulou, Evaluation of amino acid ester-based ionic liquids as buffer additives in CE for the separation of 2-arylpropionic acids nonsteroidal anti-inflammatory drugs, Electrophoresis, 35 (2014) 25732578.

238. R. Liu, Y. Du, J. Chen, Q. Zhang, S. Du, Z. Feng, Investigation of the Enantioselectivity of Tetram e thy la m monium L-hydroxyproline Ionic Liquid as a Novel Chiral Ligand in Ligand-Exchange CE and Ligand-Exchange MEKC, Chirality, 27 (2015) 58-63.

239. S. Salido-Fortuna, M. Greño, M. Castro-Puyana, M.L. Marina, Amino acid chiral ionic liquids combined with hydroxypropyl- $\beta$-cyclodextrin for drug enantioseparation by capillary electrophoresis, J. Chromatogr. A, 1607 (2019) 460375.

240. X. Yang, Y. Du, Z. Feng, Z. Liu, J. Li, Establishment and molecular modeling study of maltodextrin-based synergistic enantioseparation systems with two new hydroxy acid chiral ionic liquids as additives in capillary electrophoresis, J. Chromatogr. A, 1559 (2018) 170-177.

241. W. Yujiao, W. Guoyan, Z. Wenyan, Z. Hongfen, J. Huanwang, C. Anjia, Chiral separation of phenylalanine and tryptophan by capillary electrophoresis using a mixture of $\beta-C D$ and chiral ionic liquid ([TBA] [I -ASP]) as selectors, Biomed. Chromatogr., 28 (2014) 610-614.

242. Q. Zhang, J. Zhang, S. Xue, M. Rui, B. Gao, A. Li, J. Bai, Z. yin, E.M. Anochie, Enhanced enantioselectivity of native $\alpha$-cyclodextrins by the synergy of chiral ionic liquids in capillary electrophoresis, J. Sep. Sci., 41 (2018) 4525-4532.

243. Y. Zhang, Y. Du, T. Yu, Z. Feng, J. Chen, Investigation of dextrinbased synergistic system with chiral ionic liquids as additives for enantiomeric separation in capillary electrophoresis, J. Pharm. Biomed. Anal., 164 (2019) 413-420.

244. Y. Zhang, S. Du, Z. Feng, Y. Du, Z. Yan, Evaluation of synergistic enantioseparation systems with chiral spirocyclic ionic liquids as additives by capillary electrophoresis, Anal. Bioanal. Chem., 408 (2016) 2543-2555.

245. J. Zhang, Y. Du, Q. Zhang, Y. Lei, Evaluation of vancomycinbased synergistic system with amino acid ester chiral ionic liquids as additives for enantioseparation of non-steroida anti- inflamatory drugs by capillary electrophoresis, Talanta, 119 (2014) 193-201. 
246. L. Zuo, H. Meng, J. Wu, Z. Jiang, S. Xu, X. Guo, Combined use of ionic liquid and $\beta-C D$ for enantioseparation of 12 pharmaceuticals using CE, J. Sep. Sci., 36 (2013) 517-523.

247. Q. Zhang, Y. Du, S. Du, J. Zhang, Z. Feng, Y. Zhang, X $\mathrm{Li}$, Tetramethylammonium-lactobionate: A novel ionic liquid chiral selector based on saccharides in capillary electrophoresis, Electrophoresis, 36 (2015) 1216-1223.

248. J. Zhang, Y. Du, Q. Zhang, J. Chen, G. Xu, T. Yu, X. Hua, Investigation of the synergistic effect with amino acidderived chiral ionic liquids as additives for enantiomeric separation in capillary electrophoresis, J. Chromatogr. A 1316 (2013) 119-126

249. Q. Zhang, Y. Du, Evaluation of the enantioselectivity of glycogen-based synergistic system with amino acid chiral ionic liquids as additives in capillary electrophoresis, J. Chromatogr. A, 1306 (2013) 97-103.

250. Y. Jin, C. Chen, L. Meng, J. Chen, M. Li, Z. Zhu, Simultaneous and sensitive capillary electrophoretic enantioseparation of three $\beta$-blockers with the combination of achiral ionic liquid and dual CD derivatives, Talanta, 89 (2012) 149-154

251. Y. Su, X. Mu, L. Qi, A new chiral ligand exchange capillary electrophoresis system based on Zn(II)-I-leucine complexes coordinating with $\beta$-cyclodextrin and its application in screening tyrosinase inhibitors, RSC Adv., 4 (2014) 55280-55285.

252. J. Jiang, X. Mu, J. Qiao, Y. Su, L. Qi, New chiral ligand exchange capillary electrophoresis system with chiral amino amide ionic liquids as ligands, Talanta, 175 (2017) 451-456.

253. H. Zhang, L. Qi, Y. Shen, J. Qiao, L. Mao, L-Lysine-derived ionic liquids as chiral ligands of $\mathrm{Zn}(\mathrm{II})$ complexes used in ligand-exchange CE, Electrophoresis, 34 (2013) 846-853.

254. S. Xue, S. Ren, L. Wang, Q. Zhang, Evaluation of tetraalkylammonium amino acid ionic liquids as chiral ligands in ligand-exchange capillary electrophoresis, J. Chromatogr. A, 1611 (2020) 460579.

255. B. Sun, X. Mu, L. Qi, Development of new chiral ligand exchange capillary electrophoresis system with amino acid ionic liquids ligands and its application in studying the kinetics of L-amino acid oxidase, Anal. Chim. Acta, 821 (2014) 97-102.

256. H. Zhang, L. Qi, X. Mu, X. Zhou, D. Li, L. Mao, Influence of ionic liquids as electrolyte additives on chiral separation of dansylated amino acids by using $\mathrm{Zn}$ (II) complex mediated chiral ligand exchange CE, J. Sep. Sci., 36 (2013) 886-891.

257. I.J. Stavrou, Z.S. Breitbach, C.P. Kapnissi-Christodoulou, Combined use of cyclofructans and an amino acid esterbased ionic liquid for the enantioseparation of huperzine $A$ and coumarin derivatives in CE, Electrophoresis, 36 (2015) 3061-3068.

258. Casado, A. Salgado, M. Castro-Puyana, M.Á. García, M.L. Marina, Enantiomeric separation of ivabradine by cyclodextrin-electrokinetic chromatography Effect of amino acid chiral ionic liquids, J. Chromatogr. A, 1608 (2019) 460407

259. X.Zhu,C.Chen,J.Chen, G.Xu,Y.Du,X.Ma,X.Sun,Z.Feng,Z.Huang, Synthesis and application of tetramethylammonium carboxymethylated- $\beta$-cyclodextrin: A novel ionic liquid in capillary electrophoresis enantioseparation, J. Pharm. Biomed. Anal., 180 (2020) 113030.

260. Xu, Y. Du, F. Du, J. Chen, T. Yu, Q. Zhang, J. Zhang, S. $\mathrm{Du}, \mathrm{Z}$. Feng, Establishment and Evaluation of the Novel Tetramethylammonium-L-Hydroxyproline Chiral Ionic Liquid Synergistic System Based on Clindamycin Phosphate for Enantioseparation by Capillary Electrophoresis, Chirality, 27 (2015) 598-604.
261. D.L. Fedlheim, C.A. Foss, Foss, C. A., Metal Nanoparticles: Synthesis, Characterization, and Applications. CRC Press, ISBN 9780824706043, October 26, (2001).

262. K.N. Thakkar, S.S. Mhatre, R.Y. Parikh, Biological synthesis of metallic nanoparticles, Nanomedicine Nanotechnology, Biol. Med., 6 (2010) 257-262.

263. L. Yang, C. Chen, X. Liu, J. Shi, G. Wang, L. Zhu, L. Guo, J.D. Glennon, N.M. Scully, B.E. Doherty, Use of cyclodextrinmodified gold nanoparticles for enantioseparations of drugs and amino acids based on pseudostationary phase-capillary electrochromatography, Electrophoresis, 31 (2010) 16971705.

264. W. Hu, T. Hong, X. Gao, Y. Ji, Applications of nanoparticle-modified stationary phases in capillary electrochromatography, TrAC-Trends Anal. Chem., 61 (2014) 29-39.

265. T. Wang, Y. Cheng, Y. Zhang, J. Zha, J. Ye, Q. Chu, G. Cheng, $\beta$-cyclodextrin modified quantum dots as pseudo-stationary phase for direct enantioseparation based on capillary electrophoresis with laser-induced fluorescence detection, Talanta, 210 (2020) 120629.

266. L-I. Fang, P. Wang, X-I. Wen, X. Guo, L. da Luo, J. Yu, X-j. Guo, Layer-by-layer self-assembly of gold nanoparticles/ thiols $\beta$-cyclodextrin coating as the stationary phase for enhanced chiral differentiation in open tubular capillary electrochromatography, Talanta, 167 (2017) 158-165.

267. M. Li, X. Liu, F. Jiang, L. Guo, L. Yang, Enantioselective open-tubular capillary electrochromatography using cyclodextrin-modified gold nanoparticles as stationary phase, J. Chromatogr. A, 1218 (2011) 3725-3729.

268. L. Fang, Y. Zhao, C. Wang, C. Wang, X. Han, P. Chen, L. Zhao, J. Wang, S. Li, Z. Jiang, Preparation of a thiols $\beta$-cyclodextring/ gold nanoparticles-coated open tubular column for capillary electrochromatography enantioseparations, J. Sep. Sci., 43 (2020) 2209-2216.

269. M. Li, M. Tarawally, X. Liu, X. Liu, L. Guo, L. Yang, G. Wang, Application of cyclodextrin-modified gold nanoparticles in enantioselective monolith capillary electrochromatography, Talanta, 109 (2013) 1-6.

270. Y. Zhang, Y. Zhang, W. Chen, Y. Zhang, L. Zhu, P. He, Q. Wang, Enantiomeric separation of tryptophan by open-tubular microchip capillary electrophoresis using polydopamine/ gold nanoparticles conjugated DNA as stationary phase, Anal. Methods, 9 (2017) 3561-3568.

271. Zhang, J. Qu, X. Lv, J. Zhang, L. Fang, A novel open-tubular capillary electrochromatography using carboxymethyl- $\beta$ cyclodextrin functionalized gold nanoparticles as chiral stationary phase, J. Sep. Sci., 43 (2020) 946-953.

272. X. Yang, X. Sun, Z. Feng, Y. Du, J. Chen, X. Ma, X. Li, Open-tubular capillary electrochromatography with $\beta$-cyclodextrin-functionalized magnetic nanoparticles as stationary phase for enantioseparation of dansylated amino acids, Microchim. Acta, 186 (2019) 1-8.

273. Qu, J. Lei, L. Zhang, R. Ouyang, H. Ju, Molecularly imprinted magnetic nanoparticles as tunable stationary phase located in microfluidic channel for enantioseparation, J. Chromatogr. A, 1217 (2010) 6115-6121.

274. L.-L. Wu, R.-P. Liang, J. Chen, J.-D. Qiu, Separation of chiral compounds using magnetic molecularly imprinted polymer nanoparticles as stationary phase by microchip capillary electrochromatography, Electrophoresis, 39 (2018) 356-362.

275. X. Hua, Y. Du, J. Chen, G. Xu, T. Yu, Q. Zhang, Evaluation of the enantioselectivity of carbon nanoparticles-modified chiral separation systems using dextrin as chiral selector by capillary electrokinetic chromatography, Electrophoresis, 34 (2013) 1901-1907. 
276. X.N. Wang, R.P. Liang, X.Y. Meng, J.D. Qiu, One-step synthesis of mussel-inspired molecularly imprinted magnetic polymer as stationary phase for chip-based open tubular capillary electrochromatography enantioseparation, J. Chromatogr. A, 1362 (2014) 301-308.

277. Zhang, Y. Du, S. Du, Evaluation of ionic liquids-coated carbon nanotubes modified chiral separation system with chondroitin sulfate $E$ as chiral selector in capillary electrophoresis, J. Chromatogr. A, 1339 (2014) 185-191.

278. X. Sun, J. Guo, T. Yu, Y. Du, Z. Feng, S. Zhao, Z. Huang, J. Liu, A novel coating method for CE capillary using carboxymethylB-cyclodextrin-modified magnetic microparticles as stationary for electrochromatography enantioseparation, Anal. Bioanal. Chem., 411 (2019) 1193-1202.

279. L. Huang, Y.-T. Chen, Y.-X. Li, L.-S. Yu, Application of Chiral Ionic Liquid-Modified Gold Nanoparticles in the Chiral Recognition of Amino Acid Enantiomers, Appl. Spectrosc., 70 (2016) 1649-1654.

280. X. Dong, R. Wu, J. Dong, M. Wu, Y. Zhu, H. Zou, A mesoporous silica nanoparticles immobilized open-tubular capillary column with a coating of cellulose tris(3,5-dimethylphenylcarbamate) for enantioseparation in CEC, Electrophoresis, 29 (2008) 3933-3940.

281. Z.S. Gong, L.P. Duan, A.N. Tang, Amino-functionalized silica nanoparticles for improved enantiomeric separation in capillary electrophoresis using carboxymethyl- $\beta$ cyclodextrin (CM- $\beta-\mathrm{CD})$ as a chiral selector, Microchim. Acta, 182 (2015) 1297-1304.

282. C.-Y. Yue, G.-S. Ding, F.-J. Liu, A.-N. Tang, Water-compatible surface molecularly imprinted silica nanoparticles as pseudostationary phase in electrokinetic chromatography for the enantioseparation of tryptophan, J. Chromatogr. A 1311 (2013), 176-182.

283. X. Sun, Y. Du, S. Zhao, Z. Huang, Z. Feng, Enantioseparation of propranolol, amlodipine and metoprolol by electrochromatography using an open tubular capillary modified with $\beta$-cyclodextrin and poly (glycidyl methacrylate) nanoparticles, Microchim. Acta, 186 (2019) 1-7.

284. C. Aydoğan, V. Karakoç, F. Yılmaz, A. Denizli, Enantioseparation of Ofloxacin by Ligand Exchange Capillary Electrophoresis Using L-Histidine Modified Nanoparticles as Chiral Ligand, Hacettepe J. Biol. \& Chem., 41 (1) (2013) 29-36.

285. Svec, E.C. Peters, D. Sýkora, J.M.J. Fréchet, Design of the monolithic polymers used in capillary electrochromatography columns, J. Chromatogr. A, 887 (2000) 3-29.

286. E.F. Hilder, F. Svec, J.M.J. Fréchet, Development and application of polymeric monolithic stationary phases for capillary electrochromatography, J. Chromatogr. A, 1044 (2004) 3-22.

287. J.J. Meyers, A.I. Liapis, Network modeling of the convective flow and diffusion ofmolecules adsorbing in monoliths and in porous particles packed in a chromatographic column, J. Chromatogr. A, (1999) 3-23.

288. M. Wu, R. Wu, Z. Zhang, H. Zou, Preparation and application of organic-silica hybrid monolithic capillary columns, Electrophoresis, 32 (2011) 105-115.

289. Ye, S. Wang, S. Zhao, Preparation and characterization of mixed-mode monolithic silica column for capillary electrochromatography, J. Chromatogr. A, 1216 (2009) 8845-8850.
290. Y. Xue, X. Gu, Y. Wang, C. Yan, Recent advances on capillary columns, detectors, and two-dimensional separations in capillary electrochromatography, Electrophoresis, 36 (2015) 124-134.

291. N. Tanaka, H. Kobayashi, N. Ishizuka, H. Minakuchi, K. Nakanishi, K. Hosoya, T. Ikegami, Monolithic silica columns for high-efficiency chromatographic separations, J. Chromatogr. A, 965 (2002) 35-49.

292. M-L. Hsieh, L-K. Chau, Y-S. Hon, Single-step approach for fabrication of vancomycin-bonded silica monolith as chiral stationary phase, J. Chromatogr. A, 1358 (2014) 208-216.

293. L.L. Hench, J.K. West, The Sol-Gel Process. Chem. Rev. 1990, 90, 33-72.

294. J. Nawrocki, M. Rigney, A. McCormick, P.W. Carr, Chemistry of zirconia and its use in chromatography, J. Chromatogr. A, 657 (1993) 229-282.

295. A.P. Kumar, J.H. Park, Enantioseparation on cellulose dimethylphenylcarbamate-modified zirconia monolithic columns by reversed-phase capillary electrochromatography, J. Chromatogr. A, 1217 (2010) 4494-4500.

296. S. Dixit, J.H. Park, Enantioseparation of basic chiral drugs on a carbamoylated erythromycin-zirconia hybrid monolith using capillary electrochromatography, J. Chromatogr. A, 1416 (2015) 129-136.

297. S. Dixit, I.S. Lee, J.H. Park, Carbamoylated azithromycin incorporated zirconia hybrid monolith for enantioseparation of acidic chiral drugs using non-aqueous capillary electrochromatography, J. Chromatogr. A, 1507 (2017) 132140.

298. L.N. Tran, S. Dixit, J.H. Park, Enantioseparation of basic chiral compounds on a clindamycin phosphate-silica/zirconia hybrid monolith by capillary electrochromatography, J. Chromatogr. A, 1356 (2014) 289-293.

299. L.N. Tran, J.H. Park, Enantiomer separation of acidic chiral compounds on a quinine-silica/zirconia hybrid monolith by capillary electrochromatography, J. Chromatogr. A, 1396 (2015) 140-147.

300. M. Kim, J.H. Park, Enantioseparation of chiral acids and bases on a clindamycin phosphate-modified zirconia monolith by capillary electrochromatography, J. Chromatogr. A, 1251 (2012) 244-248

301. A.P. Kumar, J.H. Park, Fast separations of chiral $\beta$-blockers on a cellulose tris(3,5-dimethylphenylcarbamate)coated zirconia monolithic column by capillary electrochromatography, J. Chromatogr. A, 1218 (2011) 5369-5373.

302. L.N. Tran, J.-A. Jeong, J.H. Park, Enantiomer Separation of Acidic Chiral Compounds on a tert -ButylcarbamoylquinineSilica Hybrid Monolith by Capillary Electrochromatography. Bull. Korean Chem. Soc., 37 (2016) 1050-1056.

303. L.N. Tran, J.-A. Jeong, J.H. Park, Enantiomer Separation of Acidic Chiral Compounds on a tert -ButylcarbamoylquinineSilica Hybrid Monolith by Capillary Electrochromatography, Bull. Korean Chem. Soc., 37 (2016) 1050-1056.

304. Al-Hussin, R.I. Boysen, K. Saito, M.T.W. Hearn, Preparation and electrochromatographic characterization of new chiral $\beta$-cyclodextrin poly(acrylamidopropyl) porous layer open tubular capillary columns, J. Chromatogr. A, 1358 (2014) 199-207.

305. L. Fang, J. Yu, Z. Jiang, X. Guo, Preparation of a $\beta$-cyclodextrinbased open-tubular capillary electrochromatography column and application for enantioseparations of ten basic drugs, PLoS ONE 11 (2016): e0146292. 
306. Hongjun, P. Su, M.U. Farooq, Y. Yang, Microwave-Assisted Preparation of a $\beta$-Cyclodextrin-Based Stationary Phase for Open Tubular Capillary Electrochromatography, Anal. Lett., 43 (2010) 2372-2380.

307. Yuan, G. Ding, Enantioseparations in capillary electrochromatography using sulfated poly b -cyclodextrinmodi $\mathrm{fi}$ ed silica-based monolith as stationary phase, Methods Mol. Biol., 970 (2013) 489-503.

308. L. Zhou, J. Lun, Y. Liu, Z. Jiang, X. Di, X. Guo, In situ immobilization of sulfated- $\beta$-cyclodextrin as stationary phase for capillary electrochromatography enantioseparation, Talanta, 200 (2019) 1-8

309. K. Szwed, J. Ou, G. Huang, H. Lin, Z. Liu, H. Wang, H. Zou, Preparation of cyclodextrin-modified monolithic hybrid columns for the fast enantioseparation of hydroxy acids in capillary liquid chromatography, J. Sep. Sci., 39 (2016) 11101117.

310. Ghanem, F.G. Adly, Y. Sokerik, N.Y. Antwi, M.A. Shenashen, S.A. El-Safty, Trimethyl- $\beta$-cyclodextrin-encapsulated monolithic capillary columns: Preparation, characterization and chiral nano-LC application, Talanta, 169 (2017) 239-248.

311. A. Ghanem, M. Ahmed, H. Ishii, T. Ikegami, Immobilized $\beta$-cyclodextrin-based silica vs polymer monoliths for chiral nano liquid chromatographic separation of racemates, Talanta, 132 (2015) 301-314.

312. J. Guo, Y. Xiao, Y. Lin, Q. Zhang, Y. Chang, J. Crommen, Z. Jiang, Influence of the linking spacer length and type on the enantioseparation ability of $\beta$-cyclodextrin functionalized monoliths, Talanta, 152 (2016) 259-268

313. Zhang, J. Guo, F. Wang, J. Crommen, Z. Jiang, Preparation of a $\beta$-cyclodextrin functionalized monolith via a novel and simple one-pot approach and application to enantioseparations, J. Chromatogr. A, 1325 (2014) 147-154.

314. Q. Zhang, J. Guo, Y. Xiao, J. Crommen, Z. Jiang, Comparative evaluation of a one-pot strategy for the preparation of $\beta$-cyclodextrin-functionalized monoliths: Effect of the degree of amino substitution of $\beta$-cyclodextrin on the column performance, J. Sep. Sci., 38 (2015) 1813-1821.

315. Z. Zhang, M. Wu, R. Wu, J. Dong, J. Ou, H. Zou, Preparation of perphenylcarbamoylated $\beta$ - $\quad$ cyclodextrin-silica hybrid monolithic column with "one-pot" approach for enantioseparation by capillary liquid chromatography, Anal. Chem., 83 (2011) 3616-3622.

316. M. Deng, M. Li, Y. Zhao, Z. Jiang, X. Guo, A novel one-pot strategy to prepare $\beta$-cyclodextrin functionalized capillary monoliths for enantioseparation of basic drugs, Talanta, 189 (2018) 458-466.

317. R. Chen, C. Lin, H. Lyu, X. Lin, Z. Xie, Highly efficient preparation of $\beta$-CD-based chiral monolithic colu m n by "one-pot" hydroxymethyl polycondensation for enantioseparation in capillary liquid chromatography, J. Chromatogr. A, 1616 (2020) 460781.

318. P. Zhang, J. Wang, H. Yang, L. Su, Y. Xiong, F. Ye, Facile onepot preparation of chiral monoliths with a well-defined framework based on the thiol-ene click reaction for capillary liquid chromatography, RSC Adv., 6 (2016) 24835-24842.

319. W. Bragg, S.A. Shamsi, A novel positively charged achiral co-monomer for $\beta$-cyclodextrin monolithic stationary phase: Improved chiral separation of acidic compounds using capillary electrochromatography coupled to mass spectrometry, J. Chromatogr. A, 1267 (2012) 144- 155.
320. L. Zhou, B. Liu, J. Guan, Z. Jiang, X. Guo, Preparation of sulfobutylether $\beta$-cyclodextrin-silica hybrid monolithic column, and its application to capillary electrochromatography of chiral compounds, J. Chromatogr. A, 1620 (2020) 460932.

321. Aydoğan, A. Denizli, Chiral separation-based ligand exchange by open-tubular capillary electrochromatography, Anal. Biochem., 447 (2014) 55-57.

322. Y. Lin, J. Guo, H. Lin, J. Wang, G.W. Somsen, J. Crommen, Z. Jiang, Effect of fabrication strategy on the enantioseparation performance of $\quad \beta$-cyclodextrin-functionalized polymethacrylate monoliths: A comparative evaluation, J. Sep. Sci., 40 (2017) 3754-3762.

323. Noel Echevarria, E.J. Carrasco-Correa, S. Keunchkarian, M. Reta, J.M. Herrero-Martinez, Photografted methacrylatebased monolithic columns coated with cellulose tris(3,5dimethylphenylcarbamate) for chiral separation in CEC, J. Sep. Sci., 41 (2018) 1424-1432.

324. Aydoğan, F. Yılmaz, D. Çimen, L. Uzun, A. Denizli, Enantioseparation of aromatic amino acids using CEC monolith with novel chiral selector, $\mathrm{N}$-methacryloyl- I -histidine methyl ester, Electrophoresis, 34 (2013) 1908-1914.

325. C. Aydogan, A. Denizli, Electrochromatographic Enantioseparation of Amino Acids Using

Polybutylmethacrylate-based Chiral Monolithic Column by Capillary Electrochromatography, Chirality, 24 (2012) 606609.

326. Aydoğan, Z. El Rassi, Monolithic stationary phases with incorporated fumed silica nanoparticles. Part I. Polymethacrylate-based monolithic column with incorporated bare fumed silica nanoparticles for hydrophilic interaction liquid chromatography, J. Chromatogr. A, 1445 (2016) 55-61.

327. Aydoğan, Z. El Rassi, Monolithic stationary phases with incorporated fumed silica nanoparticles. Part II. Polymethacrylate-based monolithic column with "covalently" incorporated modified octadecyl fumed silica nanoparticles for reversed-phase chromatography, J. Chromatogr. A, 1445 (2016) 62-67.

328. Xu, R. Mo, C. Jin, X. Cui, R. Bai, Y. Ji, Mesoporous silica nanoparticles incorporated hybrid monolithic stationary phase immobilized with pepsin for enantioseparation by capillary electrochromatography, J. Pharm. Biomed. Anal., 140 (2017) 190-198.

329. Miao, R. Bai, S. Xu, T. Hong, Y. Ji, Carboxylated single-walled carbon nanotube-functionalized chiral polymer monoliths for affinity capillary electrochromatography, J. Chromatogr. A, 1487 (2017) 227-234.

330. Y. Li, X. Lin, S. Qin, L. Gao, Y. Tang, S. Liu, Y. Wang, $\beta-$ Cyclodextrin-modified covalent organic framework as chiral stationary phase for the separation of amino acids and $\beta$ blockers by capillary electrochromatography, Chirality, 32 (2020) 1008-1019. 